\title{
Effects of land use and land cover change on the water cycle in the Amazon basin under a changing climate
}




\section{Propositions}

1. Secondary forest growth plays an important role in reducing the impacts of deforestation on the water balance in Amazonia.

(this thesis)

2. The impact of future climate change on hydropower production in Amazonia depends on how much forest regrowth is allowed in deforested areas.

(this thesis)

3. Future changes on climate extremes are expected to be more detrimental to the ecosystem services than alterations on the average climate.

4. Planting one billion hectares of trees worldwide is not enough to solve the climate crisis.

5. Social welfare programs are useful, but it is essential that governments work together to solve the problems that generate the social differences.

6. Adopting management practices from local communities is often more effective for sustainable development than enforcing modern development practices.

Propositions belonging to the thesis

Effects of land use and land cover change on the water cycle in the Amazon basin under a changing climate

Rita C. S. von Randow

Wageningen, 14 April, 2020 



\section{Effects of land use and land cover change on the water cycle in the Amazon basin under a changing climate}




\section{Thesis committee}

\section{Promotors}

Prof. Dr. P. Kabat

Special Professor, Global Water and Climate Systems, Wageningen University \& Research

Chief Scientist and Director Research, World Meteorological Organization (WMO), Geneva, Switzerland

Prof. Dr R.W.A. Hutjes

Associate Professor, Water Systems and Global Change,

Wageningen University \& Research

\section{Co-promotor}

Dr J. Tomasella

Senior Scientist, Centre for Monitoring and Alerts of Natural Disasters (CEMADEN), Cachoeira Paulista, Brazil

\section{Other members}

Prof. Dr. A. A. M. Holtslag, Wageningen University \& Research

Prof. Dr. A. J. Dolman, VU Amsterdam

Dr. M. T. H. van Vliet, Utrecht University

Prof. Dr. E. Davidson, University of Maryland, USA

This research was conducted under the auspices of the Graduate School for Social Economic and Natural Sciences of the Environment (SENSE) 


\section{Effects of land use and land cover change on the water cycle in the Amazon basin under a changing climate}

\section{Rita de Cássia Silva von Randow}

\section{Thesis}

submitted in fulfilment of the requirements for the degree of doctor at Wageningen University

by the authority of the Rector Magnificus, Prof. Dr A.P.J. Mol, in the presence of the

Thesis Committee appointed by the Academic Board to be defended in public

on Tuesday 14 April 2020 at 4 p.m. in the Aula 
Rita C. S. von Randow

Effects of land use and land cover change on the water cycle in the Amazon basin under a changing climate

152 pages.

PhD thesis, Wageningen University, Wageningen, The Netherlands (2020)

With references, with summary in English

ISBN 978-94-6395-308-5

DOI https://doi.org/10.18174/514262 


\section{Table of Contents}

CHAPTER 1 - GENERAL INTRODUCTION ....................................................................... 1

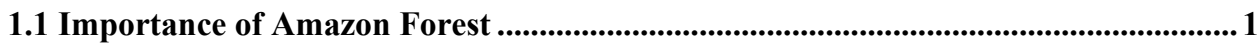

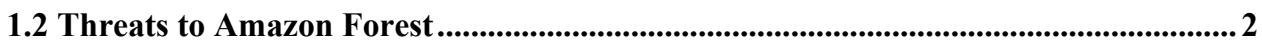

1.3. Knowledge gap ......................................................................................................................... 3

1.4. Objectives and Research Questions........................................................................4

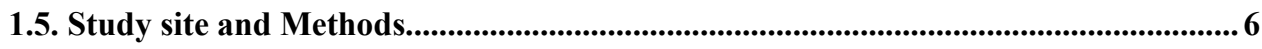

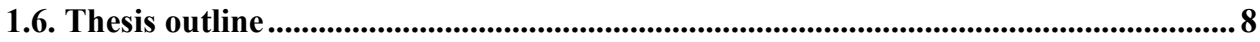

CHAPTER 2 - EVAPOTRANSPIRATION OF DEFORESTED AREAS IN CENTRAL AND

SOUTHWESTERN AMAZONIA ................................................................................................... 11

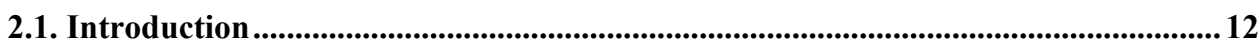

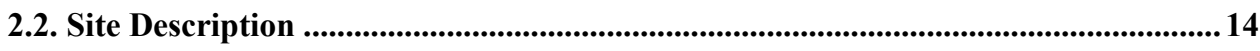

2.3. Methodology ...................................................................................................................... 16

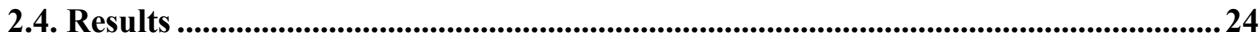

2.5. Discussion........................................................................................................................................... 33

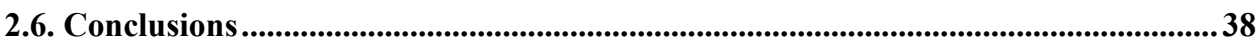

CHAPTER 3 - ANALYSIS OF BIOLOGICAL AND METEOROLOGICAL CONTROLS OF EVAPOTRANSPIRATION IN PRISTINE FORESTS AND A PASTURE SITE IN

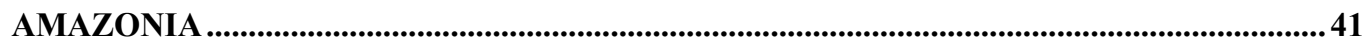

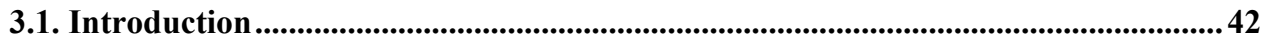

3.2. Methods and site description ......................................................................................... 44

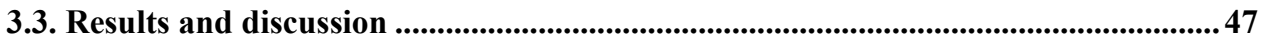

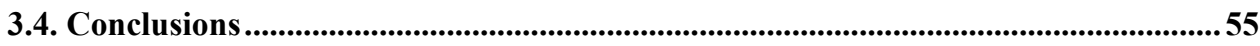

CHAPTER 4 - EVAPOTRANSPIRATION AND GROSS PRIMARY PRODUCTIVITY OF SECONDARY VEGETATION IN AMAZONIA INFERRED BY EDDY COVARIANCE....59

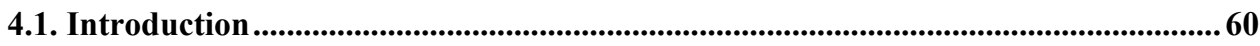

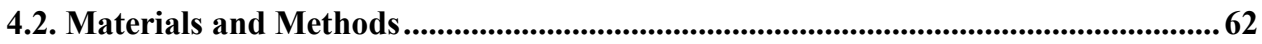




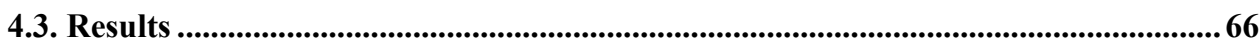

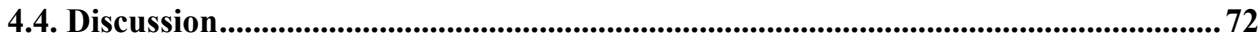

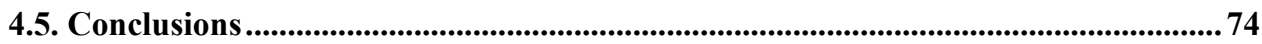

CHAPTER 5 - RESPONSE OF THE RIVER DISCHARGE IN THE TOCANTINS RIVER BASIN, BRAZIL, TO ENVIRONMENTAL CHANGES AND THE ASSOCIATED EFFECTS ON THE ENERGY POTENTIAL......................................................................77

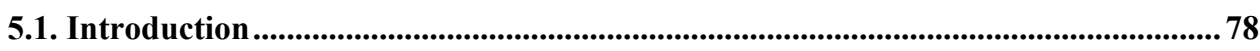

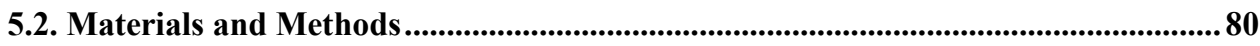

5.3. Results and Discussion............................................................................................................. 87

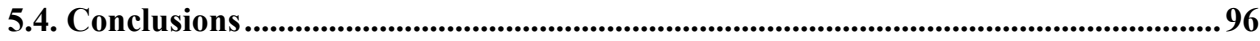

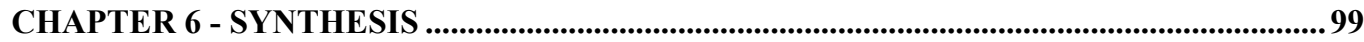

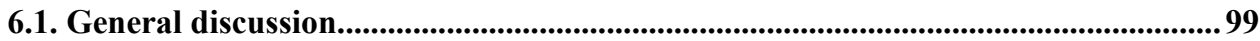

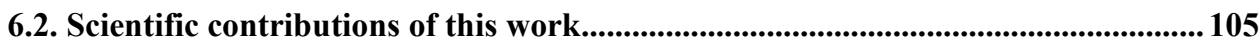

6.3. Implications and recommendations for future work ................................................. 106

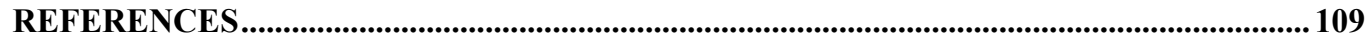

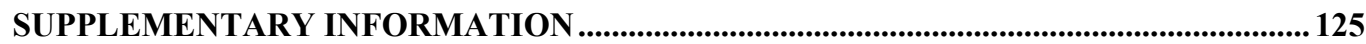

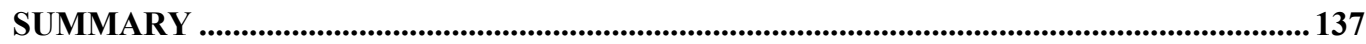

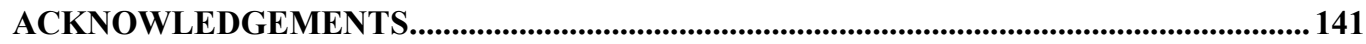

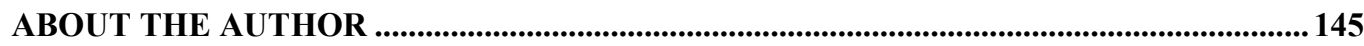

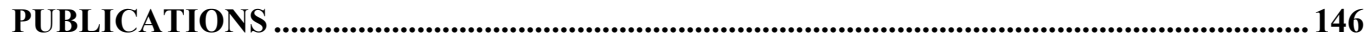






\section{Chapter 1}

\section{General Introduction}

\subsection{Importance of Amazon Forest}

The Amazon forest is the largest remaining tropical rainforest on the planet. It is a host of large biodiversity and an ecosystem services provider, on a regional and a planetary scale. The ecosystem services provided by the forest are wood and non-wood products, divided in categories by Millennium Ecosystem Assessment as provisioning category, such as food, fresh water, fiber, fuel; or as regulating category, such as regulation of air quality, climate, water, erosion, pollination and natural hazard (Chiabai et al., 2011).

Regarding the provision services, the presence of forest helps on the supplying of fresh water by increasing the infiltration, the residence time of water in the soil and consequently the recharge of the water table (Ellison et al., 2017). The river basin has the ability of regulating river flows through land-atmosphere connections caused mainly by the precipitation recycling that is heavily affected by the presence of the forest (Salazar et al., 2018). The Amazon watershed spans 6.9 million $\mathrm{km}^{2}$, connecting nine countries in South America - Brazil, Bolivia, Peru, Ecuador, Colombia, Venezuela, Guyana, Suriname and French Guiana. The hydrological connections help maintain over 1 million $\mathrm{km}^{2}$ of freshwater ecosystems, which sustain a wealth of biological diversity and productive fisheries that are a vital source of protein and income for the local population. The Amazon River network is fundamental for the regional economy (Joly et al., 2019).

The Amazon also regulates climate globally absorbing and storing carbon in its living biomass and in the soil (Aragão et al., 2014; Feldpausch et al., 2012). The carbon stored in its biomass is equivalent to around ten times the current annual emissions of fossil fuel. Moreover, vegetation modulates the regional climate diminishing the temperature and increasing the relative humidity as a result of the evapotranspiration process (Joly et al., 2019). Evapotranspiration also fosters part of the local rainfall through the moisture recycling process, and South American subtropics rainfall in combination with seasonal routes of moisture originated over the tropical 
North Atlantic, and that shifts south after reaching the eastern Andes Mountains flowing in the direction of northern Argentina and southeastern Brazil, the so-called aerial rivers (Arraut et al., 2012; Marengo et al., 2004; Poveda et al., 2014; Zemp et al., 2014). About one-third of Amazon rainfall originates within its own basin, of which two-thirds has been recycled through evapotranspiration (Staal et al., 2018; Zemp et al., 2014). Furthermore, in a large portion of the basin, high rates of evapotranspiration are maintained or even increased during the dry season (Rocha et al., 2009), which may play a relevant role in the onset of the following rainy season (Fu and $\mathrm{Li}, 2004)$.

\subsection{Threats to Amazon Forest}

Humans are using a large area of ice-free land surface, replacing natural cover as forests and other natural ecosystems as savannahs and natural grasslands by croplands, decreasing biodiversity and increasing the surface temperature as a result of carbon release into the atmosphere. Moreover, the changing on land cover may also alter the microclimate and consequently alter the rainfall regime.

Amazon forest has been threatened by several drivers such as land use and land cover change, forest degradation and fragmentation, climate change, forest fires and increase of extreme droughts and floods, which are interconnected in complex ways.

The Amazon has warmed up around $1^{\circ} \mathrm{C}$ in the last century (IPCC, 2013) due to global warming associated primarily to the increase of greenhouse gases emissions. The projections for temperature increase for this century range from $1.8^{\circ} \mathrm{C}$ to $5.1^{\circ} \mathrm{C}$ with even higher values for dry season.

Besides global warming, the land use and land cover change in the region are a result of continued deforestation that is being pushed by the global market demand growth for animal and vegetable protein and the hydropower regional needs. In the beginning of Amazon exploration, human occupation in the Brazilian Amazonia was encouraged by the Brazilian government as forest conversion to pasture and agricultural land, mediated by logging and slash and burning. With the finding of the low productivity of the region, a political approach of valuable nature conservation was adopted, creating territories legally protected from any economic and human activity outside 
indigenous people areas. Even though there are areas that are currently legally protected, changes on the environmental management law can occur depending on the economic situation that the country is facing. As Amazon is a source of natural resources, governance can be weakened encouraging the exploration of current legal protected areas, by mining, wood extraction and agriculture expansion, e.g., the last revision of Forest Code leads to additional deforestation of 41$57 \%$, depending on the commodity price scenario (Verburg et al., 2014).

Between 2005 and 2014, deforestation rates had declined by almost 80\% (PRODES, INPE, http://www.obt.inpe.br/prodes/) and the agricultural output has been increasing significantly by the use of sustainable polices (Macedo et al., 2012) what was also found by projections of future scenarios (Verburg et al., 2014). After this period, the deforestation has been continuously increasing again, reaching almost $10000 \mathrm{~km}^{2}$ in 2019.

\subsection{Knowledge gap}

Although the Amazon forest is recognized as a leading player of the regional and global climate system, the spatial and temporal variability of its hydrological functions is not completely understood; therefore, evaluating the seasonal and spatial variations of the water fluxes in the Amazon region is still influential to improve scientific understanding of its interactions with the overlying atmosphere (Costa et al., 2010; Rocha et al., 2009; Restrepo-Coupe et al., 2013; Von Randow et al., 2013). These variations mainly depend on the characteristics of the vegetation, on energy processes and on water availability (Hasler and Avissar, 2007).

Understanding of vegetation and climate interaction is commonly achieved by field measurements and by land surface and climate models simulations. Although Large-Scale Biosphere-Atmosphere Experiment in Amazonia (LBA) tower network have given a large sampling of measurements of crucial importance for understanding the forest-atmosphere interaction and provide information for the improvement of the models, several aspects related to the effects of spatial variability of land-use change on evaporation remain poorly understood. For example, there is still a lack of studies with long-term field measurements in deforested areas and of comparative studies of different deforested sites. Also, except for leaf scale measurements that 
included some pioneer species (Kunert et al., 2015), literature still lacks reports of direct observations of fluxes in secondary vegetation areas in Amazonia. Additionally, studies that investigated the impacts of climate variability and land use conversion on river discharge (Dalagnol et al., 2017; Mohor et al., 2015; Siqueira Jr et al., 2015) did not consider the impact of secondary vegetation regrowth on the water cycle, which may become an important land use in the amazon in the near future (Aguiar et al., 2016).

\subsection{Objectives and Research Questions}

Considering the importance of Amazonian evapotranspiration for Regional and Global climate, the objective of this thesis is to measure and model evapotranspiration at different land covers in Amazonia, analyzing its spatial and seasonal variability and its environmental and biotic controls.

To achieve these goals, data on pastures, primary forest and secondary forest sites were collected and analyzed. This study is the first comprehensive study of water and carbon fluxes in secondary forest in Amazonia.

Then, observations were used to parametrize a hydrological model to assess the potential combined impacts of Climate Change (CC) and Land Use and Land Cover Change (LCLUC) in river discharges in an Amazon tributary and evaluate the extent to which these effects could influence future energy production. Using this model, the effects of the growth of secondary forests on water and energy production was investigated.

To address these objectives, five research questions were formulated. They are presented in Table 1.1. 
Table 1.1: Research questions addressed in the thesis and applied methods.

\begin{tabular}{|c|c|c|c|}
\hline $\begin{array}{l}\text { Research } \\
\text { Question } \\
\text { (RQ) }\end{array}$ & Research Question & Applied Method & $\begin{array}{l}\text { Chapter where } \\
\text { the RQ was } \\
\text { explored }\end{array}$ \\
\hline RQ 1 & $\begin{array}{l}\text { Are there spatial variabilities between } \\
\text { pastures in Central and Southwestern } \\
\text { Amazonia associated to seasonality } \\
\text { differences? }\end{array}$ & $\begin{array}{l}\text { Field survey and } \\
\text { data analysis }\end{array}$ & Chapter 2 \\
\hline RQ 2 & $\begin{array}{l}\text { What are the controls of } \\
\text { evapotranspiration in pastures of different } \\
\text { regions in Amazon? }\end{array}$ & $\begin{array}{l}\text { Field survey and } \\
\text { data analysis }\end{array}$ & Chapter 2 \\
\hline RQ 3 & $\begin{array}{l}\text { How does pasture differ from the forest } \\
\text { on the evapotranspiration control in the } \\
\text { wet and dry seasons? }\end{array}$ & $\begin{array}{l}\text { Field survey and } \\
\text { data analysis }\end{array}$ & Chapter 3 \\
\hline RQ 4 & $\begin{array}{l}\text { What are the potential effects of } \\
\text { secondary regrowth after abandonment of } \\
\text { deforested areas on evapotranspiration } \\
\text { and water use efficiency }\end{array}$ & $\begin{array}{l}\text { Field survey and } \\
\text { data analysis }\end{array}$ & Chapter 4 \\
\hline RQ 5 & $\begin{array}{l}\text { What are the potential effects of climate } \\
\text { change and land cover change, including } \\
\text { secondary growth, on the local hydrology } \\
\text { and possible impacts on ecosystem } \\
\text { services? }\end{array}$ & \begin{tabular}{lr|}
\multicolumn{2}{l|}{ Hydrological } \\
Modeling & driven \\
by & Regional \\
Climate & Change \\
Model & \\
\end{tabular} & Chapter 5 \\
\hline
\end{tabular}




\subsection{Study site and Methods}

This study was carried out in the Brazilian Amazon, based on data collected in sites of different vegetation types over Southwestern and Central Amazon region and on hydrological modeling projections on the Tocantins river basin.

In Central Amazonia, two sites were selected North of Manaus. The first site is a cattle ranch known as Colosso (CO), one of the study sites from the Biological Dynamics of Forest Fragments Project (PDBFF, the portuguese acronym) (Gama, 1997). CO is covered by fragmented vegetation, of which a pasture (Brachiaria humidicola) and a secondary forest growth, resulted from an abandoned degraded pasture, were studied. The second site in Central Amazonia is a primary Terra fime rain forest located in the Cuieiras Biological Reserve, known as K34. The annual precipitation at Central region varies from 1800 to $2800 \mathrm{~mm} /$ year (Tomasella et al., 2008), presenting a weak seasonality. The temperature ranges from $19^{\circ} \mathrm{C}$ to $39^{\circ} \mathrm{C}$.

In Southwesten Amazon, also two sites were selected. One farm ranch called Fazenda Nossa Senhora Aparecida (FNS), about 50 km Northwest of Ji-Paraná, Rondônia state, covered by pasture (Brachiaria brizantha) (Zanchi et al., 2009) and one site at Jaru Biological Reserve, about $100 \mathrm{~km}$ north of Ji-Parana, covered by primary forest. The annual average precipitation at both regions varies from 1250 to $2500 \mathrm{~mm}$, and presents a well-defined dry season, with less than $50 \mathrm{~mm}$ per month in the driest 3 months (Von Randow et al., 2004). The temperature ranges from $17^{\circ} \mathrm{C}$ to $32^{\circ} \mathrm{C}$. K34, FNS and Jaru sites are long-term study sites from the LBA tower network.

Most of the data of eddy covariance measurements used were available through the LBA project, except for the $\mathrm{CO}$ pasture and $\mathrm{CO}$ secondary forest fluxes, which were collected throughout 2006 to 2011 as part of this thesis. In CO pasture fluxes were derived from scintillometer measurements and meteorological data collected by an automatic weather station, and a full eddy covariance tower was installed in CO secondary forest. The locations of these sites were selected to provide a good representation of Terra-Firme intact forests, land-use conversions to pastures and secondary forest, and also a good sense of differences in dry season responses. While the sites in Central Amazon experience year-round rainfall usually above $100 \mathrm{~mm} / \mathrm{month}$, in Southwestern Amazon dry seasons of up to 4 months are much clearer. 


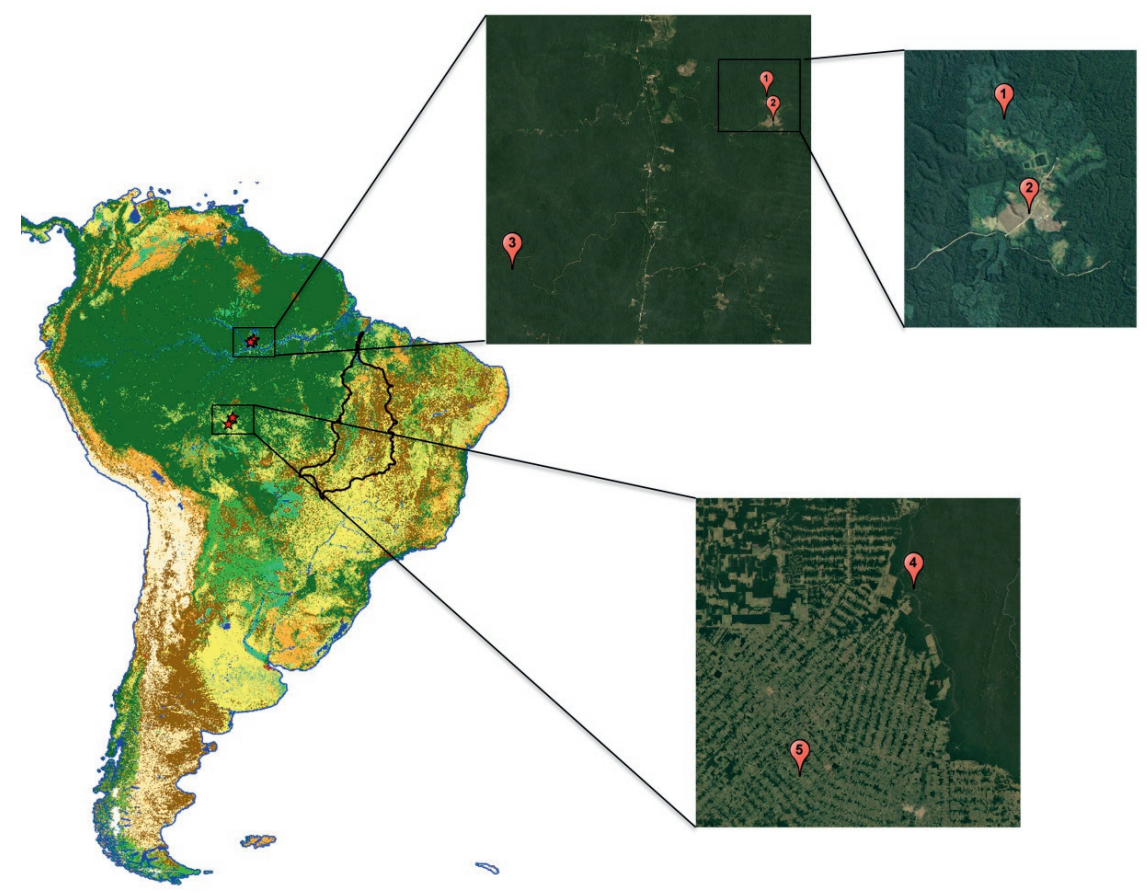

Figure 1.1 Sites location: 1) Colosso Secondary Forest; 2) Colosso Pasture; 3) Cuieras Biological Reserve; 4) Jaru Biological Reserve; 5) Fazenda Nossa Senhora Pasture; The black line delineates Tocantins River Basin.

Additionally, hydrological modelling projections in Tocantins river basin were performed by MHD-INPE model (Rodriguez and Tomasella, 2016) under climate change scenarios from EtaINPE model (Chou et al., 2012; Marengo et al., 2012) and land use and land cover change scenarios from LUCC-ME and INPE-EM modeling framework (Aguiar et al., 2012; 2016). Tocantins basin was chosen because it is one of the most anthropized basins in the North region of Brazil, and its dams are stablished for longer period than others in the region, including Tucuruí, the largest water dam in reservoir area in Brazil, with a total energy potential of $26935.83 \mathrm{MW}$, of which 13252.68 MW is operational (SIPOT-Eletrobrás, 2018). Tocantins Basin is the hub between the North/Northeast and South/Southeast power grids. Thus, it is a representative basin to investigate impacts on water supply. Furthermore, land use changes in the lower Tocantins basin are 
characterized by the replacement of tropical forest by pasture, followed by the abandonment of pasture allowing secondary forest regrowth, that are the land cover subjects of this study. Figure 1.1 shows the studied sites and the modeled basin.

\subsection{Thesis outline}

This thesis consists of six chapters that are summarized in Figure 1.2. In the Chapter 2 the spatial and seasonal variability of the evapotranspiration in pasture sites in two regions of Amazonia were studied by eddy covariance and scintillometer data analysis. Also, to understand the control of evapotranspiration for each site, it was calculated the decoupling factor proposed by Jarvis and McNaughton (1986). A comparison of evapotranspiration and functioning of one pasture and two forests on the two different regions in Amazonia was investigated in Chapter 3, also using data from eddy covariance measurements and the decoupling factor by Jarvis and McNaughton. Then, the daily, seasonal and yearly variations in evapotranspiration and the gross primary productivity of carbon and water use efficiency of a 20 year old secondary forest versus a primary forest in Central Amazonia were investigated in Chapter 4. All the information collected on Chapters 2, 3 and 4 helped to feed the vegetation parameters of the hydrological model (MHD-INPE) to run future scenarios of climate change and land use and land cover changes on Chapter 5 , to investigate the possible impacts of those changes on river discharges of an Amazon sub-basin and consequently on hydropower, one of the Amazon ecosystem services. 

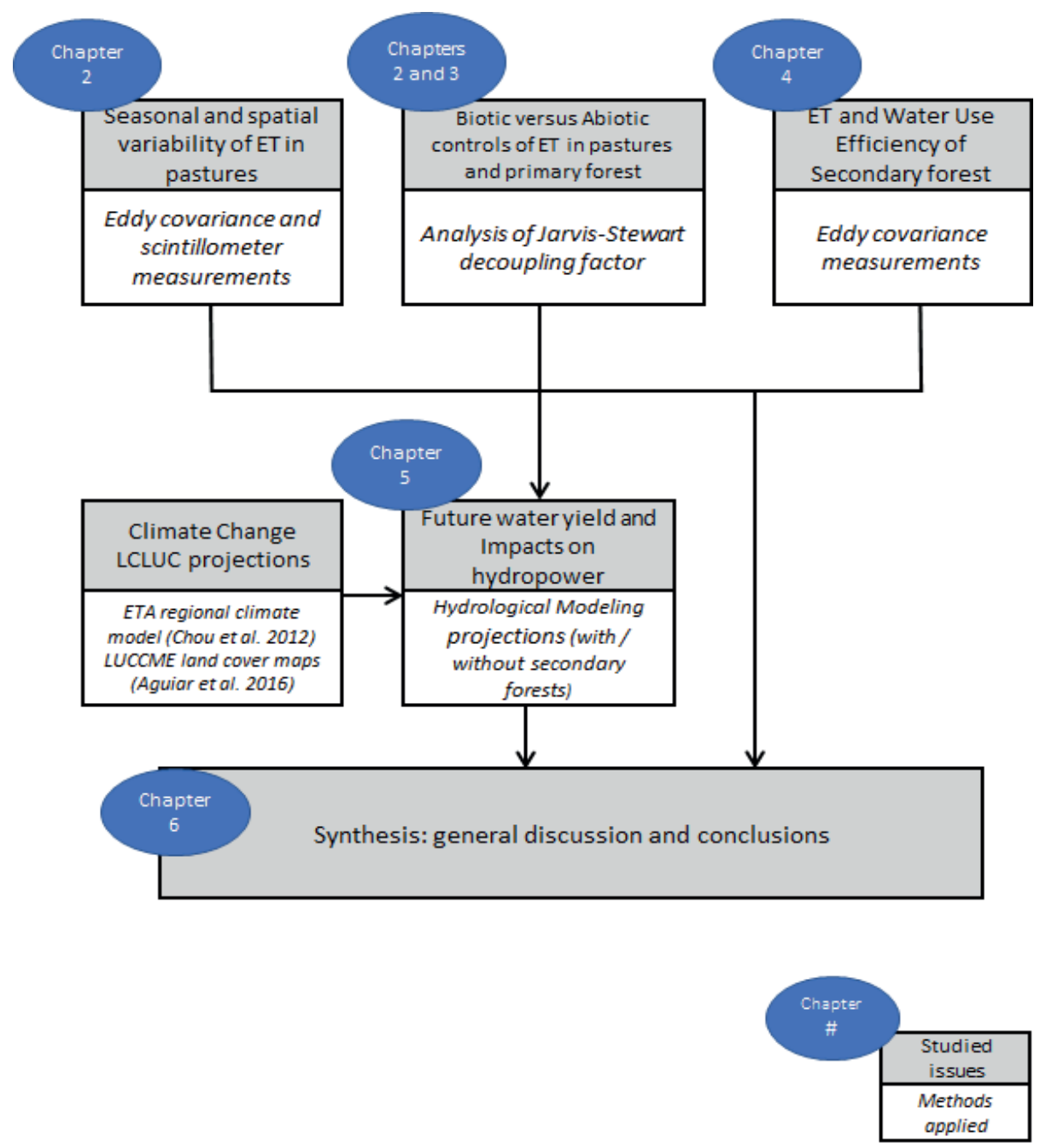

Figure 1.2 Overview of thesis structure, with main issues studies throughout the chapters and respective methods applied. 


\title{
Chapter 2
}

\section{Evapotranspiration of deforested areas in central and southwestern Amazonia ${ }^{1}$}

\begin{abstract}
Considering the high rates of evapotranspiration of Amazonian forests, understanding the impacts of deforestation on water loss rates is important for assessing those impacts on a regional and global scale. This paper quantifies evapotranspiration rates in two different pasture sites in Amazonia and evaluates the differences between the sites. In both places, measured evapotranspiration varies seasonally, decreasing during the dry season. The decrease is higher at the southwestern Amazonia site, while at the central Amazonia site, the decrease is less pronounced. During the dry season, average values of evapotranspiration are around $2.2 \pm 0.6 \mathrm{~mm}$ day $^{-1}$ in central Amazonia and $2.4 \pm 0.6 \mathrm{~mm}_{\text {day }}{ }^{-1}$ in southwestern Amazonia, while during the wet season, those values are $2.1 \pm 0.6 \mathrm{~mm} \mathrm{day}^{-1}$ in central Amazonia and $3.5 \pm 0.8 \mathrm{~mm} \mathrm{day}^{-1}$ in southwestern Amazonia. On an annual basis, the pasture in southwestern Amazonia has higher evapotranspiration than in central Amazonia. We conclude that the main reason for this difference is the lower available energy in the wet season at the central Amazonian site, combined with a lower leaf area index at this site during the whole year. Still, the evapotranspiration is significantly controlled by the vegetation, which is well coupled with the local moisture conditions in the dry season.
\end{abstract}

\footnotetext{
${ }^{1}$ This chapter is published as: Von Randow, R. C. S., Von Randow, C., Hutjes, R. W. A., Tomasella, J., \& Kruijt, B. (2012). Evapotranspiration of deforested areas in central and southwestern Amazonia Theoretical and Applied Climatology, 109(1-2), 205-220. https://doi.org/10.1007/s00704-011-0570-1
} 


\subsection{Introduction}

From a global warming and climate change perspective, changes in precipitation and temperature in the most vulnerable ecosystems, as well as in those regions with the potential of affecting climate on a regional to global scale (teleconnections), are of high concern. Amazonia is one of the regions of biggest concerns nowadays, not only because of its importance for the climate, but also because the region is under ongoing land use change that can intensify climate change through various feedback mechanisms.

Amazonia represents more than $40 \%$ of the remaining tropical rainforest in the world (Laurance and Williamson, 2001). This large biome has a strong bidirectional interaction between its land cover and the atmosphere, such as the influence of its water flow and evaporation on the regional and global climate (Marengo et al., 1994; Zeng, 1998). Amazonian Ecosystems are characterized by high evapotranspiration rates, which leads to a recycling of up to $60 \%$ of the total rainfall within the region (D'Almeida et al., 2007; Franken and Leopoldo, 1984; Salati and Nobre, 1991; Victoria et al., 1991; Vörösmarty et al., 1989) and they are also responsible for a large amount of moisture transport from the Amazon to other regions of South America (Marengo et al., 2004; Soares and Marengo, 2009).

Large-scale land use change may significantly affect the moisture regime of the region. The deforestation rate in the Brazilian Amazon from August 2009 to July 2010 was $7.0 \times 10^{3} \mathrm{~km}^{2} /$ year on average (PRODES, INPE, http://www.obt.inpe.br/prodes/), fortunately at lower rates than in previous years. Studies have shown that replacement of the native vegetation by grass or cropland (nowadays the most common is soybeans) affects the climate and hydrological cycle through changes in albedo, surface temperature, soil water content, the evapotranspiration regime and runoff (D’Almeida et al., 2007; Von Randow et al., 2004).

Measuring evapotranspiration (ET) on large spatial and temporal scales is not an easy task, particularly in Amazonia due to difficult access to the area. Therefore, modeling this process is an important strategy for scaling up the measurements. Current models do not yet well represent the seasonal and spatial variability of ET in Amazonia. While Global Climate Models (GCMs) show the annual cycle of Amazonian ET peaking in the wet season (Dickinson and Henderson-Sellers, 1988; Werth and Avissar, 2004), recent field observations show that evaporation rates increase in the dry season, coincident with increased radiation (Da Rocha et al., 2009; Hasler and Avissar, 
2007). This is presently believed to be caused by the search by forest root systems for water deep in the soil during the dry season (Negron-Juárez et al., 2007). Conversely, pastures in Amazonia have higher albedo (Bastable et al., 1993) and are very sensitive to soil moisture stress during dry spells (Hodnett et al., 1995; Wright et al., 1992), causing evapotranspiration to decline during the dry season (Da Rocha et al., 1996; Von Randow et al., 2004).

Field measurements of energy and water surface fluxes have been conducted since the early 1980s in Amazonia (e.g. Shuttleworth et al., 1984). Recently, Da Rocha et al., (2009) summarized results from the Large Scale Biosphere-Atmosphere Experiment in Amazonia (LBA) tower network. While these measurements have been of crucial importance for understanding the functioning of the forest-atmosphere interaction and for improvement of models, several aspects related to the effects of spatial variability of land use change on evaporation remain poorly understood. For example, there is still a lack of studies with long term field measurements in deforested areas and of comparative studies of different deforested sites.

The objective of the current study is to present measurements and calculations of evapotranspiration for two pasture sites in Amazonia and to evaluate the differences between them. Another related objective of this study is to provide modeling parameters for additional sites in order to address the need of the modeling community to better simulate the spatial variability of this vegetation type in the Amazonian region. 


\subsection{Site Description}

This work is based on data from two sites in the Brazilian Amazon. The first data set was collected in a pasture site located in one of the study areas of the Biological Dynamics of Forest Fragments Project (in Portuguese Projeto Dinâmica Biológica de Fragmentos Florestais, PDBFF Portuguese acronym) in a cattle ranch known as Colosso (hereafter CO). CO is about $90 \mathrm{~km}$ north of Manaus, Amazonas state, Brazil, in Central Amazonia (Figure 2.1). The site was deforested in the 1970s and it was subsequently seeded with brachiaria humidicola (Nee, 1995). Although the precipitation regime in the area is characterized by a relatively weak seasonality, two distinct seasons are perceived: rainy (starting in November to May) and dry (August to October), and the annual totals vary from 1800 to $2800 \mathrm{~mm}$ per year (Tomasella et al., 2008). The annual average

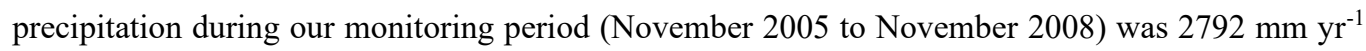
(Figure 2.2a), so we are analyzing relatively wet years for CO in this study. The climate of the area is considered Af according to the Köppen classification (tropical rainforest climate), with temperature varying from $19^{\circ} \mathrm{C}$ to $39^{\circ} \mathrm{C}$.

The topography in the Manaus area is characterized by a topographic sequence of flat or gently sloping plateaus, slopes and valleys. The plateau soils are classified as Latossolos Amarelos Álicos, textura argilosa (Soil Taxonomy Xanthic Hapludox, FAO Xanthic ferrasol). On the slopes the soils vary from yellow latosols to the eluvial soils known as Argissolos Vermelho-Amarelo Álicos (FAO Haplic Acrisol). Finally, the valley bottoms are dominated by Podzóis Hidromórficos (Soil Taxonomy Arenic Haplorthod, FAO very sandy Haplic Podzol) (Chauvel et al., 1987; Chauvel, 1982; Ranzani, 1980). More information on the geology and topography of the Manaus area can be found in the work of Tomasella et al., (2008). Soil texture is very clayey up to $2 \mathrm{~m}$ depth in the plateau area, increasing from $78.5 \pm 0.4 \%$ at $0-5 \mathrm{~cm}$ to $92.2 \pm 0.2 \%$ at $160-200 \mathrm{~cm}$ (Marques, 2009). The bedrock was not encountered within the upper $45 \mathrm{~m}$ in the plateau and $35 \mathrm{~m}$ in the slope, both accessed by a borehole that was drilled to monitor groundwater levels.

The second data set was collected at a pasture site in Southwestern Amazonia, as part of the Large Scale Biosphere Atmosphere Experiment in Amazonia (LBA). The site is a farm called Fazenda Nossa Senhora Aparecida (hereafter referred as FNS) also deforested in the late 1970s (http://lba.cptec.inpe.br/lba/prelba/abracos/climate.html) for cattle grazing. FNS is located about $50 \mathrm{~km}$ northwest of Ji-Paraná, Rondônia state, Brazil (Figure 2.1). The precipitation presents strong 
seasonality, with monthly totals of over $200 \mathrm{~mm}$ during the rainy season (November to April) and monthly totals rarely reaching $20 \mathrm{~mm}$ during the dry season (from June to August). Usually, in July, the monthly precipitation is less than $5 \mathrm{~mm}$ (Nobre et al., 1996). This monthly minimum value differs significantly from the dry season monthly values in Central Amazonia, which at the CO site presented a minimum of $45 \mathrm{~mm}$. Annual total precipitation varies from 1250 to $2500 \mathrm{~mm}$ (Rodriguez et al., 2010). The annual average precipitation during the period of January 1999 to December 2002 was $1744 \mathrm{~mm} \mathrm{yr}^{-1}$ (Figure 2.2b), which is within the climatological range of precipitation for the region. We are comparing a normal period in SW Amazonia with a wet period in Central Amazonia. In section five we will discuss the implications of this comparison on our results. The climate is equatorial, warm and moist. Based on a climatology of conventional meteorological data collected in Ouro Prêto D'Oeste, $20 \mathrm{~km}$ from FNS, the temperature in the region varies from around $17^{\circ} \mathrm{C}$ to $32^{\circ} \mathrm{C}$.

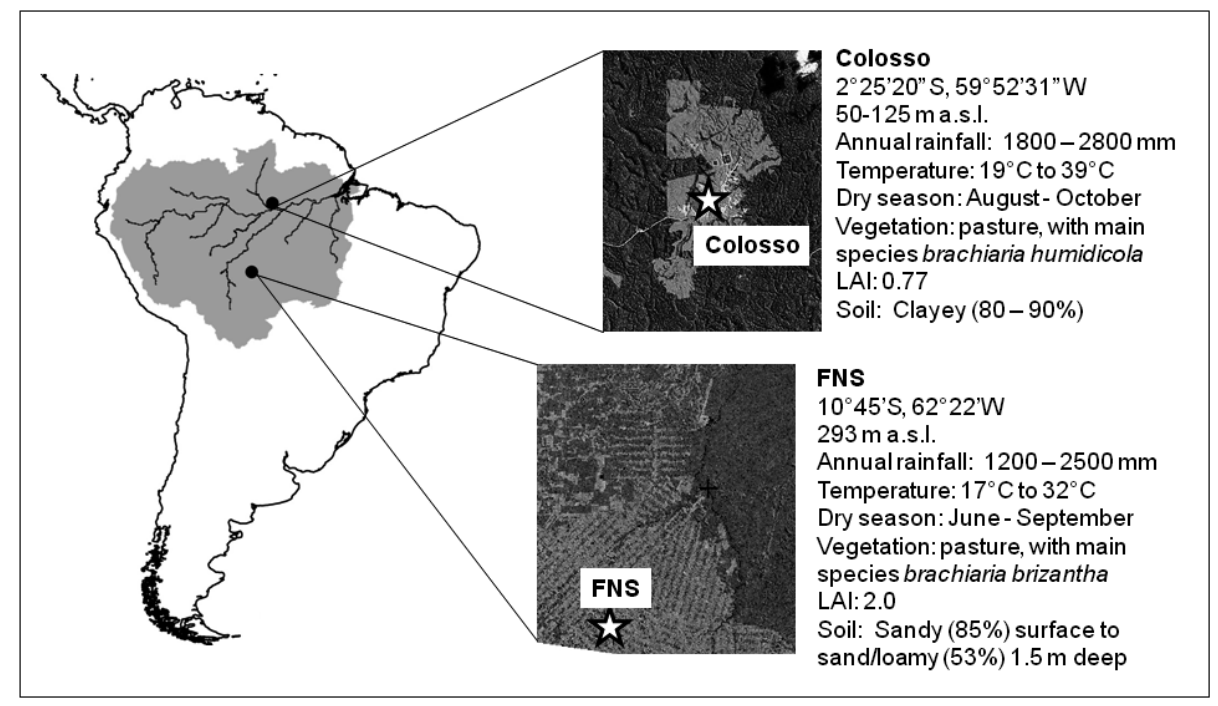

Figure 2.1 Location of Colosso and Fazenda Nossa Senhora sites

In the Rondonia area, particularly at FNS, the topography is generally flat. The soil was classified as medium textured red-yellow podzol (Podzólico vermelho amarelo A moderado textura média - Brazilian Soil Taxonomy, typic paleudult - or orthic acrisol - FAO). Soil textures varies from sand to sand/loam, with clay contents increasing with depth. At $1 \mathrm{~m}$ and $1.5 \mathrm{~m}$ the texture is sandy clay loam. Between $1 \mathrm{~m}$ and $2 \mathrm{~m}$, the soil is gravelly, merging into saprolite below $2 \mathrm{~m}$. 
Detailed information about the soil texture is found in (Hodnett et al., 1996). The bedrock was not encountered within the upper $3.8 \mathrm{~m}$ of the profile. The altitude of the region is $200 \mathrm{~m}$ above sea level.
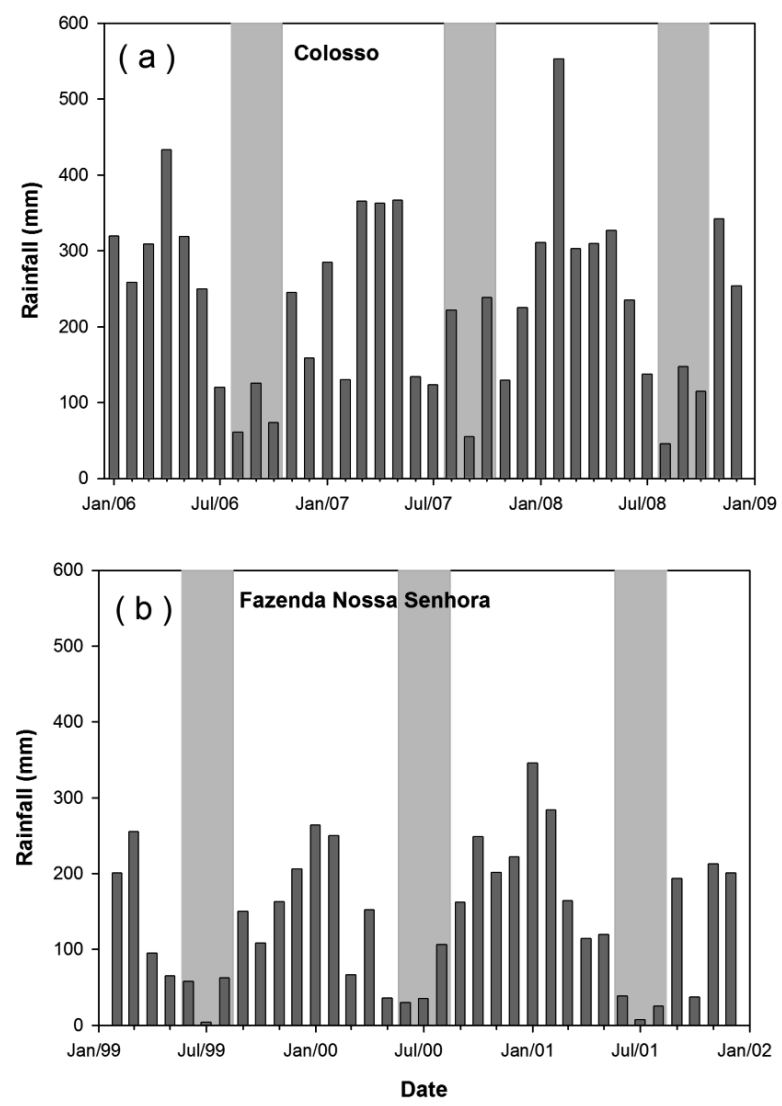

Figure 2.2 Monthly total precipitation at a) CO, from January 2006 to December 2008, averaging $2792 \mathrm{~mm} / \mathrm{yr}$ and b) FNS from February 1999 to December 2002, averaging $1744 \mathrm{~mm} / \mathrm{yr}$. The shadow indicates the dry season.

\subsection{Methodology}

For practical reasons, we assessed the evapotranspiration at the two sites using two different approaches. At the CO site (Central Amazonia) we used a Large Aperture Scintillometer (LAS) to estimate sensible heat flux, estimating evaporation by forcing the closure of the energy balance. At 
the FNS site (Southwestern Amazonia) the evapotranspiration was estimated directly through an eddy covariance (EC) system. In the following subsections we describe the two measurement approaches and the scaling methods that were used.

\subsubsection{Measurements}

An Automatic Weather Station (AWS) was installed on the plateau of the CO site, recording data from March 2005 to December 2008, with averaging intervals of 30 minutes. Precipitation was measured near the AWS with $0.25 \mathrm{~mm}$ resolution during the same period. The evapotranspiration at the CO site was estimated using a Large Aperture Scintillometer (LAS) installed on the plateau in a short campaign from September 2007 to February 2008. The receiver was installed at the AWS and the emitter was positioned about $450 \mathrm{~m}$ from the receiver, over the plateau on the opposite side of a small valley. A table with the list of deployed instruments is presented in the appendix (Table S2.1).

Micrometeorological measurements were complemented with auxiliary measurements of soil moisture and vegetation characteristics such as leaf area index (LAI). The LAI was measured in a single field campaign in the beginning of February 2008 (wet season), applying a destructive method. We chose one spot of one square meter on each topographic element of the scintillometer path, totaling five spots. All biomass, including stems and dead leaves, were cut and weighed. Beside each spot, a small sample of the grass was also taken and weighed, the green leaves were flattened and dried and the area was measured with a leaf area index measurer (model LICOR $3000 \mathrm{~A})$. LAI is the result of estimated leaf mass times specific leaf area. After accounting for leaf area loss after drying the samples, the estimated LAI for Colosso is 0.77 , considering only the green leaves, without the stems.

Data at FNS were collected by an AWS, providing measurements of all weather variables, also in 30 minute intervals. All the measurements collected at $\mathrm{CO}$ were also collected at FNS. Evapotranspiration was measured by an eddy correlation system. All details about the eddy covariance system and other instrumentation at FNS can be found in the work of von Randow et al., (2004). 


\subsubsection{Data Analysis}

\subsubsection{Large Aperture Scintillometer calculations}

In the first method, evapotranspiration is a direct outcome of the energy balance equation. The scintillometer measures the sensible heat flux $(H)$ along the path through which its beam passes. With additional measurements of net radiation $\left(R_{n}\right)$ and soil heat flux $(G)$, latent heat flux $(\lambda E)$ is obtained from the residual of the energy balance equation.

Detailed explanations of how the scintillometer functions can be found in the work of Hemakumara et al. (2003), Hill (1992), Meijninger et al. (2002) and Wesely (1976), among others. Here, we give a brief explanation of how the sensible heat flux is obtained from the scintillometer measurements, which were made by a LAS (LAS 150, Kipp \& Zonen, Delft, The Netherlands).

A scintillometer is an instrument that can measure the 'amount' of scintillations by emitting a beam of light over a horizontal path. The scintillations 'seen' by the instrument are expressed as the structure parameter of the refractive index of air $\left(C_{n}{ }^{2}\right)$, which is mainly related to fluctuations in the air temperature and humidity.

Because humidity related scintillations in the visible and near-infrared region are much smaller than temperature related scintillations, we can estimate the structure parameter of temperature $C_{T}^{2}$ from the measured $C_{n}{ }^{2}$ from the expression

$$
C_{T}^{2} \approx C_{n}^{2}\left(\frac{T^{2}}{-0.78 \cdot 10^{-6} P}\right)^{2}\left(1+\frac{0.03}{\beta}\right)^{-2}
$$

where $P$ is the atmospheric pressure, $T$ is the air temperature and $\beta$ is the Bowen ratio, which provides a correction for humidity related scintillations.

Once $C_{T}^{2}$ is known, the sensible heat flux $(H)$ can be derived from a universal function $\psi_{T T}$ that is based on Monin-Obukhov Similarity theory (MOS).

$$
\frac{C_{T}^{2}\left(z_{L A S}-d\right)^{2 / 3}}{T_{*}^{2}}=\psi_{T T}\left(\frac{z_{L A S}-d}{L_{M O}}\right)
$$


where $d$ is a zero-displacement height, $z_{L A S}$ is the effective height of the scintillometer beam above the surface along the path (Hartogensis et al., 2003), $L_{M O}$ is the Obukhov length and $T *$ is a temperature scale defined as

$$
T_{*}=\frac{-H}{\rho c_{p} u_{*}}
$$

In the latter equation, $\rho$ is the air density, $c_{p}$ is the specific heat of air and $u *$ is the friction velocity. In this work we adopted $\psi_{T T}(\zeta)=4.9(1-9 \zeta)^{-2 / 3}\left(\zeta<0, \zeta=\left(z_{L A S}-d\right) / L_{M O}\right)$, after De Bruin et al., (1993).

Note that the LAS provides only $C_{T}^{2}$ and a measurement of $u *$ is necessary. We use wind speed measurements and flux profile relationships to estimate $u^{*}$.

Since the choice of roughness length may have a significant influence on LAS calculations, and the determination of the grass height that affects the air flow in the LAS path is not straightforward, we estimated an uncertainty associated with this parameter by calculating the difference resulting from different grass heights. The grass height at the site is around $10 \mathrm{~cm}$, with some branches reaching up to $50 \mathrm{~cm}$. The resulting impact on the final calculations of $\lambda E$ from this range was around $8 \%$. This uncertainty was added to the final $\lambda E$ values.

The scintillometer measurement is a weighted average of all scintillations along the path, with the highest contributions from the middle of the path and the smallest contributions near both ends. Figure 2.3 shows a representation of the scintillometer path installed at $\mathrm{CO}$ and of the normalized weighting function that indicates the sensitivity of the scintillometer measurements.

\subsubsection{Eddy Covariance calculations}

At the second site, FNS, we used an eddy covariance system that directly measures fluxes of momentum, energy and carbon dioxide. Eddy covariance at FNS is a closed-path system, composed of a three axis sonic anemometer (Solent 1012R2, Gill Instruments, UK) and a fast-response closed path infrared gas analyzer (IRGA) (LI-6262, LICOR, USA), recording the micrometeorological variables at a sampling rate of $10.4 \mathrm{~Hz}$ (Moncrieff et al., 1997). The calculations of the eddy fluxes were performed for 30 min intervals using Alteddy software (Von Randow et al. 2004). 


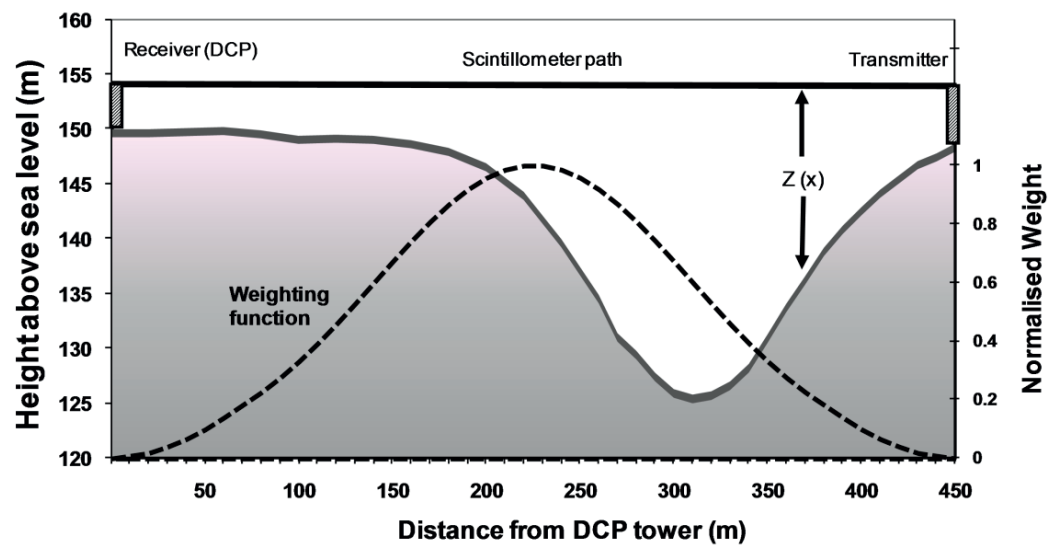

Figure 2.3 Representation of the topography at Colosso site and the weighting function along the scintillometer path (dashed line)

Gaps in the eddy covariance measurements, either related to instrument failures or unfavorable micrometeorological conditions, were filled using the algorithm described by Reichstein et al., (2005). The algorithm uses a look-up table method similar to Falge et al. (2001), but considers both the co-variation of fluxes with meteorological variables and the temporal autocorrelation of the fluxes: missing values are replaced by average values obtained under "similar" meteorological conditions within a time-window of \pm 7 days (or larger time windows when no data with similar meteorological conditions are available within the time window; see Appendix 1 in Reichstein et al. (2005), for a complete description of the algorithm).

\subsubsection{Comparison of LAS versus EC and Energy balance closure}

Before deploying the LAS in the tropics, we tested the instrument next to an EC system for about two weeks in September 2004, over a grassland field near the Cabauw Tower in the Netherlands. In order to have a good view of possible artifacts related to the differences of the two methods, several regressions between flux estimates were performed. First, the directly comparable measurements of sensible heat flux by the two approaches (H_LAS x H_EC) agree well (Table 2.1). However, the LAS-estimated latent heat flux $\left(\lambda E_{-} L A S\right.$, estimated from the residue of the energy balance) overestimates the measured $\lambda E$ from the EC by almost $50 \%$ (although with an intercept of $\sim-20 \mathrm{~W} \mathrm{~m}^{-2}$ ). 
During the test period, however, as in many studies, the sum of EC heat fluxes is underestimated by about $25 \%$ relative to independent measurements of the available energy represented by the remaining terms of the balance $R n-G$. Finally, by correcting the EC measurements for energy balance closure, either by maintaining the Bowen ratio $(H / \lambda E)$ as measured or estimating $\lambda E$ from the residue of the energy balance, similar to the LAS, the comparison of the two instruments showed good agreement (Table 2.1).

Table 2.1: Regressions with LAS-estimated heat fluxes and EC-based measurements over a grassland field near Cabauw, the Netherlands

\begin{tabular}{|c|c|c|c|}
\hline & Slope & Intercept & $r^{2}$ \\
\hline H_LAS x H_EC & 0.95 & 10.9 & 0.92 \\
\hline$\lambda E \_L A S$ (residue of EB) $x \lambda E \_E C$ & 1.47 & -19.9 & 0.88 \\
\hline$\lambda E$ LAS (residue of EB) $\times \lambda E$ EC (residue of EB) & 0.97 & -9.8 & 0.97 \\
\hline $\begin{array}{l}\lambda E \text { E_LAS (residue of EB) } \times \lambda E \_E C \\
\text { (forced closure maintaining Bowen ratio) }\end{array}$ & 1.04 & -28.0 & 0.88 \\
\hline
\end{tabular}

It is likely that the measured $\lambda E_{-} E C$ misses part of the exchanged water vapor, either due to physical limitations of the instrumentation (Massman and Lee, 2002) or losses on scales of the order of more than $30 \mathrm{~min}$. Recent studies have shown that the atmospheric boundary layer frequently presents slowly moving large eddies caused by strong convective motions and/or local circulations induced by surface heterogeneity, and turbulence is organized into 'turbulent organized structures' (Foken, 2008; Kanda et al., 2004), which are not moved with the wind fast enough to be adequately sampled in the time scales usually used in eddy covariance. Since the LAS measures a variable that represents a spatial average along the path, it samples a larger number of eddies than the EC in shorter time intervals. From the results obtained with the instruments comparison, we conclude that after correcting for lack of energy balance closure, the two methodologies are robust for identifying possible site-specific differences in our pasture sites.

The effects of non-closure of the energy balance were also not negligible at FNS and typically 0-25 percent of available energy was missing in the fluxes, depending on the season. When necessary, the eddy fluxes were adjusted for both $\mathrm{H}$ and $\lambda \mathrm{E}$, maintaining the Bowen ratio as measured. This approach is preferred when it is likely that the underestimation of the fluxes is 
caused not by the instrument limitations, but because of a failure to capture low frequency transport or advection or from a mismatch between footprint of the flux measurements compared to that of the radiation measurements. From previous studies in Amazonia (Finnigan et al., 2003; Von Randow et al., 2004), we concluded that this approach is appropriate for FNS. Moreover, we performed a sensitivity analyses with the EC measurements using both approaches. In the particular case of the FNS site, the corrections with the two approaches resulted in annual ET values that differed by less than $5 \%$ at FNS.

\subsubsection{Stomatal conductance and ET parameterization}

Complementing the analyses of seasonal variations with the LAS measurements and with the objective of estimating annual totals of ET at $\mathrm{CO}$ and providing useful information for modeling studies, we also analyzed the Jarvis-Stewart parameterization for stomatal conductance. Thus, we used the LAS data to optimize the coefficients of the parameterization for conditions at CO. Then the calibrated model was applied to the AWS measurements to estimate the ET for the whole period available using the Penman-Monteith equation.

The stomatal conductance parameterization developed by Jarvis (1976), with modifications proposed by Stewart (1988) for forest canopies and by Dolman et al., (1991; 1988) for grassland is given by

$$
g_{s}=g_{s \max } L * f(S) f(T) f(D) f(\theta)
$$

where $g_{\text {smax }}$ is the maximum stomatal conductance $(\mathrm{m} / \mathrm{s}), L^{*}$ is the leaf area index $(-), S$ is the solar radiation $\left(\mathrm{W} / \mathrm{m}^{2}\right), T$ is the canopy temperature $\left({ }^{\circ} \mathrm{C}\right), \theta$ is the soil moisture content $(\mathrm{kg} / \mathrm{kg})$ and $D$ is the specific humidity deficit $(\mathrm{g} / \mathrm{kg})$, given by the difference between the specific humidity at saturation $\left(q_{\text {sat }}\right)$ and the actual specific humidity $(q)$. The control functions are

$$
\begin{gathered}
f(D)=\exp \left(-a_{2} D\right) \\
f(S)=(S / 1000)\left[\left(1000+a_{3}\right) /\left(S+a_{3}\right)\right] \\
f(\theta)=\left\{\begin{array}{c}
0, \text { for } \theta<\theta_{w} \\
\left(\theta-\theta_{w}\right) /\left(a_{4}-\theta_{w}\right), \text { for } \theta_{w}<\theta<a_{4} \\
1, \text { for } \theta>a_{4}
\end{array}\right\}
\end{gathered}
$$


where $\theta_{w}$ is the wilting point soil moisture content. Based on the work of Wright et al. (1995), the function of temperature is not used in the parameterization because of its weak and uncertain influence on stomatal response at these pastures sites.

A non-linear optimization of the controlling parameters $g_{\text {smax }}$ and $a_{2}-a_{4}$ in Equations 4 to 7 for $\mathrm{CO}$ was done by fitting parameterized $g_{s}$ to a set of observed $g_{s}$. The latter was obtained by inverting the Penman-Monteith equation using the $\lambda E$ measured by the scintillometer. Only data where the evapotranspiration consisted mostly of transpiration were considered for the optimization. The data that could be 'contaminated' by free evaporation were ignored by excluding a period of six hours after each rain event. As a result, the data used in the optimization had a total of 925 half hour measurements.

The intercepted rainfall was not measured at CO; however, the impact of not considering the evaporation effect in the parameterization was tested by comparing the transpiration estimated by PM with the scintillometer based measurements (which represent both transpiration and possible intercepted evaporation). First, we separated data measured during rain events and 6 hours after each event, assuming these would be when the evaporation of intercepted rain would be most significant. Then, we compared the PM estimates with LAS measurements in these conditions and in "rain-free" periods. The linear regressions showed that the difference between the angular coefficients in both cases is 0.01 . This indicates that the evaporation of intercepted rain is a very small fraction of the total evapotranspiration.

The dry season at FNS is from June to August, but in order to compare the evapotranspiration measured at FNS with the evapotranspiration derived from scintillometer measurements at CO, we selected the period from July to September at FNS to avoid any remaining signal from the previous wet season and also because September is the period in which the vegetation is likely to be under stress. We compared these data with the months in which data from the dry season are available at CO: September and October. We chose the three wettest months at FNS - January, February, and March - to use in the analysis and comparison between the wet seasons of the sites. The analysis at $\mathrm{CO}$ was based on the available data: December, January and February. 


\subsubsection{Decoupling factor}

To investigate to what extent the vegetation at the site controls the transpiration, compared to conditions where the evapotranspiration is decoupled from the surface and limited by the available energy, we calculated the decoupling factor $(\Omega)$ proposed by Jarvis and McNaughton (1986), defined as

$$
\Omega=\left[1+\frac{\gamma}{\Delta+\gamma} \frac{r_{s}}{r_{a}}\right]^{-1}
$$

where $r_{s}$ is the surface resistance and $r_{a}$ is the aerodynamic resistance. Values of $\Omega$ vary between 0 and 1 , with values close to 0 indicating a strong coupling between the evapotranspiration and vegetation controls, according to atmospheric conditions, and values close to 1 indicating decoupling, where evapotranspiration is mainly limited by the available energy.

At $\mathrm{CO}$, we assumed neutral atmospheric conditions to calculate $r_{a}$ because we do not have continuously measured sensible heat flux or wind speed and temperature profiles in order to calculate the atmospheric stability.

\subsection{Results}

\subsubsection{Seasonal variations of evapotranspiration}

Ten-days running means were calculated for a better visualization of the intraseasonal variation of the evapotranspiration at the $\mathrm{CO}$ and FNS pastures. Data gaps at $\mathrm{CO}$ were filled based on the results of a linear regression between the scintillometer data and the net radiation. We divided the period to be completed according to the short periods of available scintillometer data and applied one linear regression for each period. These linear regressions had slopes varying from 0.45 to 0.60 and $R^{2}$ varying from 0.82 to 0.92 . To evaluate the effect of the dry season on the evapotranspiration at both sites, we present the resulting data series and the respective 10-day running means from September 2007 to February 2008 for CO (the whole period of available LAS data) and the period from April 1999 to March 2000 for FNS in Figure 2.4. Precipitation and soil moisture content from 0 to $2 \mathrm{~m}$ depth are also shown. The seasonal behavior of evapotranspiration 
was not significantly different between the years of available data at FNS, with a difference in the totals of up to $5 \%$ between 1999 and 2000, and less than $1 \%$ between 2000 and 2001.
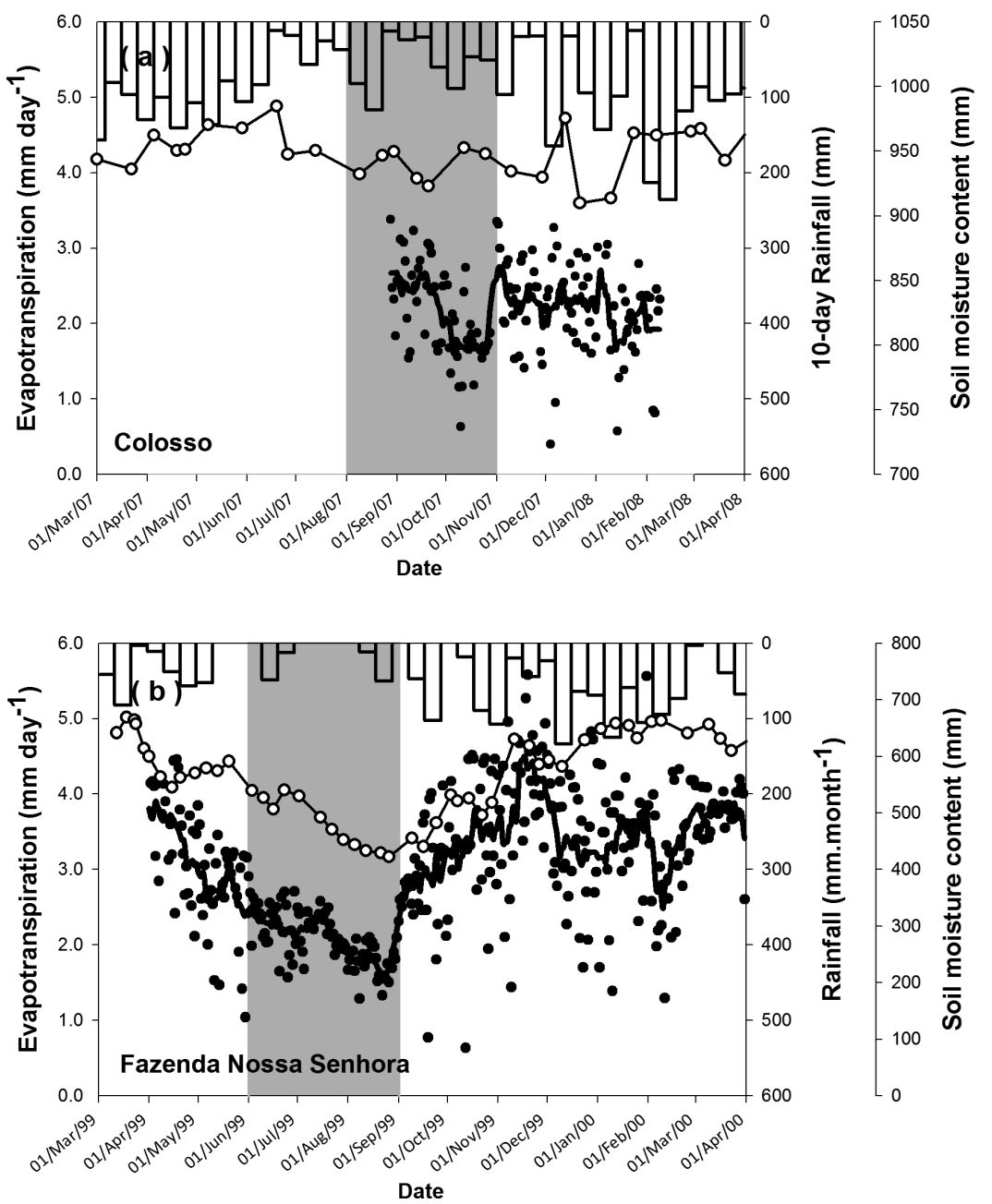

Figure 2.4 Daily evapotranspiration (dots) and 10-day running mean (line) a) derived from scintillometer measurements at $\mathrm{CO}$ and $\mathrm{b}$ ) measured by eddy correlation at FNS. The shaded area represents months during the dry period selected to avoid the remaining signal from the previous wet season. Y-axes on the right indicate measurements of 10-day accumulated rainfall (inverted bars) and soil moisture content (open circles) in the top $2 \mathrm{~m}$ of the soil 
Evapotranspiration at $\mathrm{CO}$ is likely to present seasonal behavior, with higher values during the wet season and a reduction during the dry season (Figure 2.4a), although the seasonal variations in soil moisture are small. However, values between 2 and $3 \mathrm{~mm} \mathrm{day}^{-1}$ from the previous wet season were maintained well into September. After that period the values started to decrease and reached a plateau minimum in the first half of October. At the end of October they started to rise again with the beginning of the following rainy season. The data already reached the peak plateau of the subsequent wet season in the beginning of November.

Seasonal variation of evapotranspiration is more evident at FNS than at $\mathrm{CO}$, since at $\mathrm{CO}$ the evapotranspiration remained low during both dry and wet seasons in comparison with FNS (Figure 2.4b). Although CO presents a decrease during the dry season, FNS has a quicker response to the decrease in rainfall and soil moisture, since precipitation starts to decrease in March, and this decrease is immediately reflected in the evapotranspiration. On the other hand, a similar fast response to the beginning of the wet season is present at CO and FNS. Values of evapotranspiration already started to increase in the transition from dry to wet season, in the last days of August. The values reached the peaks of the subsequent wet season in the beginning of November at both sites.

During the period of study, the daily evapotranspiration at CO, estimated using the LAS, ranged from around 0.5 to $3.5 \mathrm{~mm} \mathrm{day}^{-1}$. Daily evapotranspiration at FNS varied in from 0.6 to 6.2 $\mathrm{mm}$ day $^{-1}$ during the three years analyzed in this study. Table 2.2 presents the average daily precipitation and evapotranspiration, with respective standard deviations, for dry season, wet season and calendar years for the two sites. Differences in average evapotranspiration during the dry season were not so significant between the two sites. However, ET is significantly higher at FNS during the wet season. In the discussion section we investigate what the main drivers of ET at both sites are, to identify the reasons why FNS presents a high seasonality in ET while CO maintains low rates of ET during the whole year. 
Table 2.2: Average of daily precipitation and evapotranspiration, with respective standard deviations in parenthesis, for dry season, wet season and calendar years (mm.day $\left.{ }^{-1}\right)$

\begin{tabular}{lllllll}
\hline \multirow{2}{*}{ Period at CO } & CO & & & \multicolumn{2}{l}{ FNS } & Period at FNS \\
\cline { 2 - 3 } & P & ET & & P & ET & \\
\hline Dry season & 3.92 & $2.15(0.61)$ & & 2.71 & $2.41(0.62)$ & Dry season \\
Wet season & 10.46 & $2.13(0.63)$ & & 7.89 & $3.50(0.84)$ & Wet season \\
Jan-Dec 2006* & 7.32 & $1.94(3.16)$ & & 4.26 & $2.98(0.94)$ & Feb-Dec 1999 \\
Jan-Dec 2007* & 7.22 & $2.11(3.37)$ & & 4.85 & $3.14(0.91)$ & Jan-Dec 2000 \\
Jan-Dec 2008* & 8.41 & $2.12(3.37)$ & & 5.13 & $3.17(0.98)$ & Jan-Dec 2001 \\
2006-2008* & 7.65 & $2.06(3.30)$ & & 4.76 & $3.10(0.95)$ & 1999-2001 \\
\hline
\end{tabular}

\subsubsection{Factors controlling evapotranspiration}

We identified the main drivers of evapotranspiration during the wet and dry seasons by calculating the decoupling factor $(\Omega)$ proposed by Jarvis and McNaughton (1986) (Equation 8). Figure 2.5 shows the diurnal cycle of $\Omega$ during the dry and wet season for CO and FNS. In the dry season, $\Omega$ presented a similar pattern and magnitude at both sites, with maximum values during the morning varying between 0.5 and 0.6 at $\mathrm{CO}$, and of around 0.6 at FNS. After 8:30 am at $\mathrm{CO}$ and 9:30am at FNS, the values were lower than 0.5 and decreased with time, reaching zero at 6:00pm at both sites. In the wet season, the pattern and magnitudes differed between the two sites. On one hand, $\mathrm{CO}$ did not present a strong seasonality, with wet season values around 0.1 higher than in the dry season during almost the entire day, except for some periods in the morning when the values of the wet season were coincident with those of the dry season, and sometimes lower than in the dry season. On the other hand, $\Omega$ had a more parabolic diurnal cycle at FNS, increasing during the morning and decreasing during the afternoon, with an average higher than 0.5. 

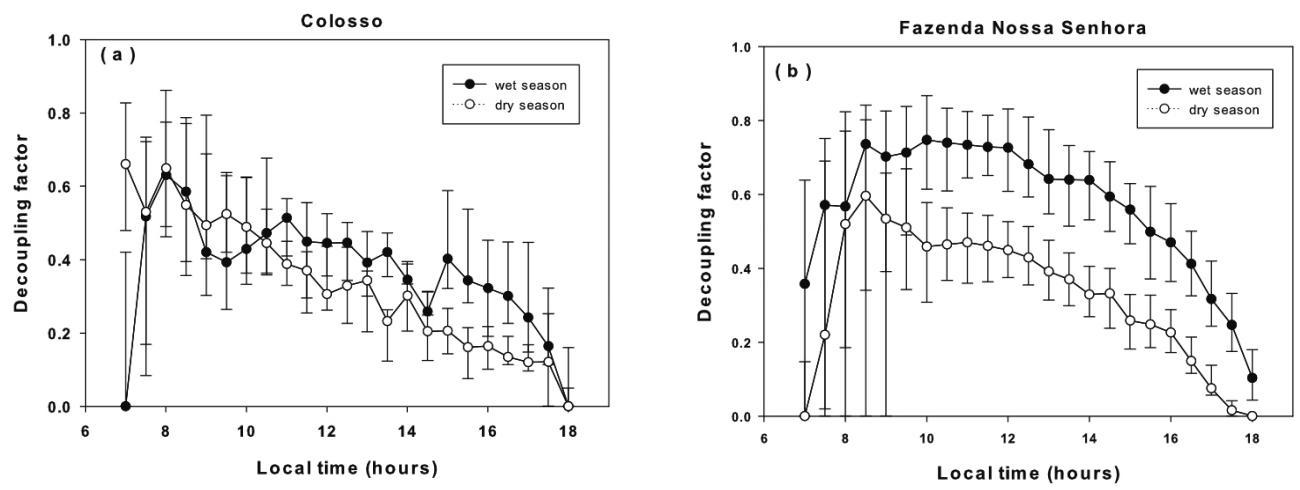

Figure 2.5 Hourly median (local time), first and third quartiles of the decoupling factor for the dry and wet seasons at a) $\mathrm{CO}$ and b) FNS

To further discuss the seasonal variation of ET at both sites, we analyzed the differences in the energy available for evapotranspiration. Hourly averages of net radiation at $\mathrm{CO}$ were higher than at FNS during the dry season, with a maximum difference of $136.6 \mathrm{~W} \mathrm{~m}^{-2}$ around 10am. However, the opposite pattern occurred in the wet season, when net radiation at CO was lower than at FNS, with a maximum difference of $131.8 \mathrm{~W} \mathrm{~m}^{-2}$ around noon (Figure 2.6). $R_{n}$ at $\mathrm{CO}$ was lower than at FNS not only during the beginning of wet season (period of data available from scintillometer), but also during the whole wet seasons of the years from 2006 to 2008 (not shown). Therefore, this difference is not related to the period of the data used for comparison with FNS.
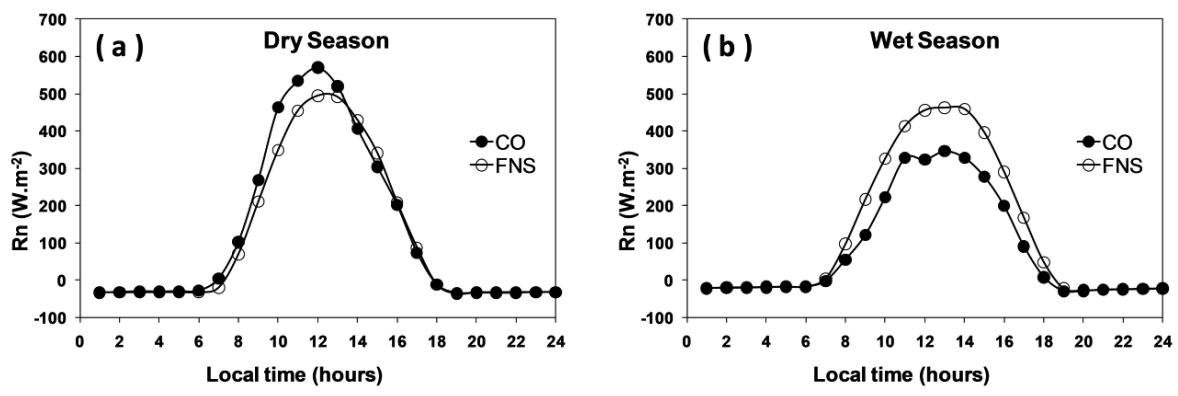

Figure 2.6 Average daily pattern of net radiation at CO and FNS for analyzed periods in the a) three driest months and b) three wettest months 


\subsubsection{Parameterization of stomatal conductance}

In order to know the total evaporation rate during an entire year we needed to extend the estimation of the evapotranspiration for the period that the scintillometer was not operable using a parameterization. For this, we applied the Jarvis Stewart model (Equation 4) with the coefficients adjusted by Wright et al. (1995) for Fazenda Dimona (Table 2.3) to parameterize the surface conductance at CO. Fazenda Dimona is a pasture site about $20 \mathrm{~km}$ from CO. Substituting the value of the leaf area index for Fazenda Dimona (1.2) by the value measured at CO (0.77), we obtained the value of the coefficient $g_{\text {smax }}$ as 19.7. We compared the results obtained from this estimate with the data derived from the scintillometer, considering only scintillometer data from days with the whole daytime period available. The comparison of the results showed that the values from the parameterization proposed by Wright et al. (1995) were higher by around $20 \%$ than the values derived from the scintillometer measurements (Figure 2.7a and Figure 2.8a).

Because of this overestimation, we adjusted the Jarvis-Stewart model to the CO conditions through a non-linear optimization (Table 2.3). The wilting point used here was the same as at Fazenda Dimona, 0.33. 

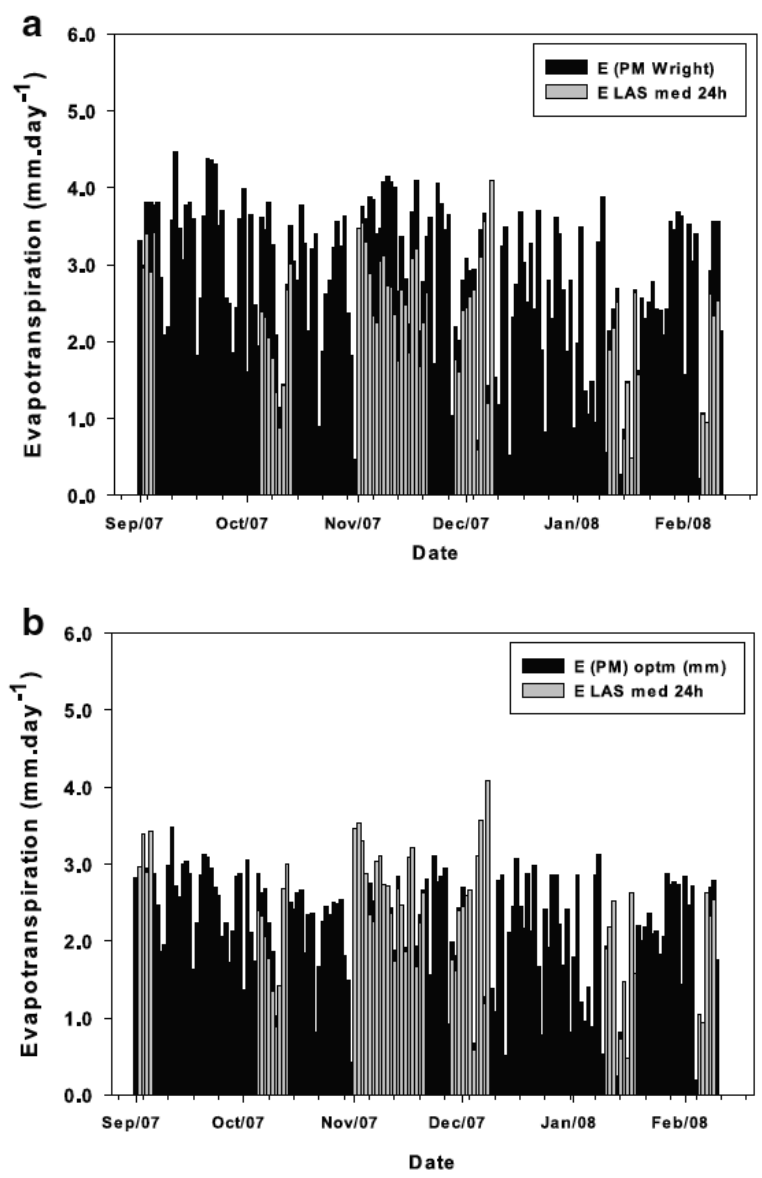

Figure 2.7 Evapotranspiration derived from scintillometer data (grey bars) and from the PenmanMonteith equation (black bars) a) with parameters adjusted by Wright et al. (1995) to Fazenda Dimona applied to data of CO and b) using the Jarvis Stewart model optimized for CO site conditions 
Table 2.3: Optimized parameters of Jarvis-Stewart model for surface conductance, for different pasture sites in Amazonia

\begin{tabular}{|c|c|c|c|c|c|c|c|}
\hline Model & $\mathrm{g}_{\text {smax }} \mathrm{L}^{*} \mathbf{a}_{1}$ & $F(D) a_{2}$ & $\mathbf{F}(\mathbf{S}) \mathbf{a}_{3}$ & $\mathbf{F}(\boldsymbol{\theta}) \mathbf{a}_{4}$ & $\theta \mathbf{w}$ & $\mathbf{R}^{2}$ & LAI \\
\hline \multicolumn{8}{|c|}{ Fazenda Dimona (Wright et al., 1995) } \\
\hline & 30.70 & 0.0369 & 470 & 0.428 & 0.33 & 0.817 & 1.2 \\
\hline \multicolumn{8}{|c|}{ Fazenda Nossa Senhora (Wright et al., 1996) } \\
\hline Mission 3 & 17.8 & 0.780 & 367 & 0.240 & 0.15 & 0.772 & $2.0^{\mathrm{d}}$ \\
\hline Mission 4 \& 5 & 37.1 & 0.1186 & 846 & 0.250 & 0.15 & 0.671 & $2.0^{\mathrm{d}}$ \\
\hline Mission 3,4 \& 5 & 33.1 & 0.1127 & 671 & 0.259 & 0.15 & 0.562 & $2.0^{\mathrm{d}}$ \\
\hline \multicolumn{8}{|c|}{ Colosso (This study) } \\
\hline & 21.04 & 0.0899 & 616.44 & 0.490 & 0.33 & 0.31 & $0.77(0.11)$ \\
\hline
\end{tabular}

Mission 3 is the transition from dry season to wet season and Missions 4 and 5 are in the transition from wet to dry season at Fazenda Nossa Senhora.

${ }^{\mathrm{d}}$ Zanchi et al. (2009)

The coefficient $a_{l}$ is the maximum conductance per unit ground area $\left(\mathrm{mm} \mathrm{s}^{-1}\right)$. Its optimized value for $\mathrm{CO}$ is lower than for Fazenda Dimona and FNS (except in the transition from dry to wet season at FNS).

The specific humidity deficit is the principal hourly control in this model at tropical pasture sites (Wright et al. 1995). The specific humidity deficit parameter $a_{2}$ obtained for CO is lower than the one obtained for FNS but is higher than for Fazenda Dimona. This means that the parameterized surface conductance is more sensitive at FNS and CO than at Fazenda Dimona. The surface conductance is reduced to half of its maximum at a specific humidity deficit of about $7-8 \mathrm{~g} \mathrm{~kg}^{-1}$ at CO. Although the variability of the $a_{3}$ parameter appears to be high among the sites, the stomatal response to solar radiation for the three sites was very similar. 

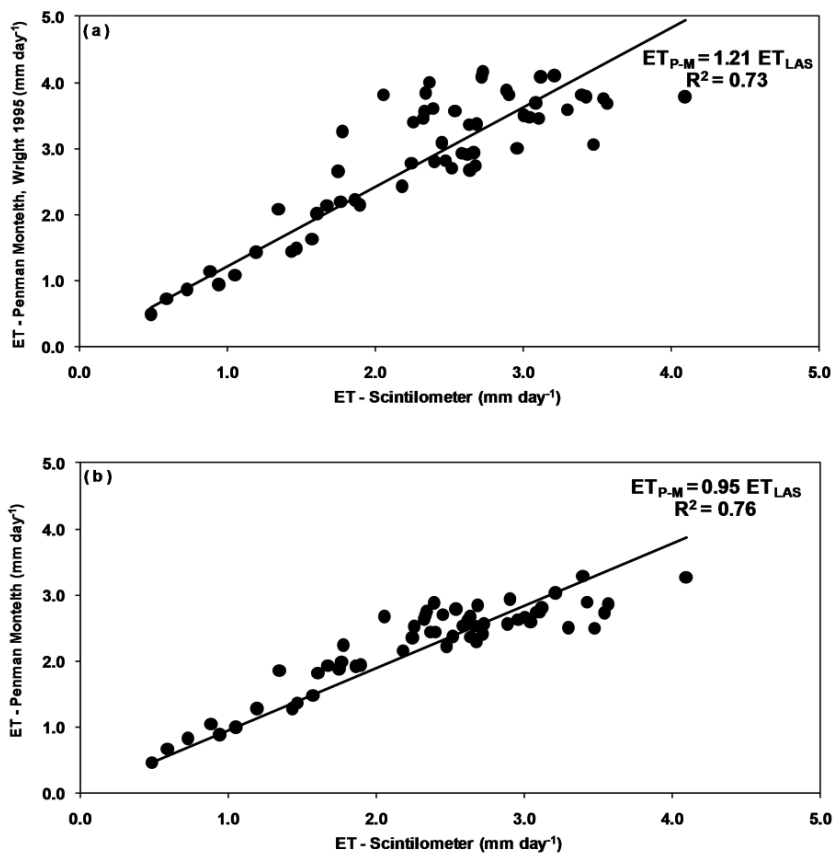

Figure 2.8 Relationship between daily evapotranspiration estimated through a large aperture scintillometer measurement and estimated by the Penman-Monteith equation a) using parameters adjusted by Wright to Fazenda Dimona applied to data from CO and b) using Jarvis Stewart model optimized for CO site conditions

The soil moisture parameter $a_{4}$ indicates the threshold soil moisture content at which transpiration begins to be attenuated by soil tension, and gives the model its principal seasonality (Wright et al. 1995). The optimized critical soil moisture obtained for CO was $0.49 \mathrm{~kg} \mathrm{~kg}^{-1}$, which is higher than at FNS and Fazenda Dimona. This means that soil tension will affect the transpiration earlier at $\mathrm{CO}$ than at FNS, for higher soil moisture content.

Figures $2.7 \mathrm{~b}$ and $2.8 \mathrm{~b}$ show that the result of the optimization fitted better to scintillometer measurements than the results using the coefficients adjusted for Fazenda Dimona. The optimization results underestimated the scintillometer based results by around $5 \%$.

Annual evapotranspiration was around $25 \%$ to $30 \%$ of annual precipitation at Colosso, while annual evapotranspiration measured at FNS varied from around $60 \%$ to $70 \%$ of annual precipitation 
(Table 2.2). This difference may be due to the difference in the amount of precipitation between the two sites and also to the low LAI at CO.

\subsection{Discussion}

\subsubsection{Implications of the difference of wet and normal years for $\mathrm{CO}$ and FNS evapotranspiration}

The reduction of evapotranspiration at pasture sites during the dry season corroborates the results of previous works ( Von Randow et al., 2004; Wright et al., 1996). Since precipitation during the study period at Colosso is at the high end of the climatological range for the region, while the precipitation during the period of study at FNS is within the climatological average, we could assume that we are comparing a wet period at $\mathrm{CO}$ with a normal period at FNS. Thus, we could expect that the evapotranspiration at $\mathrm{CO}$ would be higher than at FNS. However, this was not found in the comparison of the two sites. Although CO site is located in a wetter region and the analyzed period was wetter than the climatology, evapotranspiration rates were lower than those from FNS site. This means that evapotranspiration at CO, in average or dry years, may be even lower than what we measured in this work.

\subsubsection{Seasonal variation of evapotranspiration}

Although the evapotranspiration presents seasonal variations at both sites, responses to rainfall seasonality were clearer at FNS than at CO. At the former, seasonal variation of precipitation and the length of dry season are greater than at the latter. In fact, even a simple definition of a dry season in Central Amazonia may be slightly arbitrary, since there is still a substantial amount of rain in the driest months and soil moisture content in the top layers of the soil usually does not show a clear reduction on seasonal scales (Figure 2.4a). Additionally, although evapotranspiration at $\mathrm{CO}$ drops in the late dry season, it is generally low throughout the year (as low during many days in the wet season as in the dry season) compared to other sites in Amazonia. 
Values of the previous wet season of around 2-3 $\mathrm{mm}^{-1}$ were $^{-1}$ maintained through September, reaching a minimum in the first half of October, the last month of dry season. In the end of this month, the evapotranspiration started to increase, already reaching the level of the previous wet season at the beginning of November.

At $\mathrm{CO}$, the rainfall started to decrease in June and the evapotranspiration values dropped after September 20, that is, almost four months after the rainfall started to decrease. On the other hand, at FNS, the evapotranspiration values already started to decrease in April, the last month of wet season. Thus, the effect of the decrease of rainfall had a higher effect on the evapotranspiration at FNS than at CO.

Hasler and Avissar (2007) also examined the seasonal behavior of two pasture sites (FNS in Rondônia and Fazenda São Nicolau in Mato Grosso, located in Southwestern Amazonia) and of six primary forest sites throughout Amazonia. After correcting for the lack of energy balance closure, the authors showed that the latent heat flux of the two pasture sites also presented the same seasonal cycle, decreasing in the second half of the dry season. By contrast, at forest sites, evapotranspiration increased during the dry season. Similar results were also found by Da Rocha et al., (2009) and Costa et al. (2010). The combination of evergreen or semidecidous leaf phenology, extensive root systems and the ability to extract soil moisture from deep layers in the soil apparently allows sites dominated by well-established forest to maintain high rates of ET throughout the dry season (Da Rocha et al., 2009), reaching higher total evaporation due to higher available energy (less cloudy). Since pastures do not present those characteristics, it is evident that they suffer the reduction of moisture in the shallow top layers of the soil during the dry season (Hodnett et al., 1996).

\subsubsection{Factors controlling evapotranspiration}

The decoupling factor $(\Omega)$ proposed by Jarvis and McNaughton (1986) was calculated to identify the main drivers of evapotranspiration at CO and FNS (Figure 2.5). The diurnal cycle of $\Omega$ during the dry season presented a similar pattern and magnitude at both sites, where $\Omega$ was lower than 0.5 in the most part of the day. These values showed that during the dry season, both sites have vegetation that is relatively well coupled to atmospheric conditions and that evapotranspiration is largely controlled by the stomata. In the wet season, the pattern and magnitudes differed between 
the two sites. While CO did not present strong seasonality, with values that are likely the same for the dry season, $\Omega$ at FNS presented a more parabolic diurnal cycle, increasing during the morning and decreasing during the afternoon, with an average higher than 0.5 . These results suggest that during the wet season, evapotranspiration at $\mathrm{CO}$ is still significantly controlled by the stomata, while at FNS evapotranspiration is mainly limited by the available energy. Thus, during the wet season, vegetation at $\mathrm{CO}$ is likely to be coupled to the atmospheric conditions, while at FNS the vegetation is likely to be decoupled from atmospheric conditions.

In the analyses of the differences in the energy available for evapotranspiration, the reduction of $R_{n}$ during the wet season is a characteristic only observed at CO, since FNS did not present such a large variation of $R_{n}$ between dry and wet seasons. The higher seasonality at CO can be related to high albedo or low incoming solar radiation in the wet season. Our measurements (data not shown) showed a reduction of $25 \%$ in the average daily incoming solar radiation during the wet season in relation to the average in the dry season. This reduction was significantly higher than the reduction in incoming solar radiation at FNS, which was only 5\% (von Randow et al. 2004). Albedo at $\mathrm{CO}$ was not measured. Nevertheless, we presume that albedo is not responsible for the reduction of $R_{n}$ at $\mathrm{CO}$ because the reduction happened during the wet season. During this season, the soil becomes wetter and consequently darker than in dry season and the vegetation also grows faster, covering more open bare soil. In these situations, albedos are generally lower than usually found for light, dry and bare soils.

Another factor that might affect the ET is the amount of nutrients available in the soil, leading on one hand to reduced growth (i.e. biomass and LAI) and on the other to reduced leaf nitrogen levels, reducing photosynthesis and thus stomatal opening. It is known that deforestation leads to losses of nutrients through fire, erosion, soil emissions of gases, harvesting and hydrologic leaching in Amazonia. When land is used for cattle grazing, additional losses occur with harvest and because fire is used as a pasture management tool (Davidson et al., 2007). Hypothetically, forest to pasture conversion is likely to lead to a rise of soil $\mathrm{pH}$, effective cation exchange capacity and exchangeable calcium. On the other hand, this conversion might lead to a decline of total carbon, nitrogen and inorganic extractable phosphorus content. It is also possible that higher nutrient utilization efficiencies occur where soil nutrient pools are lower (McGrath et al., 2001).

Asner et al. (2004) showed that aboveground and soil carbon stocks decreased with pasture age in both clayey and sandy soils in Southwestern Amazonia and plant biomass declines were correlated with declines in soil carbon $(\mathrm{C})$, available phosphorus $(\mathrm{P})$ and calcium $(\mathrm{Ca})$. In order to 
analyze whether the low evapotranspiration at $\mathrm{CO}$ is related to low plant biomass/LAI as a result of low nutrient contents, we compared the measurements of C, P and nitrogen (N) by Marques (2009) at $\mathrm{CO}$ with the results presented in a review done by McGrath et al. (2001). The latter authors compiled results of studies of 100 different sites, comparing the nutrient and carbon content in the soil within groups of different types of vegetation and groups of same soil order. The comparison of values of total exchangeable $\mathrm{P}, \mathrm{N}$ and $\mathrm{C}$ measured at $\mathrm{CO}$ and at pastures presented by McGrath et al. (2001) do not show significant differences (Table 2.4). Therefore, the soil nutrient and carbon contents do not explain the low biomass and LAI and resulting low evapotranspiration at CO.

Thus, since we observed that $\Omega$ is lower than 0.5 during both dry and wet seasons at $\mathrm{CO}$, indicating that the $E T$ is well coupled to the local atmospheric humidity conditions, and that $R_{n}$ is significantly reduced in the wet season, we suggest that the reasons for the absence of high seasonality of ET at $\mathrm{CO}$ are the low available energy in the wet season and a drop in the $E T$ at the end of the dry season, probably related to the incapability of the vegetation to reach water in the soil.

Table 2.4: Total values of carbon, nitrogen, and extractable phosphorus in the soil at $\mathrm{CO}$ and means of 32 oxisols and 21 pastures in Amazon

Total Carbon in the soil Total Nitrogen in the soil Extractable Phosphorus

$\begin{array}{lll}\left(\text { g. }^{-1}\right) & \left(\text { g. } \mathrm{kg}^{-1}\right) & \left.(\mathrm{mg} \cdot \mathrm{kg})^{-1}\right)\end{array}$

CO pasture (Marques, 2009)
37.5
2.5
3.7

Pasture group (McGrath et al., 2001)
$31.2(4.9)^{\mathrm{c}}$
$2.2(0.3)$
$4.1(0.6)$

Oxisols group (McGrath et al., 2001)

$$
37.0(3.5)^{\mathrm{c}}
$$

McGrath measurements are means from $0-20 \mathrm{~cm}$

${ }^{\mathrm{a}} \mathrm{C}$ and $\mathrm{N}$ are means of $0-5 \mathrm{~cm}$ and $5-10 \mathrm{~cm}$ values

${ }^{\mathrm{b}}$ Oxisols order is the correspondent order to the soil taxonomy of $\mathrm{CO}$

${ }^{\mathrm{c}}$ Soil $\mathrm{C}$ is measured from $0-10 \mathrm{~cm}$ 


\subsubsection{Spatial variability and derivation of ET by scintillometer}

On one hand, the low values of evapotranspiration at $\mathrm{CO}$ in comparison with at FNS were explained by lower values of $R_{n}$ and LAI at CO than at FNS. On the other hand, those differences could also be artificially induced by the use of scintillometer data to derive latent heat fluxes and to calibrate the Jarvis Stewart model. The scintillometer considers the whole path $(450 \mathrm{~m}$, see Figure 2.3) to measure the sensible heat flux, while the other components of the energy balance (net radiation and soil heat flux) used to derive the latent heat flux were point measurements. The scintillometer path includes not only the plateau, where the point measurements of the tower are taken, but also slope and valley areas, the latter being wetter than the others. This wet part of the path can have high LAI, low albedo and low soil heat flux. Therefore, the available energy may be higher in the valley than on the slope and plateau. Using measurements of only the plateau can lead to an underestimation of the available energy of the whole area, and consequently, we could be underestimating the latent heat flux of the site.

Since we do not have measurements in the valley, we cannot quantify the value of errors induced due to neglecting the effect of the valley. But, based on the size that each terrain element represents in the path, we can perform a thought experiment to qualitatively estimate this amount. Based on the weighting function of contributions to the scintillometer measurements (Figure 2.3), we estimate that the valley contributes only $\sim 20 \%$ to the areal average performed by the scintillometer. Assuming that the available energy (Rn-G) in the valley is approximately $15 \%$ higher than in the plateau - this is the difference of available energy between dry and flooded conditions in a wetland in central Brazil we estimated based on data shown by Oliveira et al. (2006) - this would represent only a $3 \%$ increase in the weighted mean of the available energy for the whole path. Therefore, we estimate that the error in our calculations due to neglecting the spatial variability in the scintillometer path is small. 


\subsection{Conclusions}

This article presented measurements and calculations of evapotranspiration from two pasture sites, one in Central Amazonia (CO) and one in Southwestern Amazonia (FNS). Evapotranspiration presents seasonality at both sites, decreasing during the dry season in response to the reduction of precipitation. Nevertheless, the CO site in Central Amazonia presents a late response to the decrease of precipitation compared to the FNS site in Southwestern Amazonia, because the reduction of precipitation and the length of the dry season are more pronounced in the latter site. On the other hand, both sites have a similar quick response to the onset of the rainy season, and the evapotranspiration increases immediately with the beginning of the wet season.

While the evapotranspiration at FNS presents a significant decrease from wet to dry season, at $\mathrm{CO}$ this decrease is not so significant. Analyzing the factors that might cause these differences between the two sites, we obtained that the decoupling factor during the dry season was lower than 0.5 at both sites, which indicates that the evapotranspiration is significantly controlled by the vegetation, which is well coupled with the atmospheric moisture conditions. The same happened at CO during the wet season. Nonetheless, the wet season decoupling factor at FNS is higher than 0.5 during the large part of the time, and this indicates that the radiation conditions are the dominant limiting factor of evapotranspiration in this case. Even though no significant differences in soil nutrients at $\mathrm{CO}$ were found (relative to similar sites in Amazonia) to explain its low biomass and LAI, the short grass and lower rates of energy available during wet season cause evapotranspiration to be significantly lower than at FNS.

The results found for the pastures are contrary to the results usually found for pristine forests in Amazonia, which present higher ET during the dry season. At pasture sites, the ET decreases during the dry season because the soil has a higher propensity to dry when precipitation diminishes, and also because the roots in the pasture cannot reach the deep layers in the soil where high moisture is maintained. As a consequence, the replacement of forest by pasture may affect the regional water cycle. This can change the role of the Amazon in maintenance of moisture in the region and the transport of part of this moisture to other regions. This impact on water recycling is even higher during the dry season, since the shallow layers of the soil become dryer in the absence of rainfall. 


\title{
Chapter 3
}

\section{Analysis of biological and meteorological controls of evapotranspiration in pristine forests and a pasture site in Amazonia ${ }^{2}$}

\begin{abstract}
This work studied the behavior and seasonality of evapotranspiration influenced by biotic and abiotic factors was studied through analysis of diurnal variation of aerodynamic resistance $\left(\mathrm{r}_{\mathrm{a}}\right)$, stomatal resistance $\left(\mathrm{r}_{\mathrm{s}}\right)$ and decoupling factor $(\Omega)$. This index was proposed by Jarvis and McNaughton, 1986 as an indicative of the control of theses resistances on the evapotranspiration of vegetation. Selection of representative data from wet and dry seasons from a primary forest in Central Amazonia and a primary forest and a pasture sites in Southwestern Amazonia had shown

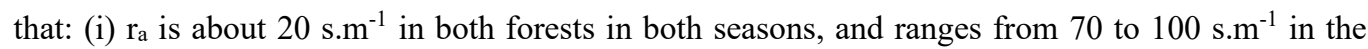
pasture site; (ii) $\mathrm{r}_{\mathrm{s}}$ varies both throughout the day and seasonally, with medians increasing from 40 in the morning, to $150 \mathrm{~s} . \mathrm{m}^{-1}$ in late afternoon, in the wet season in the forests -50 to $160 \mathrm{~s} \cdot \mathrm{m}^{-1}$ in the pasture. These values increase in the dry season, with the forests $\mathrm{r}_{\mathrm{s}}$ ranging from 50 up to 500

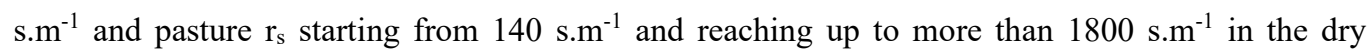
afternoons; (iii) $\Omega$ ranges from 0.5 to 0.8 during the wet season, and reduces to values below 0.5 in the afternoons during the dry season, indicating that, although a strong influence of net radiation in the evaporative loss is present, to a large extent the evapotranspiration fluxes are coupled to the biotic control of stomatal closure in the vegetation, especially in the pasture and during dry periods.
\end{abstract}

\footnotetext{
2 This chapter is published as: Paulino Junior, N., Von Randow, R. C. S., \& Von Randow, C. (2017). Analysis of biological and meteorological controls of evapotranspiration in pristine forests and a pasture site in Amazonia. Revista Ambiente e Agua, 12(2). https://doi.org/10.4136/ambi-agua.1832
} 


\subsection{Introduction}

The Amazonian rainforest is one of the most important biomes of the planet. It is of great relevance to the global climate and biodiversity, and it is considered the largest tropical rain forest of the world and a major contributor to surface evapotranspiration (Choudhury et al., 1998), influencing the global hydrological cycle and causing impacts in the atmospheric global circulation associated to tropical convection.

Besides being important for maintaining the climate and ecosystem in the region, the Amazon forest also has an important role in the climate of different regions of Brazil. The Amazonian ecosystem can be considered a source of water for other regions, as a significant amount of water vapor that evapotranspirates in Amazonia is transported to centre-west, Southeast and South regions of Brazil by low level jets (Arraut et al., 2012; Zemp et al., 2014).

Although the Amazon forest is recognized as an important component of the regional and global climate system, the spatial and temporal variability of its hydrological functions is not completely understood, therefore, evaluating the seasonal and spatial variations of the water fluxes in the tropics is important (Werth and Avissar, 2004). These variations mainly depend on the characteristics of the vegetation, on energy processes and on water availability (Hasler and Avissar, 2007). The comprehension of vegetation and climate interaction is commonly achieved by field measurements and, weather and climate models simulations. These models use variables as wind, air and soil temperatures, air humidity and soil moisture to estimate the evapotranspiration through aerodynamic conductance and stomatal conductance. Werth and Avissar (2004) presented a review of four approaches to estimate the evapotranspiration in Amazonia: the first is the relationship with the radiation, the second is the water balance, the third is the global climate and the last is data assimilation. They observed the seasonality of ET in two groups: one that follows the seasonal cycle of net radiation, and another that follows the seasonal cycle of precipitation. This division motivates the following research questions: what controls the seasonal variation of ET in Amazonia? Is it mainly related to the available radiative energy or does the vegetation significantly control its variability, through its surface conductance that is susceptible to the seasonality of soil moisture?

Souza Filho et al. (2005) presented in their study evidence that support the idea that the radiation and maybe other atmospheric variables, are the main mechanism of control of the seasonal variation of ET in the Amazonia, while the vegetation control plays a secondary role on the ET. 
They used meteorological data from Caxiuanã, in Northeast Amazonia, to calculate the aerodynamic and surface conductance and the decoupling factor proposed by Jarvis and McNaughton (1986) during dry and wet periods during the wet period the surface conductance is higher than during the dry period (Souza Filho et al., 2005). On the other hand, VPD, the aerodynamic conductance, and the solar radiation, are higher during the dry period. But, even presenting a surface conductance higher during the wet season, the vegetation does not avoid ET to be higher during the dry season. From this analysis they concluded that the control of atmospheric conditions over ET is dominant, with decoupling factor close to 1 in the wet and dry seasons.

Da Rocha et al. (2009) investigated the seasonal behavior of the water vapor flux and the sensible heat flux in 7 flux towers in Brazil. These tower sites included tropical humid and semideciduous forest, transitional forest, floodplain (with physiognomies of Cerrado), and Cerrado sensu stricto. The authors observed that the control of the seasonality of ET were different in each biome, where the evaporative demand (mainly the net radiation) plays the most important role in the tropical humid forests and the soil moisture variation plays the most important role in the Cerrado.

In a more complete evaluation of differences in control of evapotranspiration in wet forest and seasonally dry forests, Costa et al. (2010) found that the wet equatorial sites are mainly driven environmental factors, while in seasonally dry forests, ET is also controlled by biotic factors. This poses the question of whether the wet equatorial sites will remain largely resilient to dry season water stress or may begin to present signs of larger biotic control of water loss by the vegetation in case of increasing frequency of extreme dry seasons as predicted by some climate models. Moreover, a large fraction of Amazonia is also under pressure of deforestation to pasture or agriculture production, and it is interesting to investigate how a vegetation type like pasture grass compare to the pristine rainforest in terms of biotic control of evapotranspiration and experiences dry season water shortages.

On such background, the goal of this study was to present the analysis of the diurnal and seasonal variations of the aerodynamic resistance, stomatal resistance and the decoupling factor by Jarvis and McNaughton (1986) for three sites in Amazonia: a primary forest in Central Amazonia and a primary forest and a pasture in Southwestern Amazonia. The data used in the present work are measurements of evapotranspiration and meteorological variables. In Central Amazonia, the data were collected in the Cuieiras Biological Reserve close to Manaus, AM, while in Southwestern Amazonia, the data were collected in the Jaru Biological Reserve and in the cattle ranch, Fazenda Nossa Senhora (FNS), close to Ji-Paraná, RO. 


\subsection{Methods and site description}

\subsubsection{Site Description and Instruments}

This study is based on data of three sites in Amazonia. The first is located at Cuieiras Forest Reserve, about $50 \mathrm{~km}$ north of Manaus, Amazonas state, Brazil. The site is known as K34 (2 $36^{\prime}$ $32^{\prime \prime} \mathrm{S}, 60^{\circ} 12^{\prime} 33^{\prime \prime} \mathrm{W}$ ) and it is part of the LBA project, which is responsible for the maintenance and administration of the site. The second site is located at Jaru Biological Reserve (Rebio-Jaru), about $100 \mathrm{~km}$ north Ji-Parana, Rondonia state, Brazil (10'4”S; 61'56”W). The third site is a pasture located about $50 \mathrm{~km}$ northwest of Ji-Paraná, Rondonia state, Brazil. The site is a cattle ranch known as Fazenda Nossa Senhora Aparecida (FNS) (10 $\left.45^{\prime} \mathrm{S}, 62^{\circ} 22^{\prime} \mathrm{W}\right)$, deforested in the late 1970s. The second and third sites are also part of LBA project.

The K34 site is covered by primary forest, with diverse vegetation and a vast number of species. The leaf area index (LAI) of the area is about 5-6. The index is in accordance with that estimated by Hasler and Avissar (2007). The climate is classified as Af according to Köpen classification (tropical rainforest climate), with temperatures varying from 19 to $39^{\circ} \mathrm{C}$. The rainfall regime is divided in two seasons: rainy (starting in November to May) and dry (August to October). The annual average of precipitation varies from 1800 to $2800 \mathrm{~mm}$.year ${ }^{-1}$. More information about the climate of the region is found in Araújo et al. (2002).

Besides conventional meteorological and short and long wave radiation sensors, an eddy covariance system is installed at a 53-m high tower measuring the energy, water and carbon fluxes of the K34 site. The system is composed by a tridimensional sonic anemometer (Solent 1012R2, Gill Instruments, UK) and a fast response infrared gas analyzer (“Infra-Red Gas Analyzer”, IRGA) (LI-6262, Li-Cor, EUA). The data was recorded in 10,4 Hz sampling (Araujo et al., 2002).

The Rebio Jaru is a terra firme forest, with relatively stronger rainfall variability than K34, which varies annually from 1250 to $2500 \mathrm{~mm}$. The forest has a mean height of about $35 \mathrm{~m}$, but some of the higher trees reach up to $45 \mathrm{~m}$. The air temperature shows no clear seasonal pattern, ranging on average between 22 to $27^{\circ} \mathrm{C}$, however a significant drop in air humidity and a reduction in rainfall is observed during the dry seasons. The same measurements as in K34 were collected, but at the height of $62.7 \mathrm{~m}$ (Von Randow et al., 2004). 
The FNS is covered by Brachiaria brizantha (A. Rich.) Stapf. grasses, with average LAI of 2.0 (Zanchi et al., 2009). The climate of the region is considered equatorial, warm, and moist, with temperature varying from 17 to $32^{\circ} \mathrm{C}$. The rainfall regime follows the same patterns as in Rebio Jaru. The measurements from FNS analyzed in this work are from an automatic weather station (AWS) installed in a tower of $5.5 \mathrm{~m}$, providing measurements of the most common meteorological variables. The tower counts with a similar eddy correlation system to the one installed at K34. Other details of the microclimatology of the region can be found in the work of Von Randow et al. (2004).

In Rondonia, the topography is generally flat and the soil is classified as medium textured red-yellow podzol (Podzólico vermelho amarelo A moderado textura média-Brazilian Soil Taxonomy, typic paleudult — or orthic acrisol-FAO).

\subsubsection{Evapotranspiration}

In the evaporation process of a vegetated surface two resistances can be considered as controlling factors: the stomatal resistance $\left(r_{s}\right)$ and the aerodynamical resistance $\left(r_{a}\right)$. In a vegetated surface, the path of turbulent diffusion from the surface to the atmospheric boundary layer is frequently analyzed through these two resistances. The stomatal resistance is related to the physiology of the plant. It is the mechanism that better represents the control of the evapotranspiration in the plant. The transpiration in the leaves sum approximately $90 \%$ of the water loss of the plant (Lambers et al., 2008), what reflects the importance of assessing this resistance.

The stomatal resistance was calculated by inverting the Penman Monteith equation:

$$
r_{s}=\left[\frac{\left(\rho_{a} C_{p} V P D\right)}{\gamma L E}-r_{a}\left(1-\frac{\Delta H}{\gamma L E}\right)\right]
$$

where $\rho_{a}$ is the air density $\left(\mathrm{kg} \mathrm{m}^{-3}\right), C_{p}$ is the specific heat of air at constant pressure $\left(\mathrm{Jkg}^{-1}{ }^{\circ} \mathrm{C}^{-1}\right)$, VPD is given in $\mathrm{hPa}, \gamma$ is the psychometric constant $\left(\mathrm{hPa}{ }^{\circ} \mathrm{C}^{-1}\right), \mathrm{LE}$ is the latent heat flux $\left(\mathrm{Wm}^{-2}\right), \Delta$ is the slope of the saturation vapor curve $\left(\mathrm{hPa}^{\circ} \mathrm{C}^{-1}\right), \mathrm{H}$ is the sensible heat flux $\left(\mathrm{Wm}^{-2}\right)$. 
On the other hand, the aerodynamic resistance is closely related to the planetary boundary layer and to the turbulent atmospheric processes. The aerodynamic resistance can be defined as the parameter that represents the resistance to the turbulent activity in the layer of air close to the surface. This turbulent activity is responsible for the transport of sensible and latent heat and water fluxes.

The aerodynamic resistance was calculated following Costa et al. (2010) as follows:

$$
r_{a}=\frac{\bar{u}}{u_{*}^{2}}
$$

where $\bar{u}$ is the above canopy mean horizontal wind speed and $u_{*}{ }^{2}$ is the friction velocity. This formulation is simpler than an explicit account of stability effects on the turbulence aerodynamics, but we prefer to use it to avoid large possible errors introduced in the calculation of stability functions in Amazonia and to make it more comparable to previous works of Hasler and Avissar (2007) and Costa et al. (2010). The unity that commonly represents the aerodynamic and surface

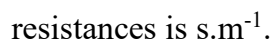

A useful tool to characterize the processes of exchange between the canopy and atmosphere, and the control of these processes considering their seasonality is the decoupling factor $(\Omega)$ proposed by Jarvis and McNaughton (1986) as follows:

$$
\Omega=\frac{1}{1+[\gamma /(\delta+\gamma)]\left(\mathrm{r}_{\mathrm{s}} / \mathrm{r}_{\mathrm{a}}\right)}
$$

The decoupling factor is an index that allows evaluating whether the evapotranspiration process is mainly controlled by the vegetation or it is decoupled from the surface and mainly limited by the energy available: the closer to 1 the greater the control of the atmospheric conditions (mainly available energy), while a value close to 0 indicates a strong influence of vegetation (strong coupling between the evapotranspiration and biological activity of stomata opening or closure).

The analysis in this work comprises the wet and dry periods of 2000. In the three sites, the period analyzed was of 90 days, from January to March (wet season) and also 90 days from August 
to October (dry season). These periods were chosen to represent the seasonality of the sites; therefore, we choose the months that most likely the vegetation is subject to contrasting wet/dry stress conditions (middle of wet season versus end of dry season).

All data were recorded in half hourly intervals and the calculations of the eddy fluxes were performed using an in-house-developed software written in FORTRAN, which can be adapted to a number of different hardware configurations and program options. The program was configured to apply two-axis rotations to align the coordinate frame with the mean streamlines and force the mean vertical component $(\mathrm{w})$ to zero and to perform standard frequency-response corrections. No detrending method was applied to the signals. Generally for these sites and instrumental setup, apart from the coordinate rotations, the corrections are relatively small and do not represent large uncertainty factors in the final values (Kruijt et al., 2004).

Based on this information, the aerodynamical and stomatal resistances, and the decoupling factor were calculated and only daytime periods (from 8 am to $6 \mathrm{pm}$ ) are presented, to focus the study on the analysis of time periods where the vegetation control of evapotranspiration would be greatest.

\subsection{Results and discussion}

In Central Amazonia, the maximum monthly precipitation registered during the year 2000 was $458 \mathrm{~mm}$ in April and the minimum was $89 \mathrm{~mm}$ in August. The total precipitation of the year was about $2620 \mathrm{~mm}$. In Southwestern Amazonia, the total precipitation of the year was $1760 \mathrm{~mm}$, while the highest monthly precipitation was $274 \mathrm{~mm}$ in October (what already indicates the beginning of the following wet season), followed by $264 \mathrm{~mm}$ in January. The driest month was in August, reaching $30 \mathrm{~mm}$.

Figure 3.1 presents the monthly values of precipitation minus reference evapotranspiration (P-ETo), as calculated using FAO standard recommendations (Allen et al., 1998), for the three sites. We observe that the sites in Southwestern Amazonia (Jaru and FNS) are subject to drier conditions during june through august, with significantly negative values of P-ETo.

Daily averages of the net radiation in K34 from January to March vary between 24 and 223 $\mathrm{Wm}^{-2}$ (not shown). This variation is slightly lower in the period from August to October, when the 
net radiation varied from 59 to $207 \mathrm{Wm}^{-2}$. Corresponding values in Rebio Jaru vary from 30 to 243 $\mathrm{Wm}^{-2}$ (wet period) and from 40 to $205 \mathrm{Wm}^{-2}$ (dry period). In the pasture site, the net radiation variation is lower when compared to the forests. The highest variation in daily average net radiation in the pasture also happened from January to March, but in a lower range: from 42 to $202 \mathrm{Wm}^{-2}$, and during the dry months (June to August), varied from 37 to $149 \mathrm{Wm}^{-2}$.

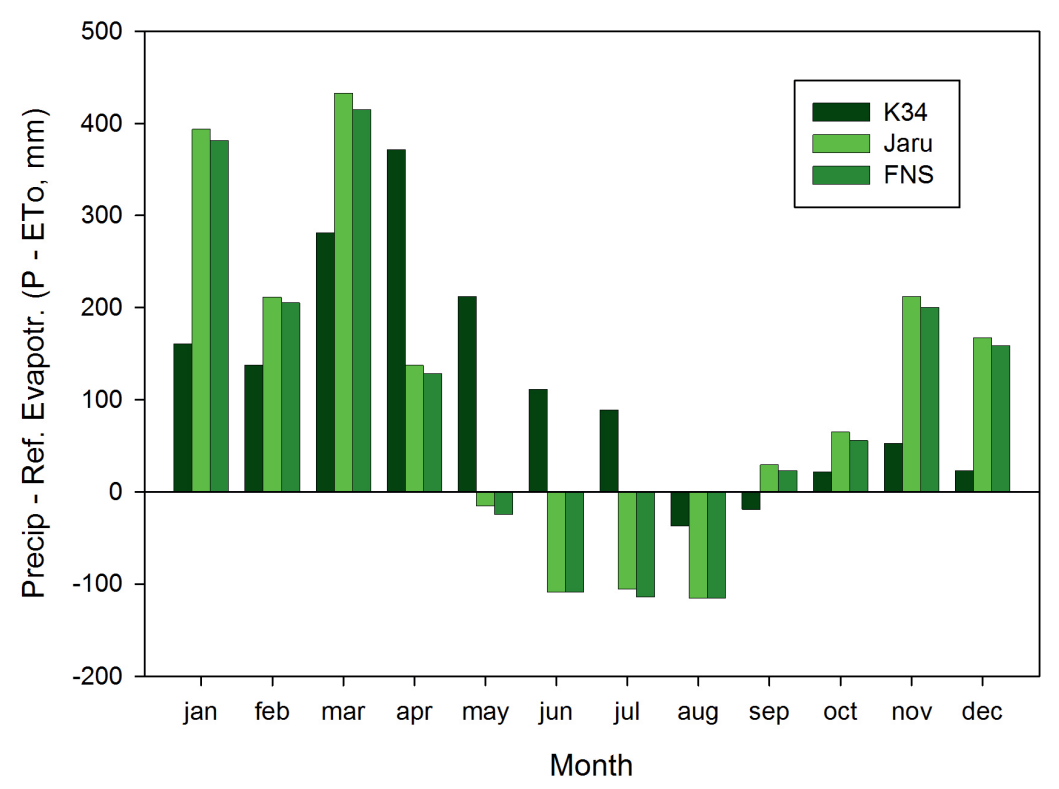

Figure 3.1 Monthly totals of the difference between precipitation and reference evapotranspiration (P - ETo), computed using FAO standard method.

Results of the measurements of vapor pressure deficit $(V P D)$, aerodynamic resistance $\left(r_{a}\right)$, stomatal resistance $\left(r_{s}\right)$ and decoupling factor $(\Omega)$, during wet and dry season periods, are presented in Figures 3.2 to 3.4. Each point in the line graphs is the median of observed values at each half hour, and the bars present the interval between the first and third quartiles. In this way, the values presented within the bars include 50 percent of the observations at each time.

Figure 3.2 shows the diurnal median values for the K34 forest site, which is located in Central Amazonia (Amazonas state). Figures 3.3 and 3.4 show the same variables, but measured at the Jaru forest site and FNS pasture site, which are located in South-West Amazonia (Rondonia 
state). In general, results from the two forest sites are similar, but some changes in the values are noted in the pasture vegetation.

First observing the measurements at the forest sites (Figures 3.2 and 3.3), clear effects of the dry season are noted in the measurements of VPD (Figures 3.2a and 3.3a), where the maximum diurnal values reach $\sim 20 \mathrm{hPa}$ in both forests, compared to less than $10 \mathrm{hPa}$ during wet season. $r_{a}$, on the other hand, almost does not change from the wet to the dry season (Figures $3.2 \mathrm{~b}$ and $3.3 \mathrm{~b}$ ), remaining below $30 \mathrm{~s} / \mathrm{m}$ during daytime hours. This means that the turbulent activity and roughness characteristics change little from one season to the other at those forests.

The forest stomatal resistances also vary significantly between seasons (Figure 3.2c and $3.3 \mathrm{c}$ ). During the wet season, the daily variation is lower than during the dry season, ranging from around 30 to $150 \mathrm{~s} / \mathrm{m}$ in the wet season and from 50 to $500 \mathrm{~s} / \mathrm{m}$ in the dry season (with higher dispersion of values at Jaru, Figure 3.3c).

Figures $3.2 \mathrm{~d}$ and $3.3 \mathrm{~d}$ present the diurnal variation of $\Omega$ for both forests. During the wet season, $\Omega$ shows a decrease trend throughout the day, ranging from 0.8 to 0.5 . During the dry season, $\Omega$ remains around 0.6 in the morning at K34 (Figure 3.2d), then dropping to 0.4 in the afternoon, however drops significantly lower at Jaru throughout the day (Figure 3.3d). According to Jarvis and McNaughton (1986) this means that for both forests, the evapotranspiration in the wet season is mainly controlled by the available energy, especially during morning hours but trending to some influence of stomatal resistances along the day. During the dry season, the stomata play a stronger role in controlling forest transpiration, especially in the afternoon hours. Understanding mechanisms of how evapotranspiration is controlled in vegetated surfaces is of crucial importance, since the evapotranspiration processes connect the vegetation function and regional climate via their role in the partitioning of radiative energy into heat and moisture supply from the surface to the atmosphere. 

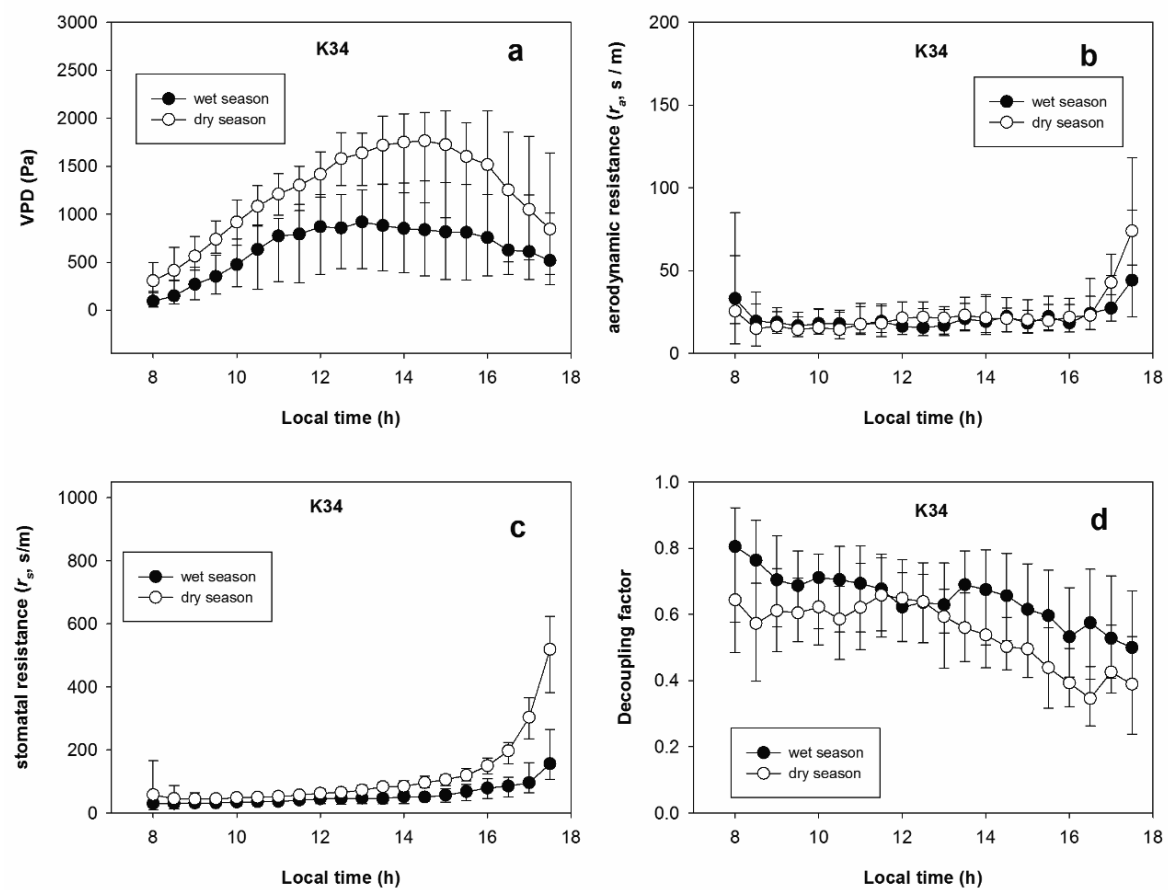

Figure 3.2 Distribution of hourly measurements of (a) vapor pressure deficit (VPD), (b) aerodynamic resistance, (c) stomatal resistance and (d) the decoupling factor, $\Omega$, along daytime, observed in wet and dry periods of 2000 at K34 forest site. Symbols represent the median of observations in each hour and the vertical bars represent the interval between 1st and 3rd quartiles. 

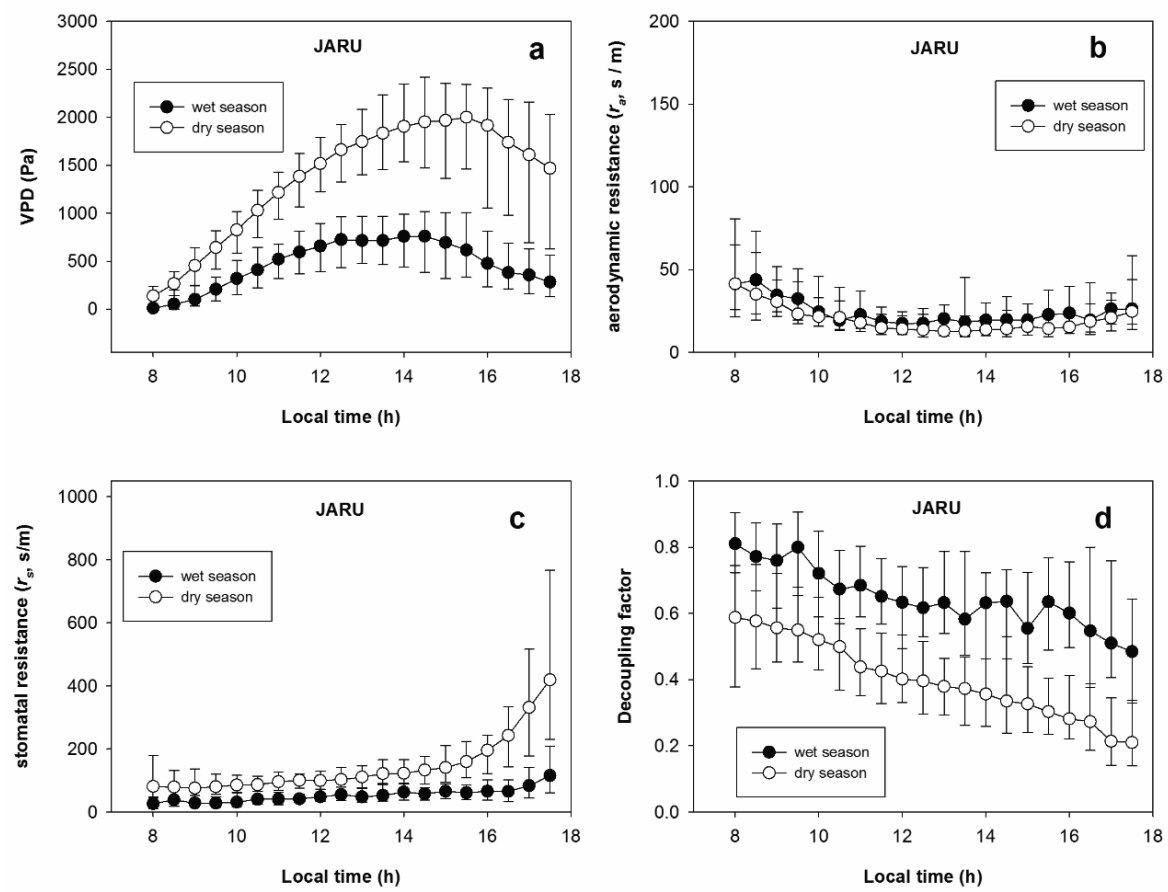

Figure 3.3 Distribution of hourly measurements of (a) vapor pressure deficit (VPD), (b) aerodynamic resistance, (c) stomatal resistance and (d) the decoupling factor, $\Omega$, along daytime, observed in wet and dry periods of 2000 at Jaru forest site. Symbols represent the median of observations in each hour and the vertical bars represent the interval between 1st and 3rd quartiles.

The measurements at the pasture site are even more sensitive to the seasonal variations (Figure 3.4). Median VPD reaches $23 \mathrm{hPa}$ in the dry season (Figure 3.4a), while remains below 11 $\mathrm{hPa}$ in the wet season. Variations in $r_{a}$ are also more pronounced than in the forests (Figure 3.4b), but these seasonal changes are more complex to interpret, because they are largely sensitive to the grazing by the cattle, which alters the roughness of the grass vegetation not necessarily consistent with our selection of wet and dry periods. Still, it can be observed that the pasture $r_{a}$ is higher than in the forests in both seasons, as a result of higher roughness of the forest vegetation.

The seasonal variations in $r_{s}$ at FNS is similar to that in the forest sites in the wet season, varying from 50 to $150 \mathrm{~s} / \mathrm{m}$, while in the dry season the variation is much higher, from 100 to 1000 $\mathrm{s} / \mathrm{m}(\sim 2000$ at $6 \mathrm{pm}$, Figure 3.4c), pointing to a more intense water stress during the dry season in the pasture vegetation. 
The behavior of $\Omega$ at the pasture is also different than at the forests, although also qualitatively indicating the higher control of transpiration by stomatal resistance during the dry periods (Figure 3.4d). $\Omega$ remains high $(\sim 0.8)$ during the whole day in the wet season and drops significantly (from 0.8 to 0.3 ) during the day in the dry season.
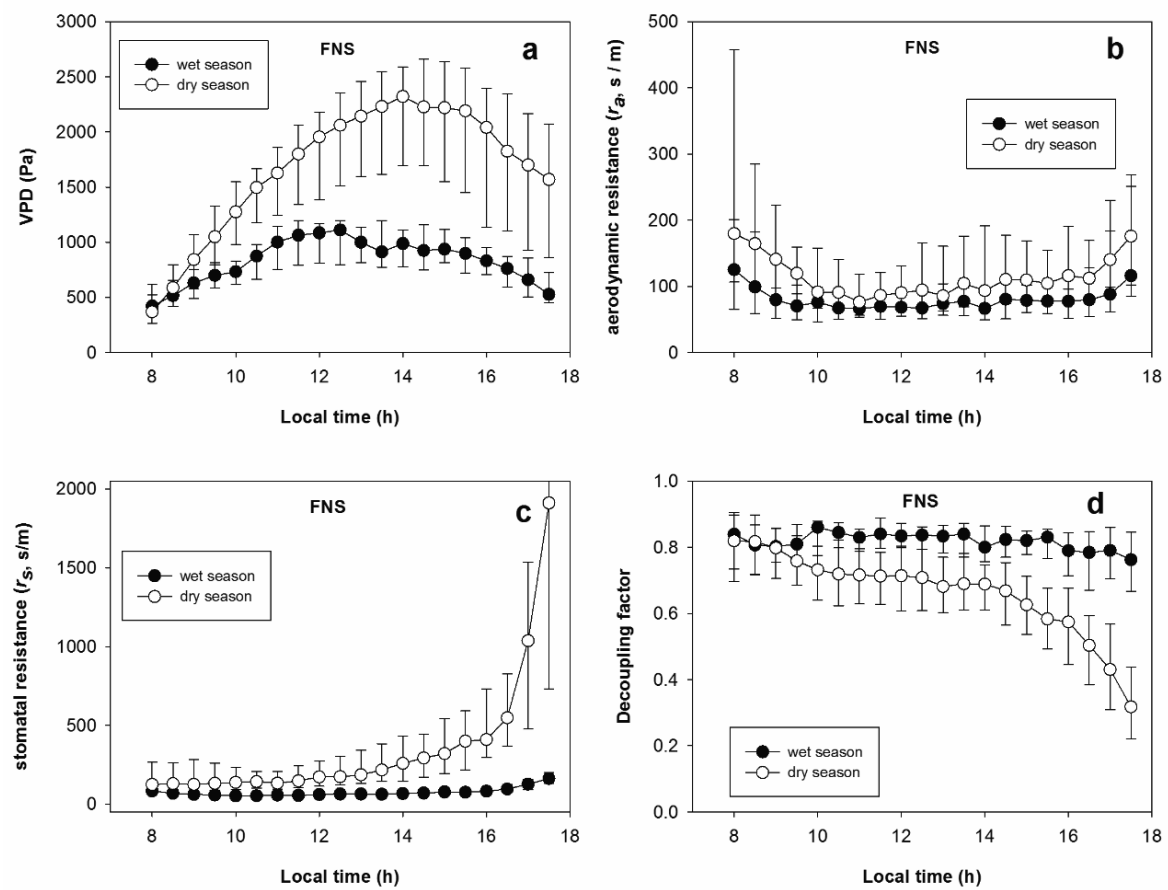

Figure 3.4 Distribution of hourly measurements of (a) vapor pressure deficit (VPD), (b) aerodynamic resistance, (c) stomatal resistance and (d) the decoupling factor, $\Omega$, along daytime, observed in wet and dry periods of 2000 at FNS pasture site. Symbols represent the median of observations in each hour and the vertical bars represent the interval between 1st and 3rd quartiles.

For reference use in climate models, we synthesize in Table 3.1 recommended values of the aerodynamic and stomatal resistances in the three sites. $r_{a}$ values were estimated from an approximate average of the medians from 9:00 to 16:00 h, to avoid the hours of transition to nighttime. $r_{s}$ reference values are presented as a range from lower resistances recommended for use in the morning time to higher resistances to represent stronger stomatal control during afternoon. 
Table 3.1: Reference values for aerodynamic and stomatal resistances, estimated in this study.

\begin{tabular}{lll}
\hline & $r_{a}(\mathrm{~s} / \mathrm{m})$ & $r_{s}(\mathrm{~s} / \mathrm{m})$ \\
\hline Forest K34, wet season & 20 & $40-150$ \\
Forest K34, dry season & 20 & $50-500$ \\
Forest Jaru, wet season & 20 & $40-100$ \\
Forest Jaru, dry season & 20 & $90-400$ \\
Pasture (FNS), wet season & 70 & $50-160$ \\
Pasture (FNS), dry season & 100 & $140-1800$ \\
\hline
\end{tabular}

Some previous studies in the Amazon region have already identified that evapotranspiration is directly connected to available energy, but also to aerodynamic transport mechanisms and biological control of transpiration, and that these controls vary according to the vegetation type or depending on periods of seasonal water deficits (e.g. Souza-Filho et al., 2005, Hasler and Avissar, 2007, Costa et al., 2010, Von Randow et al., 2012, Christoffersen et al., 2014). Hasler and Avissar (2007) analyzed the seasonality of evapotranspiration in 8 sites in Amazonia, where three of them are the K34, Rebio Jaru and FNS sites. However, the authors used a preliminary version of the dataset, which were possibly subject to large uncertainties due to problems in data collection and incomplete quality assessment. We now update and extend the analyses to address in more detail how these mechanisms vary throughout the daytime and seasonally, in the two contrasting vegetation types of rainforest and pasture in the same region, and a rainforest in a wetter climate.

Results obtained in this study show that the biological control of transpiration (represented by the stomatal resistance) presents both a diurnal and seasonal variability. Daily, a low resistance marks it in the morning, increasing throughout the day to reach high values in the evening. Since the stomatal resistance is related to the opening or closure of stomata, these results indicate that there is restriction of transpiration related to water deficit in the plants.

Analyzing the aerodynamic resistances, we also obtained that turbulence caused by the roughness of the surface can be an important secondary factor and almost invariable from the wet to dry seasons, in the production of evapotranspiration in the sites, especially in the forest - this is 
indicated by the low aerodynamic resistance observed, or, in its turn, high aerodynamic conductance related to high roughness of the forest surface.

The results obtained from the analysis of the Jarvis and McNaughton (1986) decoupling factor $(\Omega)$ may further bring insight into our discussion. The parameter varies between 0 and 1 , with values close to 1 indicating that the conditions of evapotranspiration are decoupled from surface resistances (that is, evapotranspiration is mainly related to the amount of available energy), and values close to 0 indicating a strong coupling between evapotranspiration and the atmospheric turbulent conditions and biological activity (that is, evapotranspiration is controlled not only by energy, but also by vegetation and other atmospheric conditions). Our results show that $\Omega$ presents not only a diurnal variation, but also a seasonal variation, for both forests. During the wet season, the evapotranspiration is controlled by the atmospheric conditions, especially during the morning, dropping to around 0.5 in the end of the afternoon in both forest sites. On the other hand, in the dry season, stomata is responsible for controlling the transpiration in both forests, mainly in the end of the afternoon, with $\Omega$ dropping from around 0.6 to less than 0.4. A strong drop happens in Rebio Jaru, which is lower than 0.5 already in the end of the morning. This indicates that, although energy limitation is a strong influence, there is a significant contribution of the biotic factors to the variability of evapotranspiration. FNS, in turn, shows that its evapotranspiration is controlled by the atmospheric conditions in the wet season, as well as in the dry season. However, during the dry season, $\Omega$ presents a diurnal variation, dropping to lower than 0.5 in the end of the afternoon, showing once more the restriction of transpiration related to water deficit in the plants in this period.

The radiative energy provided by solar radiation is the main forcing of the biophysical processes of interaction between the biosphere and the atmosphere, acting as the primary driver of evapotranspiration in Amazonia. This has been observed before, especially in the more 'equatorial' sites of Amazonia, such as the K34 (e.g. Da Rocha et al., 2009, Costa et al, 2010). However, there is also indication that some species in equatorial sites are sensitive to water stress if the dry season is prolonged or in artificially rainfall exclusion experiments (Meir et al., 2013). Our results further highlight the strong sensitivity that a land use change to a pasture vegetation would cause: the pasture site clearly shows a large increase in stomatal resistance and transpiration control by the vegetation during the dry season.

Da Rocha et al. (2009) and Costa et al. (2010) discussed in their results a general seasonal behavior in evapotranspiration in different sites in Amazonia, corroborating the main control of 
evapotranspiration by abiotic / environmental conditions of available energy. The climate conditions that produce the tropical forests are generally characterized by frequent and abundant rainfall, which is certainly the case of forest in Central Amazonia near Manaus, and this makes less likely the occurrence of severe water stress. Due to this and also due to the large soil depth that tree roots may reach in the region, it is expected that these forests will remain resilient to annual dry seasons in the near future. However, if the occurrence of anomalous dry years increases frequency due to climate change or a combination of climate change and increasing pressures of land use change substantially affect the ecosystem, it is realistic to expect a significant degradation of the forest into a less resilient forest type.

\subsection{Conclusions}

Analyzing measurements of vapor pressure deficit, aerodynamic resistance, stomatal resistance and of the decoupling factor, we studied the diurnal and seasonal variability of control of evapotranspiration in contrasting sites in Amazonia: a pristine rain forest in Central Amazonia (K34 site) and a pristine forest (Jaru) and a pasture (FNS) in Southwestern Amazonia. Seasonal variations in the precipitation minus reference evapotranspiration totals conditions are similar in the sites, however the pasture presents slightly higher vapor pressure deficit (drier conditions) in the dry season, and, especially because of the shallower roots in the pasture vegetation, we observe that these conditions reflect a different seasonal behavior of the evapotranspiration in the pasture, compared to the forest sites.

Aerodynamic resistance does not change significantly from wet to dry season in both forest sites, but it is higher in the pasture, compared to the forests, due to its lower roughness, and it is sensitive to cattle grazing. Stomatal resistance, on the other hand, exhibits large changes both throughout the day and from wet to dry seasons, at the three sites. Daily, the stomatal resistance shows low values in the morning, increasing to reach its maximum in the afternoon and early evening, which highlights the effect of increasing stomatal control of evapotranspiration as the day progresses. This effect is even more pronounced in the dry season, which evidences the occurrence of water stress in the pasture vegetation. During the wet season, soil water conditions are likely much more favorable, and the stomatal resistance is similar in the two vegetation types. 
Results obtained for the decoupling factor also corroborate conclusions from previous studies that evapotranspiration is primarily driven by the conditions of available energy in Amazonia (decoupled from surface conditions) in the wet season, but, still, a significant biological control of transpiration by plants is observed in the dry season, especially in the pasture cover and in the afternoon. 


\title{
Chapter 4
}

\section{Evapotranspiration and Gross Primary Productivity of Secondary Vegetation in Amazonia Inferred by Eddy Covariance $^{3}$}

\begin{abstract}
The conversion of primary forest (PF) to other types of land cover, such as pasture and agriculture, in Amazonia, affects regional carbon and water balances, significantly contributing to increased carbon emissions and reduced evapotranspiration. However, secondary forest (SF) growth, resulting from the abandonment of low-productivity pasture areas, offers a potential alternative to counterbalance the effects of deforestation on carbon release to the atmosphere and evapotranspiration reduction. In this work, we present four years of eddy flux measurements of a SF that is approximately 20 years old, located in Central Amazonia, and we compare these measurements with those of a PF in the same region, analyzing daily, seasonal and yearly variations in evapotranspiration, gross primary productivity of carbon and water use efficiency. On average, evapotranspiration is $20 \%$ higher in the SF $\left(3.64 \mathrm{~mm}^{- \text {day }^{-1}}\right)$ than in the PF $\left(3.05 \mathrm{~mm} \cdot \mathrm{day}^{-1}\right)$, while gross primary productivity is only $5 \%$ higher in the SF $\left(8.0 \mathrm{gC} . \mathrm{m}^{-2} \cdot \mathrm{day}^{-1}\right)$ than in the PF $\left(7.7 \mathrm{gC} \cdot \mathrm{m}^{-2}\right.$.day $\left.{ }^{-1}\right)$, except during the dry season, when the gross carbon uptake is the same in both sites. Conversely, water use efficiency is lower in the SF than in the PF (10\% during the wet season and $15 \%$ during the dry season), showing that in comparison to the PF, the SF seems to have less control over water loss to assimilate the same amount of carbon.
\end{abstract}

\footnotetext{
3 This chapter is submitted to publication as: Von Randow, R.C.S., Tomasella, J., Von Randow, C., Araújo, A.C., Manzi, A.O., Hutjes, R. W, Kruijt, B. (2019). Evapotranspiration and Gross Primary Productivity of Secondary Vegetation in Amazonia Inferred by Eddy Covariance. Submitted to Agricultural and Forest Meteorology
} 


\subsection{Introduction}

Hydrological cycle components, such as evapotranspiration (ET) and precipitation, in the Amazonian region are important not only locally but also regionally since the moisture produced by Amazon forest ET provides precipitable water to the south and southeast of South America (Arraut et al., 2012; Marengo et al., 2004; Zemp et al., 2014).

Human settlement in the Brazilian Amazon accelerated in the 1970s due to governmental incentives. Settlement usually begins through forest conversion to pasture and agricultural land, mediated by logging and slash and burning. This process has several undesired consequences, such as reducing ET (Lathuillière et al., 2012) and soil water recharge and increasing discharge (Bruijnzeel, 1991). In the long term, this process might impact regional climate by reducing precipitation in the region, which then may feedback reducing discharge (Lima et al., 2014). Moreover, deforestation is considered one of the major sources of $\mathrm{C}$ emissions in Brazil contributing to climate change (MCTIC, 2017)

Unsustainable practices, such as the slash and burning technique for pasture management, ultimately deplete soil resources and lead to loss in soil productivity (Castro, 2006; Zarin et al., 2005), inducing the abandonment of pasture lands.

Abandoned pastureland provides an opportunity for forest recovery of degraded areas. Although constrained by the duration of pasture use and its management, natural regeneration in abandoned pastures generally occurs relatively rapidly based on the high occurrence of pioneer species, which result in secondary succession (Rocha et al., 2016).

Forest recovery partially offsets carbon emissions from land-use change and fossil fuels by accumulating carbon in forest biomass. Estimations by Pan et al. (2011) indicated that secondary forests have the potential to accumulate $0.86 \mathrm{Pg} \mathrm{C}_{\mathrm{gear}}{ }^{-1}$ in Latin America, while in the case of the Brazilian Amazon, Aragão et al. (2014) estimated that C accumulation in secondary forests varies between 0.04 and $0.06 \mathrm{Pg} \mathrm{C}_{\mathrm{Cear}}{ }^{-1}$. The large uncertainties in these numbers are related to the fact that the increment of aboveground biomass varies because of not only past land-use history (Vieira and Martin, 2015) but also forest physiology, controlled by environmental and climatic conditions such as the length of the dry season (Gehring et al., 2005). 
Almeida et al. (2010) estimated that until 2006, secondary forests covered an area of approximately $131000 \mathrm{~km}^{2}$. More recent estimations (INPE, 2016) indicated that secondary vegetation growth is approximately $23 \%$ of deforested areas. Despite differences in numbers, carbon uptake by secondary forests is likely to account for $17-44 \%$ of the total carbon emissions from deforestation (Cassol et al., 2019). In addition to the benefits in terms of carbon fixation, secondary forests may provide an important contribution to the water cycle of the region, presenting a higher evaporative fraction than that of pristine forests (Giambelluca, 2002), which can partially compensate for the effects of the conversion of forest to pasture and agriculture on energy and water balances.

Field measurements of carbon and water surface fluxes in Amazonia using the eddy covariance technique have been conducted since the early 1980s in the pioneering studies of Shuttleworth (1988) and Fitzjarrald et al. (1988) and later at a much broader scale as part of the Large Biosphere-Atmosphere (LBA) tower network (e.g., Araújo et al., 2002; Da Rocha et al., 2009; von Randow et al., 2004), with crucial importance for understanding the functioning of the forest-atmosphere interaction and effect of land-use change (Von Randow et al., 2012). However, except for leaf-scale measurements that include some pioneer species (Kunert et al., 2015), the literature still lacks reports of direct observations of fluxes in secondary vegetation areas in Amazonia.

In this context, this study is the first comprehensive study of water and carbon fluxes in a secondary forest in Amazonia. We analyzed four years of eddy flux measurements in a 20year old secondary forest and performed comparisons with data from a primary forest site, both located in Central Amazonia. We quantified daily, seasonal and yearly variations in $E T$, gross primary productivity $(G P P)$ of carbon and water use efficiency and assessed the potential effects of secondary regrowth in the local water balance.

Considering that a recent study suggested that tree restoration is one of the most effective strategies for climate change mitigation (Bastin et al., 2019), reliable data on the potential benefits of secondary regrowth are essential for quantifying the economic and social benefits of mitigation policies. In addition, a recent study of Von Randow et al. (2019) suggests that secondary forest can also have impacts on hydroelectricity under a changing climate, therefore water consumption in secondary forest might have additional implications for competing water uses. 


\subsection{Materials and Methods}

\subsubsection{Site description}

The measurements analyzed in this study took place from 2008 to 2011 at two flux towers in Central Amazonia, in the Manaus region: the first in a primary forest and the second in a secondary succession.

The first site is located in the Cuieiras Biological Reserve, at kilometer 34 of the road that accesses the reserve. For this reason, the site is known as K34, as part of the LBA. The K34 flux tower is situated on the plateau of a tropical terra firme humid forest $\left(2^{\circ} 36^{\prime} 32.67^{\prime \prime} \mathrm{S} ; 60^{\circ} 12^{\prime}\right.$ $33.48 \mathrm{"} \mathrm{W})$, located approximately $60 \mathrm{~km}$ north of Manaus. The flux tower is located $1.5 \mathrm{~km}$ south of the nearest unpaved road. The trees in the primary forest are approximately $35 \mathrm{~m}$ high.

The second site is located at Colosso Farm Ranch, one of the sites of the Biological Dynamics of Forest Fragments Project (BDFFP). The road that accesses the farm is known as Colosso (CO). The flux tower of the site is also located on a plateau; however, the vegetation is part of 20 year old secondary succession, resulting from the abandonment of a slash and burn pasture (Moreira, 2003). The most important pioneer species in the region are Vismia spp., Cecropia spp. and Bellucia spp. (Lucas et al., 2002) where Vismia spp is the dominant species in regions with more intense land use, such as pasture and slash and burn management (Mesquita et al., 2001). This site is located approximately $105 \mathrm{~km}$ northeast of Manaus (02 $\left.23^{\circ} 26,5^{\prime \prime} \mathrm{S} ; 59^{\circ} 53^{\prime} 0,7^{\prime \prime} \mathrm{W}\right)$. The flux tower is located approximately $700 \mathrm{~m}$ northeast of the closest pasture patch. Trees in this secondary forest are approximately $24 \mathrm{~m}$ high.

In both regions, plateaus, slopes and valleys form the topography. The soils in the plateau were classified as Oxisol (or Latossolo Amarelo - Embrapa, 2006), with clayey to very clayey texture (Marques et al., 2015).

During the period presented in this article, the annual average precipitation at both sites was approximately $2600 \mathrm{~mm}$, while 2008 was the wettest year, with more than $2900 \mathrm{~mm}$ in precipitation. As the sites have the same precipitation regime, when the gaps in the data from one site are filled with data from the other, the annual totals are similar, such as for that in 2011 (year without missing gaps). Table 4.1 presents the annual precipitation for both sites for the period of study, without gap-filling of missing periods. 
Table 4.1: Annual precipitation (in $\mathrm{mm}$ ) for the primary and secondary forest sites.

\begin{tabular}{ccc}
\hline Year/Site & Primary forest - K34 & Secondary forest - CO \\
\hline 2008 & $2916^{\mathrm{a}}$ & 2984 \\
2009 & 2509 & $1826^{\mathrm{b}}$ \\
2010 & $2114^{\mathrm{c}}$ & 2665 \\
2011 & 2706 & 2730 \\
\hline
\end{tabular}

${ }^{a}$ Gaps of 56 days during the dry season

${ }^{\mathrm{b}}$ Gaps of 56 days during the wet season

${ }^{\mathrm{c}}$ Gaps of 15 days during the wet season

For analyses of possible seasonal change effects, we followed previous works in the region and used two separate periods to represent the rainy (from November to May) and dry seasons (from August to October).

To ensure the identification of the comparison between sites would be understood by the reader, from here on out, the primary forest will be referred to as PF, and the secondary forest will be referred to as SF.

\subsubsection{Data processing and gap-filling}

The PF tower was instrumented with a closed-path eddy covariance system consisting of a Gill R3 sonic anemometer (Gill Instruments, UK) and a LI-COR LI-7000 infrared gas analyzer (LICOR, USA), except for 2 months in 2008 due to the malfunctioning of the infrared gas analyzer (IRGA) and temporary replacement by an open-path LI-7500 IRGA (LI-COR, USA). Other details about the eddy covariance system and other instrumentation at the site are presented in Araujo et al. 2002. The SF tower holds a three-dimensional CSAT3 sonic anemometer (Campbell SI, USA) connected to an LI-7500 open-path IRGA.

Fluxes were calculated in half-hour intervals using the in-house developed software Alteddy (Elbers et al., 2011), which can be adapted to a number of different hardware configurations and program options. The program was configured to apply two-axis rotations to align the coordinate 
frame with the mean streamlines and force the mean vertical component (w) to zero (McMillen, 1988) to compensate for the time delay in the IRGA signals, to include cross-wind and humidity corrections of the sonic temperature signal (Schotanus et al., 1983) and to apply the WebbPearman-Leuning (WPL) correction in the open-path gas analyzer data in SF (Gu et al., 2012; Leuning, 2007).

Gaps in the data were filled using the look-up table approach described by Reichstein et al. (2005) that attempts to fill each gap with an average of good records taken under similar environmental conditions of net radiation, air temperature and vapor pressure deficit. The algorithm is described in Appendix A of Reichstein et al. (2005) and publicly available through an R software package called ReddProc.

The absolute values of latent and sensible heat fluxes must be interpreted with caution because the estimates of turbulent fluxes have potential site-specific uncertainties related to energy balance closure; therefore, in this paper, we estimate the evaporative fraction as the ratio $L E /(H+L E)$.

In addition to the measurement of ecosystem ET through the eddy covariance system, we also compute the net ecosystem exchange of carbon $(N E E)$ in the sites and estimate the amount of water used by the vegetation per unit of absorbed carbon, the water use efficiency (WUE), after following the applicable procedure.

First, changes in storage of $\mathrm{CO}_{2}$ below the measurement point at the top of the tower must be accounted for, ideally by direct measurements of the $\mathrm{CO}_{2}$ concentration at different levels along the tower, or at least by some estimate of nighttime accumulation in the canopy airspace (e.g., Von Randow et al. 2004, Iwata et al. 2005). At the PF site, measurements of $\mathrm{CO}_{2}$ concentrations were available, but at the SF site, there were no direct measurements except the eddy covariance system; thus, in this case, we used an approach based on Iwata et al. (2005) to estimate average storage using only the concentration in the top level and the amount of turbulence that occurred the night before.

Second, conditions of low level of turbulence that could hinder the validity of the eddy covariance method inferred from low-friction velocity $\left(\mathrm{u}^{*}\right)$ values were filtered out and later replaced by modeled values in the gap-filling analyses. The $\mathrm{u}^{*}$-threshold was estimated by the moving point test according to Papale et al. (2006), which resulted in values of approximately 0.17 at the SF site and 0.10 to 0.14 at the PF site. 
Third, the method based on light-response curves fit to daytime NEE measurements, which avoided the use of potentially problematic nighttime data, as discussed by Lasslop et al. (2010), was used to partition NEE into the GPP (the gross amount of $\mathrm{CO}_{2}$ taken up by photosynthesis) and ecosystem respiration $\left(R_{e c o}\right.$, the amount of $\mathrm{CO}_{2}$ released by the ecosystem by autotrophic and heterotrophic respiration) terms.

Finally, ecosystem $W U E$ was calculated by the ratio $W U E=G P P / E T$ where $G P P$ is given in $\mathrm{gC} . \mathrm{m}^{-2}$.day ${ }^{-1}$ and $E T$ is given in mm.day ${ }^{-1}$. WUE represents gC gained per $\mathrm{kg} \mathrm{H}_{2} \mathrm{O}$ consumed by the vegetation.

\subsubsection{Aerodynamic and stomatal resistance}

The aerodynamic resistance, commonly used to express the degree of resistance in the turbulent transport in the atmospheric surface layer, was calculated following Costa et al. (2010) as follows:

$$
r_{a}=\frac{U}{u_{*}^{2}}
$$

where $\mathrm{U}$ is the mean horizontal wind above the canopy and $\mathrm{u}^{*}$ is the friction velocity. This formulation is simpler than an explicit account of the stability effects on the turbulence aerodynamics, but we preferred to use it to avoid large possible errors introduced in the calculation of stability functions in Amazonia. Due to the difference in the height measurements between the sites, we corrected the measured wind speed at the SF site to correspond to the same height as measured at the PF site assuming a neutral profile.

The stomatal resistance, representing an inhibition of the loss of water through stomatal transpiration, was calculated by inverting the Penman Monteith equation:

$$
r_{s}=\left[\frac{\left(\rho_{a} C_{p} V P D\right)}{\gamma L E}-r_{a}\left(1-\frac{\Delta H}{\gamma L E}\right)\right]
$$


where $\rho_{a}$ is the air density $\left(\mathrm{kg} \mathrm{m} \mathrm{m}^{-3}\right), c_{p}$ is the specific heat of air at constant pressure $\left(\mathrm{J} \cdot \mathrm{kg}^{-1} \cdot{ }^{\circ} \mathrm{C}^{-1}\right)$, $V P D$ is the vapor pressure deficit $(\mathrm{hPa}), \gamma$ is the psychometric constant $\left(\sim 0.66 \mathrm{hPa} .{ }^{\circ} \mathrm{C}^{-1}\right), L E$ is the latent heat flux $\left(\mathrm{W} \cdot \mathrm{m}^{-2}\right), \Delta$ is the slope of the saturation vapor curve $\left(\mathrm{hPa} .{ }^{\circ} \mathrm{C}^{-1}\right)$, and $H$ is the sensible heat flux $\left(\mathrm{W} \cdot \mathrm{m}^{-2}\right)$.

\subsection{Results}

In this section, we present the flux data and inferred resistances as daily averages for the wet and dry seasons separately as well as for the whole period and as time series of centered running means.

The seasonal variation in net radiation was similar at both sites, with the daily average increasing from the wet season to the dry season by $26 \%$ for the PF and $21 \%$ for the SF. The difference among the daily averages of net radiation for the three periods was not significant, with the greatest difference reaching $8 \mathrm{~W} \cdot \mathrm{m}^{-2} \cdot$ day $^{-1}$ during the wet season. The available energy was partitioned more into $E T$ than into $H$ at both sites (Table 4.2). The daily average latent heat flux, and consequently ET, was approximately $20 \%$ higher in the SF than in the PF during the whole year and dry and wet seasons, while the sensible heat flux was approximately $36 \%$ lower in the SF than in the PF during the wet season and the whole period analyzed, and $40 \%$ lower during the dry season. Even though the ET increased at both sites during the dry season, the evaporative fraction decreased slightly at both sites. The decrease in evaporative fraction during the dry season in comparison with that in the wet season was smaller in the SF than in the PF, showing that the PF had a stronger control over the transpiration loss during the dry season, even though the region does not experience a marked shortage of water during the dry season.

The time series of evaporative fractions from 2008 to 2011 for the PF and SF are presented in Figure 4.1, where shaded bars show the dry periods. The average evaporative fraction in the SF was constantly higher than that in the PF, with both sites presenting the same seasonal variation. 
Table 4.2: Sensible and latent heat fluxes, net radiation and evaporative fraction means annually and in the wet and dry seasons and the ratio between secondary forest (SF) and primary forest (PF).

\begin{tabular}{|c|c|c|c|c|c|c|}
\hline \multirow{2}{*}{$\begin{array}{c}2008-2011 \\
\text { Site }\end{array}$} & \multicolumn{3}{|c|}{$\mathrm{H}\left(\mathrm{W} \cdot \mathrm{m}^{-2}\right)$} & \multicolumn{3}{|c|}{ LE $\left(\mathrm{W} \cdot \mathrm{m}^{-2}\right)$} \\
\hline & Annual & Wet & Dry & Annual & Wet & $\overline{\text { Dry }}$ \\
\hline PF (K34) & 29 & 26 & 36 & 87 & 83 & 98 \\
\hline $\mathrm{SF}(\mathrm{CO})$ & 18 & 16 & 22 & 104 & 98 & 116 \\
\hline $\mathrm{SF} / \mathrm{PF}$ & 0.64 & 0.64 & 0.60 & 1.19 & 1.19 & 1.18 \\
\hline $2008-2011$ & \multicolumn{3}{|c|}{$\operatorname{Rn}\left(\mathrm{W} \cdot \mathrm{m}^{-2}\right)$} & \multicolumn{3}{|c|}{$\mathrm{EF}(L E /(L E+H))$} \\
\hline Site & Annual & Wet & Dry & Annual & Wet & Dry \\
\hline PF (K34) & 131 & 122 & 154 & 0.76 & 0.77 & 0.73 \\
\hline $\mathrm{SF}(\mathrm{CO})$ & 139 & 130 & 158 & 0.85 & 0.86 & 0.84 \\
\hline $\mathrm{SF} / \mathrm{PF}$ & 1.06 & 1.06 & 1.03 & 1.11 & 1.12 & 1.15 \\
\hline
\end{tabular}

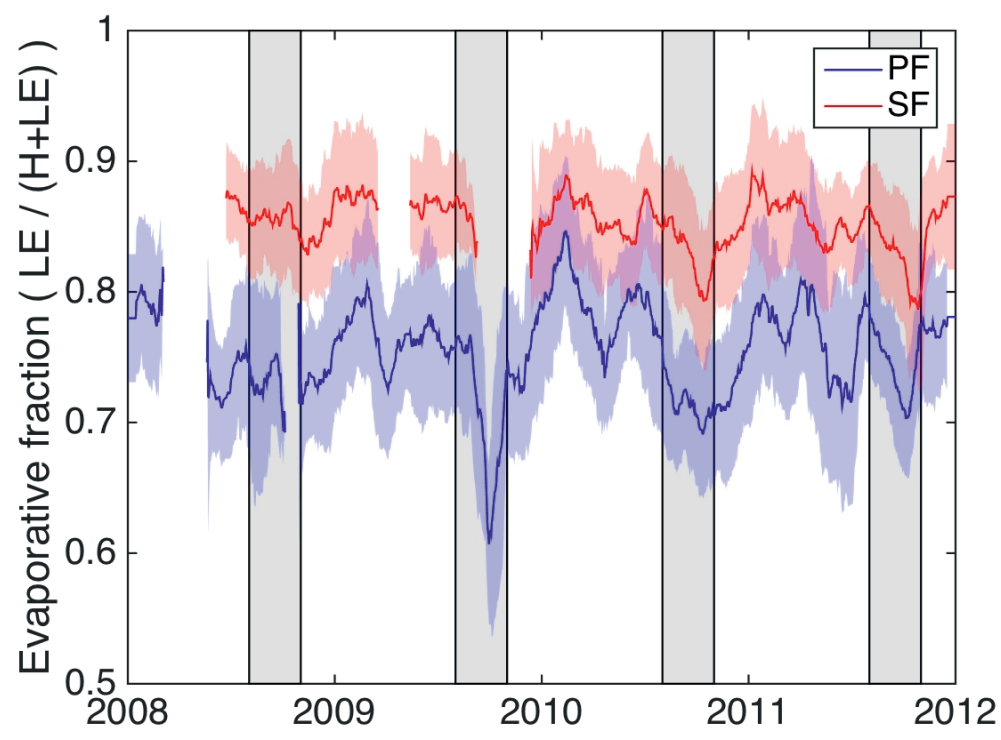

Figure 4.1 Time series of 31 day centered running means of the evaporative fraction for primary forest (PF) in the blue line and secondary forest (SF) in the red line and the respective standard deviations (shadow area in the same color of the mean values) for both sites. 
The radiation balance components, air temperature and specific humidity at both sites were generally similar during all periods evaluated; therefore, the differences in ET between the sites were not related to meteorological conditions. The average values of the albedo from the SF and PF were calculated during the diurnal period from 7:30 am to $5 \mathrm{pm}$. At the SF, the albedo was 0.125 $( \pm 0.006)$, and at the PF, the albedo was $0.121( \pm 0.006)$. Nonetheless, in the PF, the highest albedo value occurred at the beginning of the dry season, while at the SF, the albedo presented a shift with its highest value occurring at the end of the dry season (Figure 4.2).

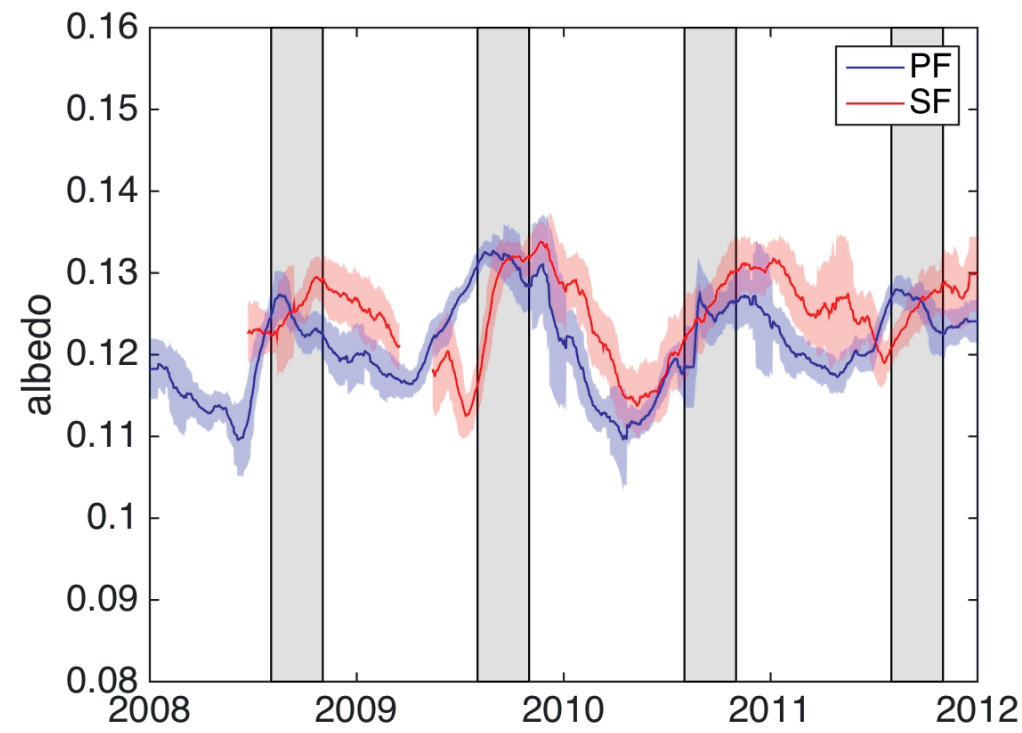

Figure 4.2 Time series of 31 day centered running means of albedo for primary forest (PF) in the blue line and secondary forest (SF) in the red line and respective standard deviations (shadow area in the same color of the mean values) for both sites.

Aerodynamic resistance was slightly higher in the SF than in the PF (approximately 5\% higher during the dry season and approximately $15 \%$ higher during the wet season and the whole period with available data). The average aerodynamic resistance in the SF in the period was approximately $40 \mathrm{~s} . \mathrm{m}^{-1}$, while in the PF, it was $35 \mathrm{~s} . \mathrm{m}^{-1}$ (Figure 4.3). 


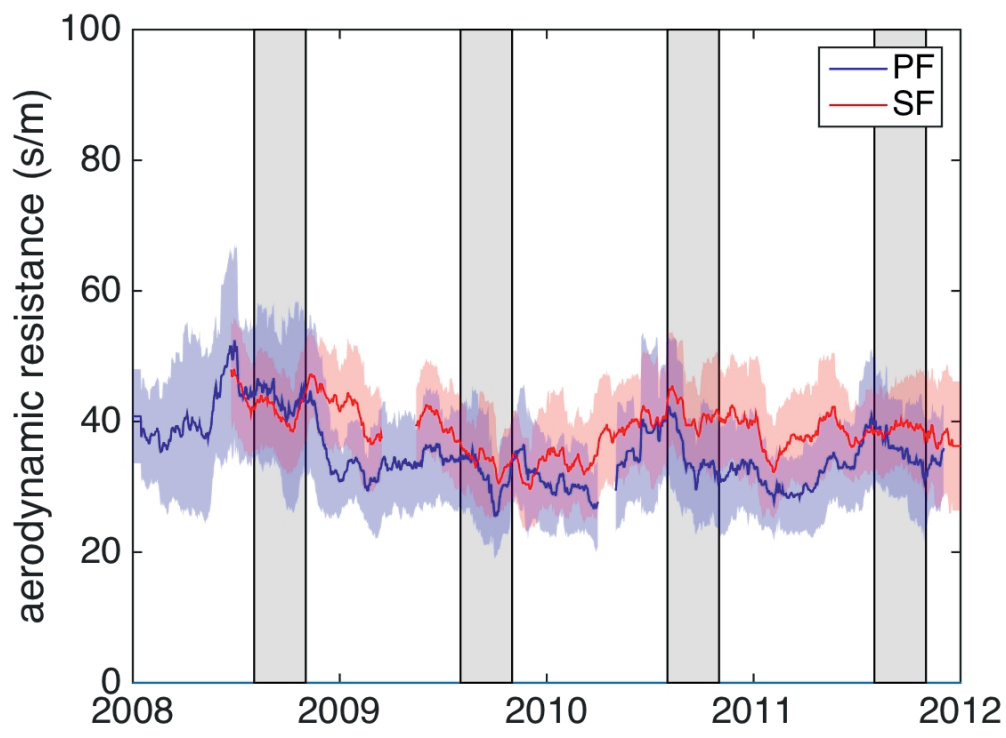

Figure 4.3 Time series of 31 day centered running means of aerodynamic resistance for primary forest $(\mathrm{PF})$ in the blue line and secondary forest (SF) in the red line and respective standard deviations (shadow area in the same color of the mean values) for both sites.

On the other hand, stomatal resistance was considerably lower in the SF than in the PF, approximately $40 \%$ lower during all time periods analyzed. Throughout the seasons, the stomatal resistance changed by approximately $50 \%$ at both sites (Figure 4.4 ). During the dry season, the daily average of $r_{s}$ in the SF was $97 \mathrm{s.m}^{-1}$, while in the PF, it was $175 \mathrm{s.m}^{-1}$. During the wet season, the daily average $r_{s}$ in the SF decreased to $33 \mathrm{~s} . \mathrm{m}^{-1}$, while in the PF, it decreased to $81 \mathrm{~s} . \mathrm{m}^{-1}$. Notably, inferring stomatal resistance from the inversion of the Penman Monteith equation can provide insight into the possible stress on the forest under drier conditions, which could lead to stomatal closure and higher resistances. The average values of aerodynamic and stomatal resistance for all time periods analyzed are shown in Table 4.3. 


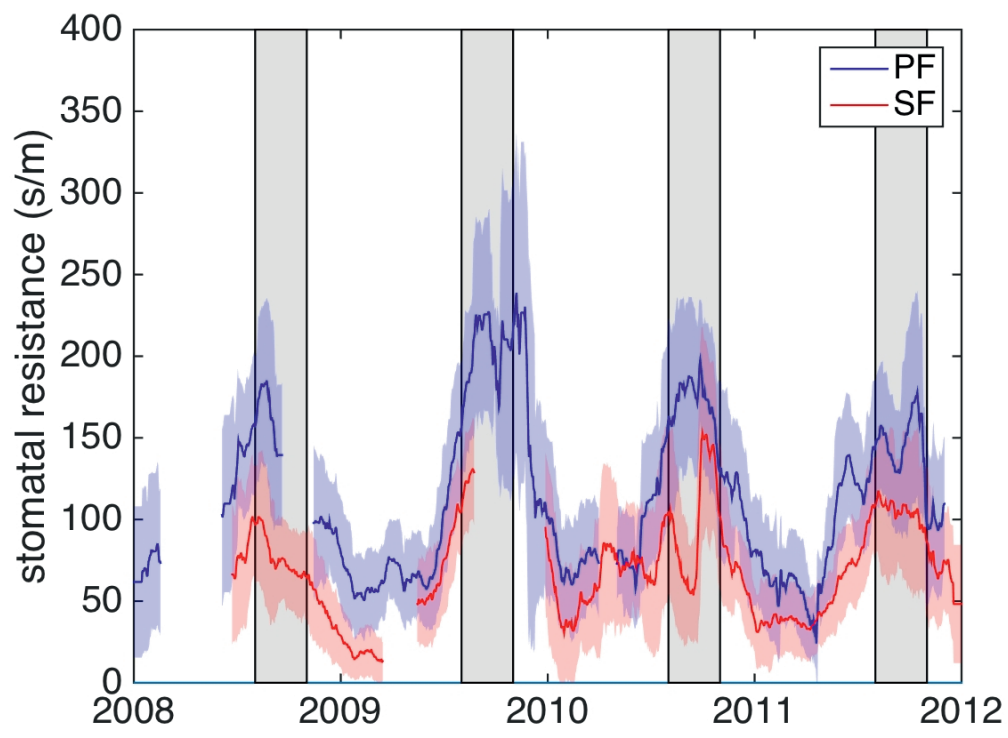

Figure 4.4 Time series of 31 day centered running means of stomatal resistance for primary forest $(\mathrm{PF})$ in the blue line and secondary forest (SF) in the red line and respective standard deviations (shadow area in the same color of the mean values) for both sites.

Table 4.3: Aerodynamic resistance $\left(r_{a}\right)$ and stomatal resistance $\left(r_{s}\right)$ means annually and in the wet and dry seasons and the ratio between secondary forest (SF) and primary forest (PF).

\begin{tabular}{ccccccc}
\hline Site & \multicolumn{3}{c}{$r_{a}$} & & \multicolumn{3}{c}{$r_{s}$} \\
& & $(\mathrm{~s} / \mathrm{m})$ & & & $(\mathrm{s} / \mathrm{m})$ & \\
\hline $2008-2011$ & Annual & Wet & Dry & Annual & Wet & Dry \\
PF (K34) & 35.51 & 33.71 & 37.28 & 112.35 & 81.54 & 175.16 \\
SF (CO) & 38.77 & 38.05 & 38.93 & 67.99 & 48.01 & 97.38 \\
SF/PF & 1.09 & 1.13 & 1.04 & 0.61 & 0.59 & 0.56 \\
\hline
\end{tabular}

Despite the higher ET in the SF than in the PF, during the whole period, the $W U E$ was slightly higher in the PF than in the SF (Figure 4.5 and Table 4.4). 


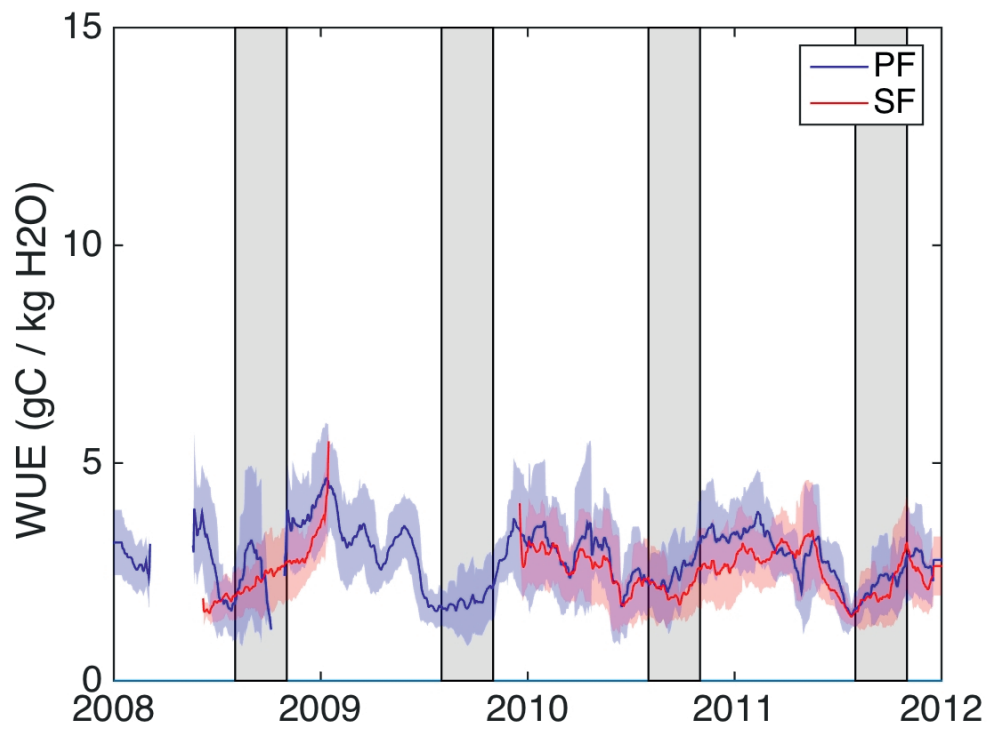

Figure 4.5 Time series of 31 day centered running means of water use efficiency for primary forest $(\mathrm{PF})$ in the blue line and secondary forest (SF) in the red line and respective standard deviations (shadow area in the same color of the mean values) for both sites.

As previously mentioned ET was approximately $20 \%$ higher in the SF than in the PF and increased by approximately $15 \%$ at both sites from the wet to dry season. The GPP was slightly higher in the SF than in the PF in terms of the annual average and in the wet season ( $\sim 5 \%$ higher), but during the dry season the GPP was same at both sites. Analyzing the seasonal variation in the sites, the GPP diminished $13 \%$ in the PF, while it decreased $18 \%$ in the SF from the wet to dry season (Table 4.4). As shown in Table 4.4, the average GPP and $W U E$ were based only on data from 2010 and 2011 because the method used to estimate GPP from the light-response curves did not estimate the sensitivity to night time temperature variations for 2008 and 2009, and we preferred not to include the data from this period that had relatively high uncertainty (Lasslop et al., 2010).

The $W U E$ was calculated as the ratio of GPP to ET. The $W U E$ was approximately $10 \%$ higher in the PF than in the SF during the whole period and the wet season, while during the dry season, the carbon gain in mm of water used was higher in the PF $(\sim 15 \%)$ than in the SF (Table 4.4). Considering the seasonal differences, the $W U E$ was higher in the wet season than in the dry season at both sites. In addition, the decrease was slightly larger in the SF than in the PF. 
Table 4.4: Evapotranspiration, gross primary productivity and water use efficiency means annually and in the wet and dry seasons and the ratio between secondary (SF) and primary (PF) forests

\begin{tabular}{cccccc}
\hline Variable & Site & Annual & Wet & Dry & $\begin{array}{r}\text { Wet to Dry } \\
\text { change (\%) }\end{array}$ \\
\hline ET & PF (K34) & 3.1 & 2.9 & 3.4 & 15.3 \\
$($ mm.day-1) & SF (CO) & 3.6 & 3.4 & 4.0 & 15.1 \\
& SF/PF & 1.19 & 1.19 & 1.18 & \\
\hline GPP & PF (K34) & 8.0 & 8.6 & 7.6 & -12.7 \\
$(\mathrm{gC} . \mathrm{m}-2$. day-1) & $\mathrm{SF}(\mathrm{CO})$ & 8.3 & 9.0 & 7.6 & -18.3 \\
& $\mathrm{SF} / \mathrm{PF}$ & 1.04 & 1.05 & 1.00 & \\
\hline WUE & $\mathrm{PF}(\mathrm{K} 34)$ & 2.4 & 2.8 & 2.1 & -29.7 \\
$(\mathrm{gC} . \mathrm{m}-2 . \mathrm{mm}-1)$ & $\mathrm{SF}(\mathrm{CO})$ & 2.2 & 2.5 & 1.8 & -36.2 \\
& $\mathrm{SF} / \mathrm{PF}$ & 0.90 & 0.90 & 0.86 & \\
\hline
\end{tabular}

* GPP and WUE are averages of the values in 2010 and 2011 to avoid the uncertainties in the light-response curve method.

\subsection{Discussion}

The difference in available energy did not account for the differences in ET between the sites because available energy had a maximum daily average of $7.8 \mathrm{~W} . \mathrm{m}^{-2}$, which was within the accuracy range of the net radiometer and corresponded to only $0.28 \mathrm{~mm}$.day ${ }^{-1}$. This result indicated that the difference in $E T$ was one-third lower between sites in the time periods analyzed.

The values of albedo in both sites were similar and consistent with those presented in the works of Culf et al. (1995) and Giambelluca et al. (1997) for forest sites. Due to the similarity between the albedo values at both sites, the higher evaporative fraction in the SF than in the PF was not explained by albedo. The only difference between the albedo at the two sites was the peak in the albedo annual cycle in the PF at the beginning of the dry season, which was earlier than that in the SF. In the latter, the highest annual values of albedo occurred during the transition of the dry to the wet season. The peak of the albedo in the PF was related to the early flushing of the leaves at this 
site as an evolutionary strategy to increase photosynthetic efficiency since light increases as a result of the decrease in cloud cover during the dry season (Lopes et al., 2016). Nonetheless, the region does not present a strong seasonality and provides enough water in the soil that can be accessed by the deep roots of the old trees to take advantage of both light and water supply (Broedel et al., 2017). The data suggest that pioneer species do not account for the same evolutionary strategy.

The PF roughness was greater than that in the SF as a result of tree height differences between the sites. The greater roughness in the PF implied a lower aerodynamic resistance that in principle would enhance evaporation compared to that in the SF. However, site scale latent heat flux measurements show that SF species use water and energy resources without parsimony, transpiring more water than PF species during the wet and dry seasons and the whole period. This result was corroborated by sap flow measurements that show that trees of secondary species transpire more than primary species (Kunert et al., 2015). As expected, related to the high ET in the $\mathrm{SF}$, the GPP at the site was also higher than that in the PF but at a lower percentage and only during the whole year and wet season. During the dry season, the GPP was the same at both sites. Consequently, the WUE was lower in the SF than in the PF, which could indicate that old forest species better adapted to the climate conditions, and use water and assimilate carbon more efficiently than the pioneer species of the SF.

In general, forest edges situated downwind of a lower vegetation or bare soil are expected to show higher ET rates than those in other areas, due to energy advection and enhanced turbulence (Giambelluca et al., 2003). Sap flow data from previous studies (Kunert et al. (2015) indicated decreases from forest edges, that had more pioneer tree species, towards the interior (Kunert et al., 2015). Nevertheless, the sap flow in the SF increased in the opposite direction, with sap flow higher close to the tower inside the fragment and lower in the direction of the road adjacent to a small pasture plot that was frequently burned. Since burnings affect the heterogeneity of the SF fragment in relation to the distance from the edges, it was difficult to relate the ET solely to the edge effect (Van Baalen, 2010).

The lower WUE in the SF than in the PF could also be related to the difference in soil nutrients between the two sites. The amount of nutrients, such as nitrogen and phosphorus, in SFs declines with forest age (Feldpausch et al., 2004). In forests 12 to 14 years old in the same region of this study, nitrogen and phosphorus reached approximately $15 \mathrm{~g} . \mathrm{kg}^{-1}$ and $0.6 \mathrm{~g} . \mathrm{kg}^{-1}$, respectively, while in the PF, those values reached 22 g. kg ${ }^{-1}$ and 1 g. $\mathrm{kg}^{-1}$ (Feldpausch et al., 2004; Fyllas et al., 2009). If nutrients continue decreasing with forest age, then this amount will decrease even more, 
and accordingly, the secondary species would need to assimilate $\mathrm{CO}_{2}$ more efficiently to obtain the same amount of carbon. For this purpose, these species would need to leave their stomata open wider to obtain more $\mathrm{CO}_{2}$, losing more water.

Placing the estimates obtained at the SF site in context with findings from recent literature, we can perform a thought experiment to extrapolate a potential role of secondary forests in Amazonia reabsorbing part of carbon emitted by deforestation. Assuming a carbon use efficiency (the ratio of Net Primary Productivity, NPP, to GPP) of $\sim 0.3-0.5$ (e.g. Malhi et al., 2009), our estimates of GPP would point to a potential NPP of 0.9 to 2 tonC/ha/year, which would in turn represent a total of 0.16 to $0.27 \mathrm{GtC}$ taken up per year by NPP of the $173387 \mathrm{~km} 2$ of secondary forests in Brazilian Amazon (area estimated by TerraClass system, INPE 2016). However, we should acknowledge that the estimates of GPP obtained from flux partitioning methods, such as used in this study, are subject to inherent uncertainties and should be taken with caution.

\subsection{Conclusions}

SF ET was approximately $20 \%$ higher than PF ET both seasonally and in daily averages. Higher ET was not related to significant differences in available energy or albedo, resulting in the evaporative fraction always being higher in the SF (0.85) than in the PF (0.75). Albedo differed between sites only at the onset of the wet season, and albedo was higher earlier in the PF than in the $\mathrm{SF}$, due to an earlier leaf flush in the PF as an evolutionary strategy to increase photosynthetic efficiency, as concluded in recent studies. In terms of seasonal variations, even though the ET increased during the dry season, the evaporative fraction decreased slightly at both sites.

Aerodynamic resistance was slightly higher in the SF than in the PF due to the higher roughness of the latter, which promoted higher aerodynamic conductance. Nonetheless, the stomatal resistance was considerably lower in the SF than in the PF, approximately $40 \%$ lower at both seasonal and daily scales. Throughout the seasons, aerodynamic resistance was nearly constant, but the average values of stomatal resistance changed by approximately $50 \%$ at both sites.

$G P P$ was also higher in the SF than in the PF during the wet season but at a lower percentage than the ET difference (only $\sim 5 \%$ ). During the dry season, GPP was the same at both sites. GPP decreased from the wet to dry season at both sites but was more pronounced in the SF (18\%) than in the PF (13\%). In contrast, WUE was lower in the SF than in the PF during the wet 
season $(10 \%)$ and even lower during the dry season (15\%), showing that PF was better adapted to drought conditions.

These results highlight the importance of secondary regrowth to the Amazon regional water balance, with the potential to compensate for reductions in ET in deforested and unproductive areas. Additionally, the results highlights its importance on the carbon balance since the SF can potentially assimilate more carbon than the $\mathrm{PF}$, reinforcing the potential of tree restoration to serve as an efficient and low-cost strategy for mitigating climate change.

It is important to mention that secondary forest plays an important role on the maintenance of moisture production and transport to other regions of South America and on sequestration of carbon emitted by deforestation. Nonetheless, primary forest cannot be replaced by secondary forest because the latter presents lower efficiency on using water to assimilate carbon (potentially impacting other water uses such as hydroelectricity) than the primary forest; much lower biodiversity, as well as poorer ecosystem services. Therefore, secondary forest can be considered an ally of primary forest to minimize the effects of deforestation, but never a substitute. 


\title{
Chapter 5
}

\section{Response of the river discharge in the Tocantins River Basin, Brazil, to environmental changes and the associated effects on the energy potential ${ }^{4}$}

\begin{abstract}
Climate change is expected to impact the hydrological regime worldwide, and land use and land cover change may alter the effects of the former in some cases. Secondary growth in deforested and abandoned areas is one of the main consequences of land use and cover changes in Amazonia. Among land uses, the effects of the secondary growth in water availability in large scale basins are not well understood. This work analyzes the potential effects of secondary growth under climate and land use change on water availability and hydropower in the Tocantins basin, in the Legal Amazon region of Brazil, using the MHD-INPE hydrological model driven by different climate scenarios and two future socio-economic based potential land use scenarios. The model projects decrease on discharge under climate change scenarios, which further cause the simulated hydropower energy potential to decrease significantly. When only deforestation scenarios are included, the effects of climate change are weakened, but when secondary growth is also considered, the effects of climate change are enhanced. Results suggest that different aspects of environmental change, such as secondary growth, may affect water production and the sectors depending on it.
\end{abstract}

\footnotetext{
${ }^{4}$ This chapter is published as: Von Randow, R. C. S., Rodriguez, D. A., Tomasella, J., Aguiar, A. P. D., Kruijt, B., \& Kabat, P. (2019). Response of the river discharge in the Tocantins River Basin, Brazil, to environmental changes and the associated effects on the energy potential. Regional Environmental Change, 19(1), 193-204. https://doi.org/10.1007/s10113-018-1396-5
} 


\subsection{Introduction}

In order to satisfy future country's energy needs, hydroelectric expansion plans in Brazil are concentrated in Amazonia, where projections of precipitation based on different models largely vary under climate change scenarios (Christensen et al., 2013). Therefore, it becomes crucial to assess how changing climate is likely to affect the energy security of the country.

In addition to the effects of climate change, the Amazon basin has been affected by the conversion of pristine forest to other types of land use since the 1970's due to agricultural expansion and resource extraction (Davidson et al. 2012; Walker et al. 2000). Singular policies for the region have been developed by the government (Brazilian Growth Acceleration Program BRASIL, 2013). These policies include the establishment of several protection areas and indigenous territories (Folhes et al., 2015). However, a substantial amount of deforestation occurs each year in the region (PRODES, INPE, http://www.obt.inpe.br/prodes/). The conversion of forest to pasture and crops promotes a decrease in evapotranspiration (Lathuillière et al., 2012) and soil water recharge and increases fast fluxes responses in the basin (Bruijnzeel, 1991). Conversely, secondary forest growth in previously deforested and later abandoned areas has higher evaporative fractions (Giambelluca, 2002) and higher evapotranspiration rates (Von Randow et al., 2017) than pristine forest areas. Thus, these areas can reduce the excess soil water and runoff.

The hydrological impacts due to climate change (CC) combined with land use and land cover change (LULCC) affect the availability of water resources and have important consequences for environmental and socioeconomic activities. Therefore, these effects should be carefully studied to improve water management and planning, even when considering that their impacts on water cycle are strongly dependent on scale and heterogeneity of landscape (D’Almeida et al., 2007).

To assess the effects of CC and LULCC on water resources, both climate and hydrological numerical models are frequently used (Bravo et al., 2014; Cloke et al., 2013; Demaria et al., 2013; Nóbrega et al., 2011; Siqueira Jr et al., 2015). This approach entails substantial uncertainty associated with the propagation of errors in the model chain (Jones, 2000). Still, climate and hydrological projections provide important information for performing exploratory analyses of risk and uncertainties associated with decision-making processes related to $\mathrm{CC}$ adaptation (Mohor et al., 2015). 
LULCC projections generally consider various public policies, biophysical properties and socioeconomic assumptions (Prestele et al. 2016). In the context of the high level of uncertainty regarding future scenarios, scenario-based techniques can be used to explore and understand the consequences of alternative conditions in environmental studies. Aguiar et al. (2016) proposed three updated scenarios for the Brazilian Amazon through 2100. These scenarios combined exploratory and normative approaches, participatory methods, and qualitative and quantitative elements (Raskin et al., 2005).

Due to its abundant water resources, Brazil has become highly dependent on water availability for several economic activities, such as hydropower generation and agriculture (Nóbrega et al., 2011). Brazil currently gets three-quarters of its electricity from hydroelectricity (Horner et al., 2016). In this context, an increased need for energy to sustain economic growth has boosted governmental plans to expand hydropower in Amazonia. The new plants will increase the contribution of the Amazon region to Brazilian power generation from 10\% to 24\% (EPE - Empresa de Pesquisa Energética, 2012).

Located in the eastern divide of the Amazon Basin and on the transition between the Amazon forest and the Brazilian savanna (cerrado), the Tocantins River is considered one of the most important rivers for water supply, irrigation, transportation and hydropower in the country. In terms of hydropower, the Tocantins Basin is the hub between the North/Northeast and South/Southeast power grids. Thus, the basin is a strategic point in Brazil (EPE - Empresa de Pesquisa Energética, 2006). Previous studies have shown impacts of climate variability and land use conversion on the basin: Costa et al. (2003) analyzed 50-years of data and found $25 \%$ of increase on the discharge, but no statistically significant trend in the precipitation. Coe et al. (2009), modelled the same data set and attributed 2/3 of the increase in discharge to deforestation that occurred in that period. However, those studies did not consider the impact of secondary vegetation regrowth on the water cycle.

The objective of this work is to analyze the combined effects of CC and LULCC in water yield and evaluate the extent to which these effects could influence future energy production in the Tocantins Basin. In addition, we analyzed the effects of the growth of secondary forests on water and energy production, because secondary forest vegetation is generally not included on LULCC maps; its associated effects, in combination with climate and hydrological effects, are largely unknown. 


\subsection{Materials and Methods}

\subsubsection{Study Site}

The Tocantins River Basin is the largest basin completely located within the Brazilian territory. The drainage area of the basin is more than $960000 \mathrm{~km}^{2}$, or $11 \%$ of the Brazilian territory (ANTAQ - Agência Nacional de Transportes Aquaviários, 2013). The main rivers in the basin are Tocantins River and Araguaia River. The altitude of the Tocantins River Basin before it reaches the Araguaia River varies from 200-500 $\mathrm{m}$ in the majority of the area and is higher than $1000 \mathrm{~m}$ in the upstream portion of the basin. The average precipitation in the basin is $1869 \mathrm{~mm}$ per year, with a maximum of $2.565 \mathrm{~mm}$ on the Pará state coast. The precipitation regime occurs from south to north. Low amounts of precipitation are received along the border with Goiás and in the Northeast region, with an average of $1 \mathrm{~mm} /$ month between June and August (Tomasella et al., 2009). The precipitation decreases from $1850 \mathrm{~mm}$ in the west to $1000 \mathrm{~mm} / \mathrm{year}$ in the east (MMA, 2006). Additionally, evapotranspiration averages approximately $1.371 \mathrm{~mm} /$ year, and the long-term mean discharge is approximately $14000 \mathrm{~m}^{3} / \mathrm{s}$ (MMA, 2006). The main soils in the region are classified as Latossolos Vermelho-Amarelos and Vermelhos, with textures that range from average to clay. Although the land use has become more intense over the last two centuries, the Tocantins Basin still maintains some of the original phytophysiognomies. In the northern part of the basin, the original cover is tropical rain forest, and in the central and southern parts of the basin, known as Alto Tocantins, the original cover is mainly Brazilian savanna (cerrado) (Tomasella et al. 2009). However, this original cover is being replaced by other land use and land cover types. In Alto Tocantins, the cerrado that covered approximately $63 \%$ of the region in 1984 decreased to $47.9 \%$ in 2013 due to increases in anthropogenic cover (49.8\%) and open water (2.3\%) (Martins et al., 2015). The Tocantins-Araguaia region is one of the most important Brazilian hydrographic regions because of its location and hydropower potential which totals 26.285 MW. Additionally, the installed hydropower potential of the region is $6981 \mathrm{MW}$. 


\subsubsection{Distributed Hydrological Model - MHD-INPE}

The Distributed Hydrological Model of the National Institute for Space Research (MHDINPE) (Rodriguez and Tomasella, 2016) is a regular grid-cell model that includes modules to solve the soil water budget, potential evaporation, transpiration, surface, sub-surface and baseflows in each grid cell where several types of soil and land use are considered. Each grid cell is sub-divided into hydrological response units (HRUs), which are used to solve the water balance. The model uses the percentage of each type of land use and soil to determine the fluxes of a grid cell based on a weighted arithmetic mean. Further details about the MHD-INPE model are provided by Siqueira Jr et al. (2015) and (Rodriguez and Tomasella, 2016).

The model has been applied successfully in Amazonian basins such as the Ji-Paraná (Rodriguez and Tomasella 2016), Madeira (Siqueira Jr et al., 2015), Purus (Dalagnol et al., 2017) and Tapajos (Mohor et al. 2015) basins, as well as for flood forecasting in the Tocantins Basin (Falck et al., 2015).

\subsubsection{Hydrological Model Calibration and Validation}

The Tocantins Basin was divided into nine sub-basins (Figure 5.1). The MHD-INPE model was calibrated for each sub-basin using observed discharge data from 1970 to 1990 and the shuffled complex evolution method of automatic calibration developed at the University of Arizona (SCEUA) by Duan et al. (1992) and Duan et al. (1994). Observed meteorological data were used as input drivers for the model. Vegetation parameters were based on literature values for most vegetation types, of the same than those used by Rodriguez and Tomasella (2016). For the secondary forest parameters, we changed albedo and stomatal resistance based on flux tower data measured in a 21year old secondary forest in Central Amazonia. Those parameters affect directly the evapotranspiration rates in the model. We also changed the vegetation height, zero displacement height and roughness length, based on the vegetation characteristics of the site (Von Randow et al. 2017). Additionally, the calibration performance of MHD-INPE was qualitatively and quantitatively evaluated. The qualitative evaluation was based on a visual analysis of the hydrographs of observed data and simulated estimates of flow. In addition, for the quantitative evaluation, three different 
performance indices were used: the Nash-Sutcliffe efficiency (NSE), Nash-Sutcliffe efficiency of the logarithmic values of discharge (NSELog) and relative volume error $(\Delta \mathrm{V})$ (Krause et al., 2005; Moriasi et al., 2007). Thus, the objective function was based on the average of NSE and NSELog efficiency coefficients and the convergence criteria was defined based on the minimal percentage of improvement in the objective function, which was fixed in 0.001 .
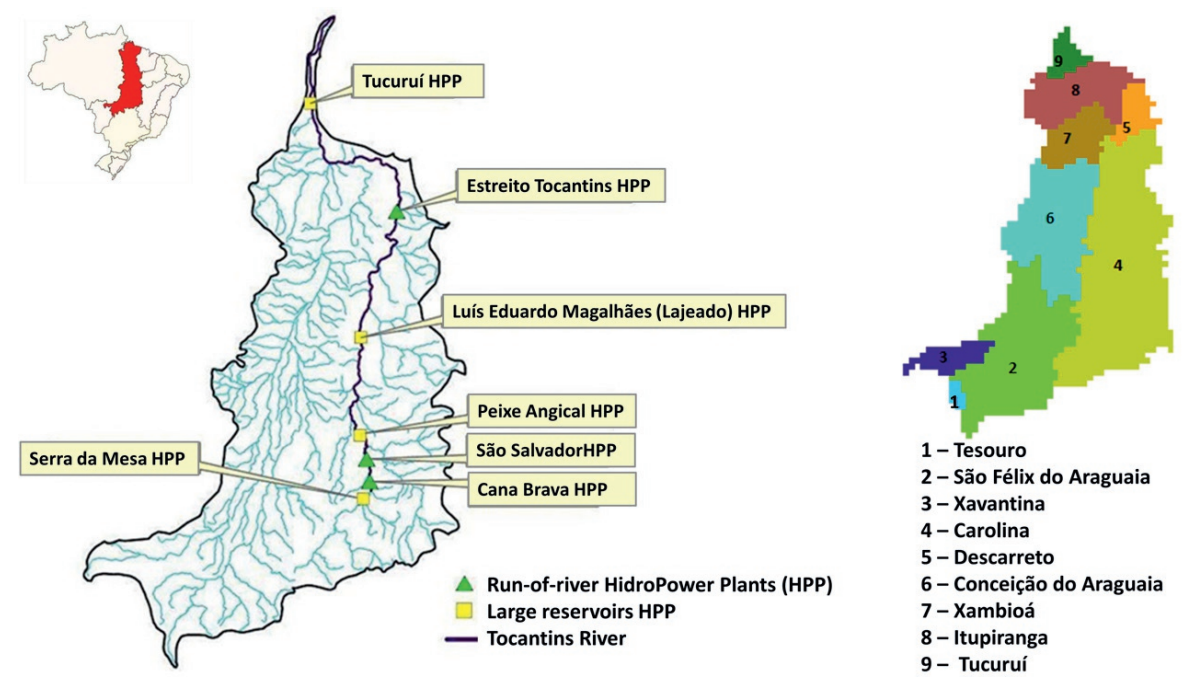

Figure 5.1 Tocantins River Basin, the hydropower plant locations (left) and the sub-basins considered for calibration of the MHD model (right)

For validation purposes, the ability of the model to simulate the present climate conditions was assessed using two different runs: (i) hydrological simulations based on observed meteorological data and (ii) hydrological simulations based on meteorological conditions provided by a regional climate model. The latter validation is important for the assessment of uncertainties in analyses of future hydrological projections resulting from bias in the climate model. Both runs were evaluated using four different indices derived from flow duration curves (FDCs) (Ley et al., 2011; Yilmaz et al., 2008): a measure of the high flow volume, $\mathrm{MWH}$, which represents the high part of an FDC; a measure of the low flow volume, MWL, which represents the low part of an FDC; SEASON, an index that represents the difference between dry and wet seasons; and QSM, the slope between the 0.2 and 0.8 quantiles of an FDC. 


\subsubsection{Input Data}

To drive the hydrological model, different input data are needed to represent current or future environmental conditions. Current vegetation cover was obtained from the Radar da Amazonia Project of the Instituto Brasileiro de Geografia e Estatística (IBGE, 1992) and the Projeto de Elaboração de Mapas de Vegetação (PROVEG - Sestini et al., 2002). Notably, these sources provided a vegetation map of 15 vegetation classes that was previously used in the SiB land surface model (Sellers et al., 1986). Yearly information regarding LULCC was obtained from the historical reconstruction of (Leite et al., 2011) based on historical census data and contemporary land use classification and considering cultivated areas, natural areas, and planted pastures in Amazonia. The soil type distribution was extracted from the SOTERLAC/ISRIC soil map (Dijkshoorn et al., 2005), and meteorological and hydrological data were assembled from ANA, INMET and INPE. Geomorphologic information was derived from the Shuttle Radar Topography Mission (SRTM) (Farr et al., 2007).

In the analyses of the effects of $\mathrm{CC}$, dynamically downscaled data from the regional atmospheric model Eta-INPE (Chou et al. 2012, Marengo et al. 2012) were used as meteorological drivers in MHD-INPE. Eta downscaling uses a range of members of a perturbed physical ensemble of the HadC-M3 model as boundary conditions (Collins et al., 2001; Gordon et al., 2000), with different sensitivities based on the emission scenario SRES A1B (Nakicenovic et al., 2000). This approach is used because it accounts for the uncertainties of different possible outcomes of climate projections, from low to high emissions (Chou et al., 2012; Collins et al., 2006). In this work, the set of HadCM3 boundary conditions passed to Eta-INPE, described by Chou et al (2012) and Marengo et al. (2012), are the unperturbed member (hereafter referred to as M1), the low-sensitivity member (referred to as M2) and the high-sensitivity member (referred to as M4).

The use of meteorological data from climate models in hydrological applications has spatial and temporal resolution constraints, and biases in the distributions of variables should be addressed before they are used as drivers in the hydrological models (Wood et al., 2004; Wood et al., 2002). Similar to Mohor et al. (2015), we corrected biases in the precipitation data using a percentile-topercentile approach based on Bárdossy and Pegram (2011), and linear scaling (Lenderink et al., 2007; Teutschbein and Seibert, 2013) was applied to correct the other meteorological data. 
The future LULCC scenarios used in this study are the results of a combination of the LUCC-ME Modeling Framework and INPE-EM Emission Modeling Framework, as described in Aguiar et al. (2016). The LUCC-ME modeling framework was used to generate annual rainforest deforestation maps through 2050, and the INPE-EM modeling framework (Aguiar et al., 2012) was used to generate the subsequent secondary vegetation dynamics in deforested areas based on a spatially explicit grid of $25 \times 25 \mathrm{~km}^{2}$. Because information about savanna deforestation was not available, LUCC-ME projections were restricted to the Amazon Forest and, consequently, changes in savanna vegetation were not considered in this work.

The Land Use maps combine qualitative and quantitative elements using the Story and Simulation (SAS) approach proposed by (Alcamo 2001). The qualitative scenarios were built using a participatory approach (Folhes et al. 2015; Aguiar et al. 2016), and the resulting storylines were aligned with the Intergovernmental Panel on Climate Change (IPCC) Shared Socioeconomic Pathways (SSP). Storylines were constructed considering two main scenarios. The first, sustainability scenario A, was an ideal/desired scenario with equilibrium between socioeconomic achievements and the environment. This scenario was aligned with SSP 1. The second, fragmentation scenario $\mathrm{C}$, was the opposite of scenario A and considered the depletion of natural resources and significant social inequality. This scenario was aligned with SSP 3.

In quantitative scenarios, the main goals are to choose elements from storylines to use in quantitative models and to define the adequate model parameters. The elements selected from the storylines were related to natural resources and land use dynamics. In the model of scenario A, the elements are as follows: a decrease in old-growth forest degradation; clear-cut deforestation reaching 'zero (non-authorized) deforestation' by 2025; the regeneration of all illegally deforested areas on private properties; and high-value secondary vegetation. The final element will allow areas to become secondary forests by not disrupting regrowth in these areas. The quantification of scenario C considers deforestation rates at levels prior to those in 2004 in response less environmental protection due to agricultural expansion. 


\subsubsection{Analysis of the Impacts on Hydrology and on Hydroelectricity}

Changes in the discharge response as a result of different CC and LULCC scenarios were assessed through the comparison between projected long-term average (LTA) discharge and LTA discharge simulated for the historical period.

The Brazilian interconnect generation system includes more than a 100 hydropower plants, in addition to solar and wind mills. Operational rules are defined to provide synergy of the system considering constrains such as power transmission lines, ecological and navigation requirements, hydrological seasonal regimes, cascade optimization, market regulations and power plant profitability (Corrêa da Silva et al., 2016). It is clear that, under climate change scenarios, those operational rules are likely to change drastically in response to climate and market future conditions. Because of the large source of uncertainties, and considering this study is restricted to the Tocantins Basin only, the operational rule adopted in this study maximize the generation of each reservoir regardless the rest of the cascade system. Although this simplification do not reflect the future operational conditions, it allows comparisons between current and potential future scenarios on an equal basis in each dam.

The impact on energy production was accessed separately on large reservoirs and run-ofriver (ROR) hydropower plants (HPP) because of the different management rules. While large hydropower plants have seasonal and multi-annual management rules and continuous energy production, ROR have limited management capacity (usually between days and weeks) and long non-production period during dry season. For large reservoirs, we calculated the potential energy generation as recommended by Paish (2002) using equation 1

$$
E p[M W m]=0.0088 \times H m \times Q m
$$

where Ep is the average energy potential [MW]; Hm is the average net head [m], which is assumed constant in all scenarios; and Qm is the mean net flow $\left[\mathrm{m}^{3} \mathrm{~s}^{-1}\right]$. The coefficient 0.0088 results from the product of the specific weight of water $\left(1000 \mathrm{~kg} \mathrm{~m} \mathrm{~m}^{-3}\right)$, the efficiency factors of the turbine (0.93) and generators $(0.97)$, the force of gravity $\left(9.81 \mathrm{~m} \mathrm{~s}^{-2}\right)$ and the coefficient $1.10^{-6}$, which is used to the average energy to units of MW. 
The effects of CC and LULCC on the potential energy generation of large reservoirs were studied at four HPP: Serra da Mesa HPP, which has been operational since 1998 and has an energy capacity of 1275 MW (MMA, 2006) and a net head of 129 m (FURNAS Centrais Elétricas SA, 1996 apud Oliveira Mesquita, 2006); Peixe Angical HPP, which has been operational since 2006 and has an energy capacity of $452 \mathrm{MW}$ and a net head of $26 \mathrm{~m}$ (Martins-Filho et al., 2009); Luiz Eduardo Magalhães-Lajeado HPP, which has been operational since 2001 and has an energy capacity of 903 MW (MMA, 2006) and a net head of 29 m (Hahner, 2009); and Tucuruí, which has been operational since 1984 and has an energy capacity of 8370 MW and a net head of $60.8 \mathrm{~m}$ (Cidade Tucuruí, 2016).

For ROR HPPs, we used the method proposed by Vogel and Fennessey (1995) to assess the impacts of CC and LULCC on the hydrological regime. The method analyzes the viability of an ROR HPP through the use of power duration curves (PDCs) derived from annual FDCs. First, we sorted the values of daily discharge in each simulation year, which resulted in an FDC for each year. Second, for each day of a year, we calculated the median of all years, which led to one FDC for a typical (hypothetical) year. Third, we calculated the energy production associated with each discharge to obtain a PDC for a typical (hypothetical) year. Fourth, the area under the PDC was integrated to determine the typical annual energy production (Vogel and Fennessey, 1994).

We analyzed the viability of three ROR HPPs under different scenarios. The first is Cana Brava, which has been operational since 2002 and is permitted thorough 2033. It is an ROR HPP with an installed capacity of $450 \mathrm{MW}$, a head fall of 43.1 meters, a minimum flow discharge (MFD) of $150 \mathrm{~m}^{3} \mathrm{~s}^{-1}$ (ANA - Agencia Nacional de Aguas, 2006) and a reservoir with a $139 \mathrm{~km}^{2}$ surface area. Cana Brava is located in sub-basin "Carolina" (4) (ENGIE, 2016; MMA, 2006). The second is São Salvador, which has been operational since 2009 (Tractebel Energia, 2010) and is permitted to operate through 2023. It is an ROR HPP with an installed capacity of $243 \mathrm{MW}$, a head fall of 22.84 meters, an MFD of $102 \mathrm{~m}^{3} \mathrm{~s}^{-1}$ and a reservoir with a $104 \mathrm{~km}^{2}$ surface area. The São Salvador plant is located in sub-basin "Carolina" (4) (ENGIE, 2016; MMA, 2006). The third is Estreito, which has been operational since 2011. It is an ROR HPP with an installed capacity of $1087 \mathrm{MW}$, a head fall of 18.9 meters, an MFD of $585 \mathrm{~m}^{3} \mathrm{~s}^{-1}$ and a reservoir with a $555 \mathrm{~km}^{2}$ surface area. The Estreito plant is located between the outfall of sub-basin "Carolina" (4) and sub-basin "Descarreto" (5) (ENGIE, 2016; MMA, 2006). Figure 5.1 shows the locations of the ROR HPPs and large reservoir dams in the Tocantins Basin. For energy production purposes, we estimated the operational time of the plant as the time period when the river discharges were above the MFD. 


\subsection{Results and Discussion}

\subsubsection{Hydrological Model Calibration and Validation}

Model calibration and validation show that MHD-INPE performed well in simulating historic stream flow at gauging stations in the Tocantins Basin. The NSE and NSELog indices were considered satisfactory at one of the gauging stations (Tesouro, superior to 0.5 ) and good and very good at the others (varying from 0.66 to 0.94 ) according to the range proposed by (Moriasi et al., 2007). The volumetric errors were lower than $10 \%$ in most of the basin, except in São Félix do Araguaia, where a volumetric error of $13 \%$ was observed. The performance indices of the calibration of MHD-INPE model in the Tocantins Basin are shown in Table 5.1.

For validation purposes, we calculated the regression lines between the indices derived from FDCs of hydrological simulations based on observed meteorological data and of modeled hydrographs based on meteorological conditions provided by a bias-corrected regional climate model, both for historical period. The modeled hydrographs showed good agreement with simulations for the nine sub basins, compared to the 1:1 line. For MWH, SEASON and QSM indices, the slopes were between 1.01 and 1.07. A small deviation is observed for MWL in some sub basins (slope $=0.84$ ), indicating a possible underestimate of base flow. The coefficient of determination was higher than 0.89 for all indices, except for QSM $\left(\mathrm{R}^{2}\right.$ is 0.73$)$. Figure S5.1 details the validation results. 
Table 5.1: Performance index results obtained for the calibration of nine gauging stations in the Tocantins Basin

\begin{tabular}{llcccc}
\hline $\begin{array}{c}\text { Sub- } \\
\text { basin }\end{array}$ & Gauging Station & NSE & NSELog & $\mathbf{R}^{2}$ & $\Delta \mathbf{V}$ \\
\hline 1 & Tesouro & 0.51 & 0.61 & 0.52 & 0.09 \\
2 & São Félix do Araguaia & 0.78 & 0.73 & 0.82 & 0.13 \\
3 & Xavantina & 0.66 & 0.74 & 0.68 & 0.06 \\
4 & Carolina & 0.94 & 0.93 & 0.94 & 0.06 \\
5 & Descarreto & 0.94 & 0.95 & 0.94 & 0.02 \\
6 & Conceição do Araguaia & 0.69 & 0.68 & 0.78 & -0.08 \\
7 & Xambioá & 0.67 & 0.66 & 0.76 & -0.09 \\
8 & Itupiranga & 0.89 & 0.87 & 0.91 & 0.06 \\
9 & Tucuruí & 0.87 & 0.81 & 0.91 & 0.05 \\
\hline
\end{tabular}




\subsubsection{Impacts on Hydrology}

To evaluate the effects of CC on water production, the land cover was held constant based on 2008 conditions, and only the effect of CC was analyzed. Then, LULCC was included in the projection to compare the effects of $\mathrm{CC}$ and the effects of interactions between CC and LULCC (CC+LULCC).

In the Tocantins Basin, the three CC scenarios considerably affected the LTA discharge compared to the historical period (Figure 5.2). For simplicity, the baseline used as a reference corresponds to the average of the simulations in the historical period using all Eta climate scenarios. The highest impact occurred in the M1 scenario with a decrease of approximately $20 \%$ from 20112040 and 32\% decrease from 2041-2070 in precipitation, resulting in corresponding decreased of $39 \%$ and $57 \%$ in discharge. The second highest impact occurred in the M4 scenario, which also exhibited reductions in precipitation of 12\% from 2011-2040 and 24\% from 2041-2070, resulting in corresponding decreases of $30 \%$ and $50 \%$ in discharge. The M2 scenario exhibited precipitation reductions of $11 \%$ from 2011-2040 and 13\% from 2041-2070, resulting in discharge reductions of $26 \%$ and $28 \%$.

To address the combined impacts of CC and LULCC on the water production, Table 5.2 presents the change in discharge resulting from CC and CC + LULCC compared to the baseline. Additionally, Table 5.2 illustrates the importance of considering the presence of regrowth (secondary forest) in the analysis. The decrease in discharge caused by $\mathrm{CC}$ was slightly minimized by deforestation effects. However, considering the presence of secondary forest growth in abandoned pastures reduced the attenuation caused by deforestation on the discharge in scenario $\mathrm{C} 1$ and enhanced the effects of $\mathrm{CC}$ in scenario A by further decreasing the discharge compared to CC only simulations. Scenario $\mathrm{C} 1$ is a less sustainable scenario, in which the deforestation rate increases over time. This increase in deforestation can lead to a discharge increase due to the replacement of forest by pasture (Roberts, 2009). In scenario A, the decrease in deforestation and the abandonment of deforested areas lead to an increase in secondary forests (Figure S5.2). Subsequently, the discharge decreases due to the increased evapotranspiration rate (Giambelluca, 2002; Von Randow et al., 2017), in spite of the low percentage of secondary forest. Table 5.2 shows the results for CC scenario M1, which had a major effect on discharge. Note that the model does not consider the potential effects of soil erosion caused by deforestation, which may diminish the soil 
moisture input, affect soil moisture storage, and consequently influence runoff production (Wang and Shao, 2013).

a)

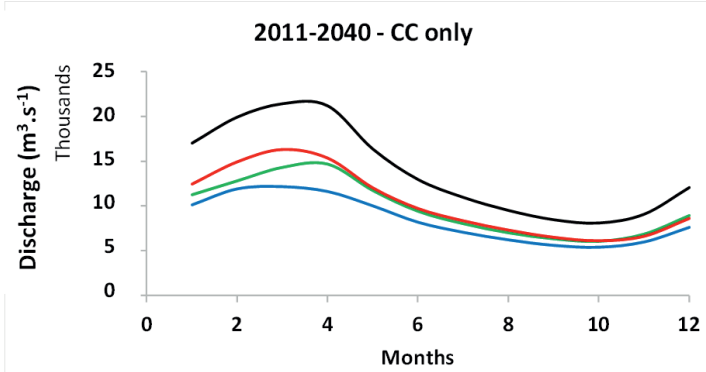

b)

2041-2070 - CC only

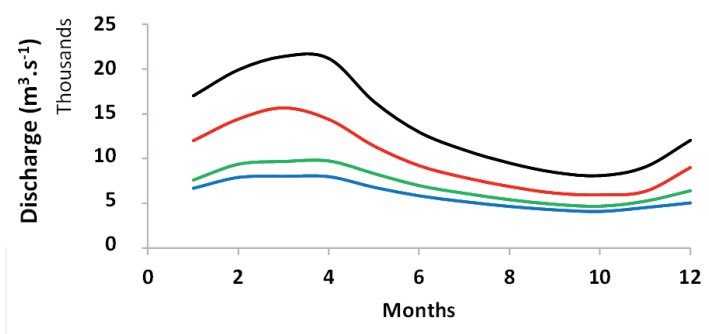

c)

2071-2099 - CC only

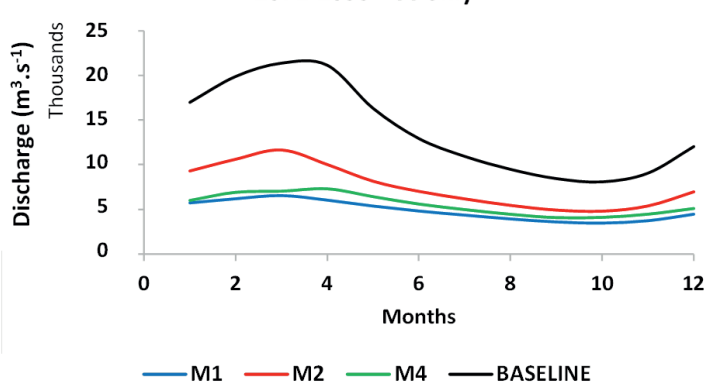

Figure 5.2 Projections of monthly long-term discharge at Tucuruí gauging station (representing the entire Tocantins Basin) for the periods between a) 2011 and 2040, b) 2041 and 2070, and c) 2071 and 2099. The baseline is the average of simulations of MHD in the historical period fed with all Eta climate variants 


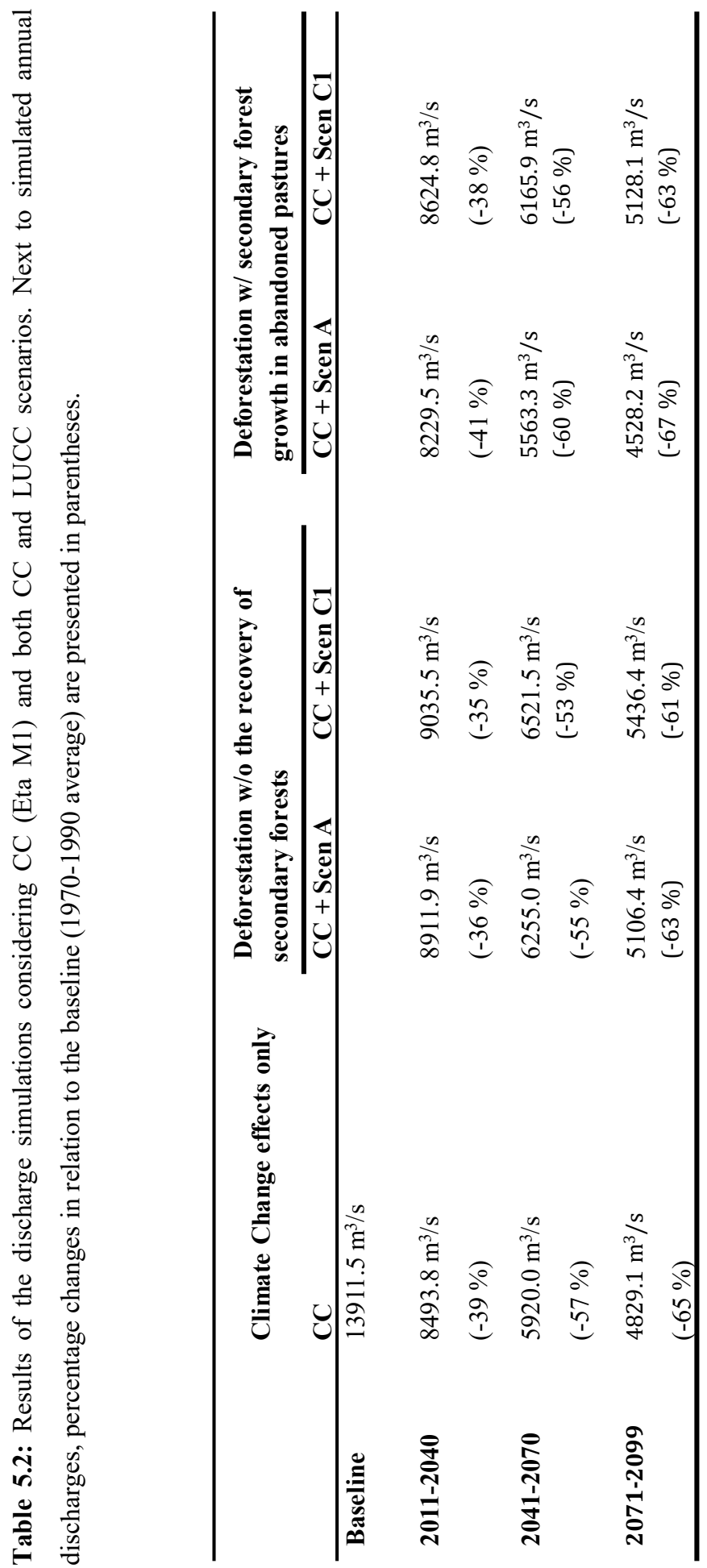




\subsubsection{Impacts on Energy Production}

We analyzed the effects of CC and CC+LULCC on energy production in three sub-basins: Carolina, which contains the majority of the HPPs in the Tocantins Basin, Descarreto and Tucuruí. Carolina and Descarreto did not exhibit a significant difference between the A and C1 LULCC scenarios because most of these areas are covered by savanna (Figure S5.2a and S5.2b), for which deforestation is not considered in the LUCC-ME scenarios. The Tucuruí basin includes areas drained by the Tocantins River where forest cover is expansive and differences exist between LULCC scenarios (Figure S5.2c). Therefore, for simplicity, analyses of the Carolina and Descarreto sub-basins were only performed for scenario $\mathrm{C} 1$, but both scenarios were analyzed in the Tucuruí sub-basin.

\subsubsection{Impacts on the Energy Production of Large Dams}

Changes in potential energy production in the future are assessed using historical simulations as a baseline. The energy potential of all three large hydropower dams decreases (Figure 5.3 and Figure S5.3) because the average reductions in precipitation were similar in all three sub-basins. However, the projected LUCC-ME scenario only induces significant changes to the vegetation cover in the Tucuruí dam basin (Figure S5.2c).

As expected, changes in the potential energy production are similar to the changes on discharge. CC only causes a reduction of $27 \%$ to $38 \%$ in the first time-slice, and $29 \%$ to $56 \%$ in the second time-slice, in comparison with the energy production estimated with baseline discharge. When the C1 LUCC-ME scenario is considered the reduction is slightly lower (reduction of $26 \%$ to $37 \%$ in the first time-slice, and $27 \%$ to $56 \%$ in the second time-slice), mainly because deforestation increases under this scenario, which increases discharge in each basin. Conversely, the decrease in the energy potential becomes more pronounced when scenario A is considered (reduction of $29 \%$ to $40 \%$ in the first time-slice and $32 \%$ to $58 \%$ in the second time-slice). Under this scenario, the deceleration of deforestation increases secondary forest growth (Figure S5.2c.1) and promotes higher evapotranspiration rates (see Table S5.1) and lower water excess and runoff. Thus, the combined effects of CC and LULCC are enhanced. 


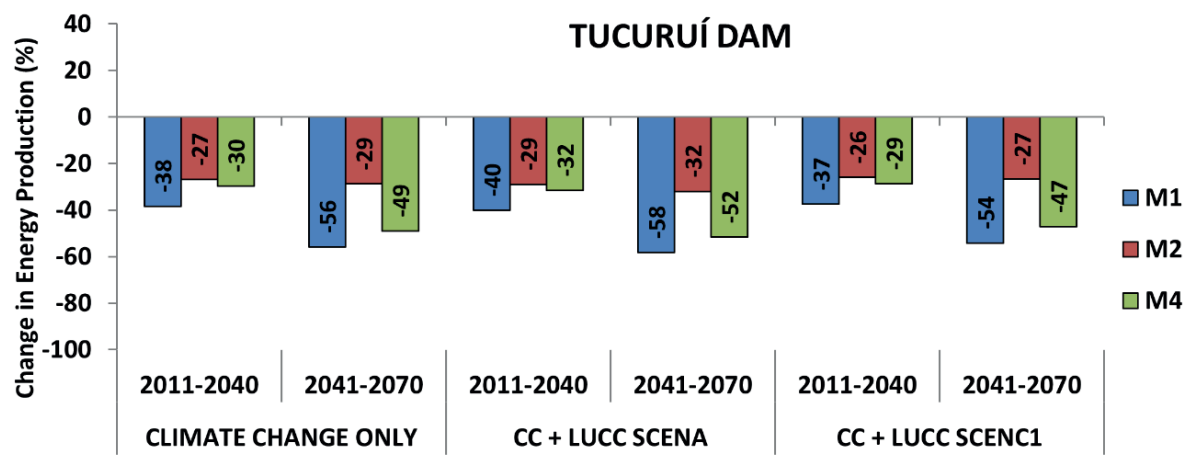

Figure 5.3 Projected impacts on the energy potential at Tucuruí dam caused by climate change only and climate change plus land use change scenarios

The offset of CC due to LULCC can be seen in scenario C1. In this scenario, primary forest cover decreases and pasture land increases, while the areas of secondary forest remain nearly unchanged. When the LULCC scenario $\mathrm{C} 1$ is considered, the energy production decrease is lower than when only $\mathrm{CC}$ is taken into account.

In scenario A, even with only approximately $10 \%$ of secondary vegetation, in addition to the decrease on energy potential caused by $\mathrm{CC}$, evapotranspiration further decreases the energy potential from $2011-2040$ by $2 \%$ and that from $2041-2070$ by $3 \%$.

In scenario $\mathrm{C}$, when deforestation increases over time and the area of secondary forest is small and unchanged, the energy potential increases only 1\% from 2011-2040 and 2\% from 20412070 compared to only considering CC.

In the Carolina and Descarreto sub-basins, the decrease occurs mainly as a result of CC in both the 2011-2040 and 2041-2070 periods (Figure S5.3) because these basins do not undergo significant LULCC (Figures S5.2a and S5.2b). Although the precipitation reduction varied from $10 \%$ to $38 \%$ in the CC scenarios, reductions in the discharges were higher resulting in more severe impacts on the energy potential, which varied from $30 \%$ to $80 \%$ reductions based on the current potential. As expected, the highest impact occurred in the M1 scenario, which was associated with the most significant decrease in precipitation in comparison to that in the historical period. 
Our results are comparable to the findings of other studies in Southern Amazon Basin (Mohor et al., 2015; Siqueira Jr et al., 2015; Stickler et al., 2013), which showed that the increase in deforestation rates may partly counterbalance effects of precipitation reduction. However, and unless previous studies, our analysis showed that secondary forest regrowth in abandoned areas might play an important impact on water availability.

\subsubsection{Energy Production of Run-of-River Dams}

The typical PDCs for hydroelectric generation at the Cana Brava, São Salvador and Estreito HPPs are presented in Figure 5.4, considering the median values from 2041-2070, which is assumed as the HPP lifetime. For comparison, the baseline represents the PDC of the historical period simulations (1970 to 1990) obtained using observed data. We can see that in historical period simulation, although there was a reduction on the energy production during part of the time, the discharge was above the minimum flow of the plant, and the plant remained operational $100 \%$ of the time.

As previously discussed for large dams, in sub-basins 4 and 5, the impact on runoff is due to $\mathrm{CC}$; therefore, only CC is examined in this section. The most critical projection scenario (M1) indicates that Estreito is the plant that is affected the most based on the time of operation. Notably, the plant is non-operational $77 \%$ of the time. The second most affected plant is São Salvador, which is non-operable $65 \%$ of the time from 2041-2070. Additionally, Cana Brava does not operate 59\% of the time in this period (Figure 5.4). In terms of the effect on energy production per year based between 2041 and 2070, the Estreito HPP production is $5.2 \times 10^{5} \mathrm{MWh} /$ year, which is $87 \%$ lower than the hypothetical production of $3.96 \times 10^{6} \mathrm{MWh} /$ year simulated for the historical period for this HPP. Cana Brava exhibited the second highest reduction in production per year of $85 \%$, which represents a decrease of $2.16 \times 10^{6} \mathrm{MWh} /$ year from the hypothetical production in the historical period to $3.2 \times 10^{5} \mathrm{MWh} /$ year. Finally, São Salvador exhibited a production of $2 \times 10^{5} \mathrm{MWh} /$ year, which represents a reduction of $83 \%$ of the hypothetical production of $1.2 \times 10^{6} \mathrm{MWh} / \mathrm{year}$ in the same period. Therefore, we noted that a reduction of $12 \%$ to $38 \%$ in precipitation causes a drastic reduction of up to $90 \%$ in the operating time of the HPPs. 

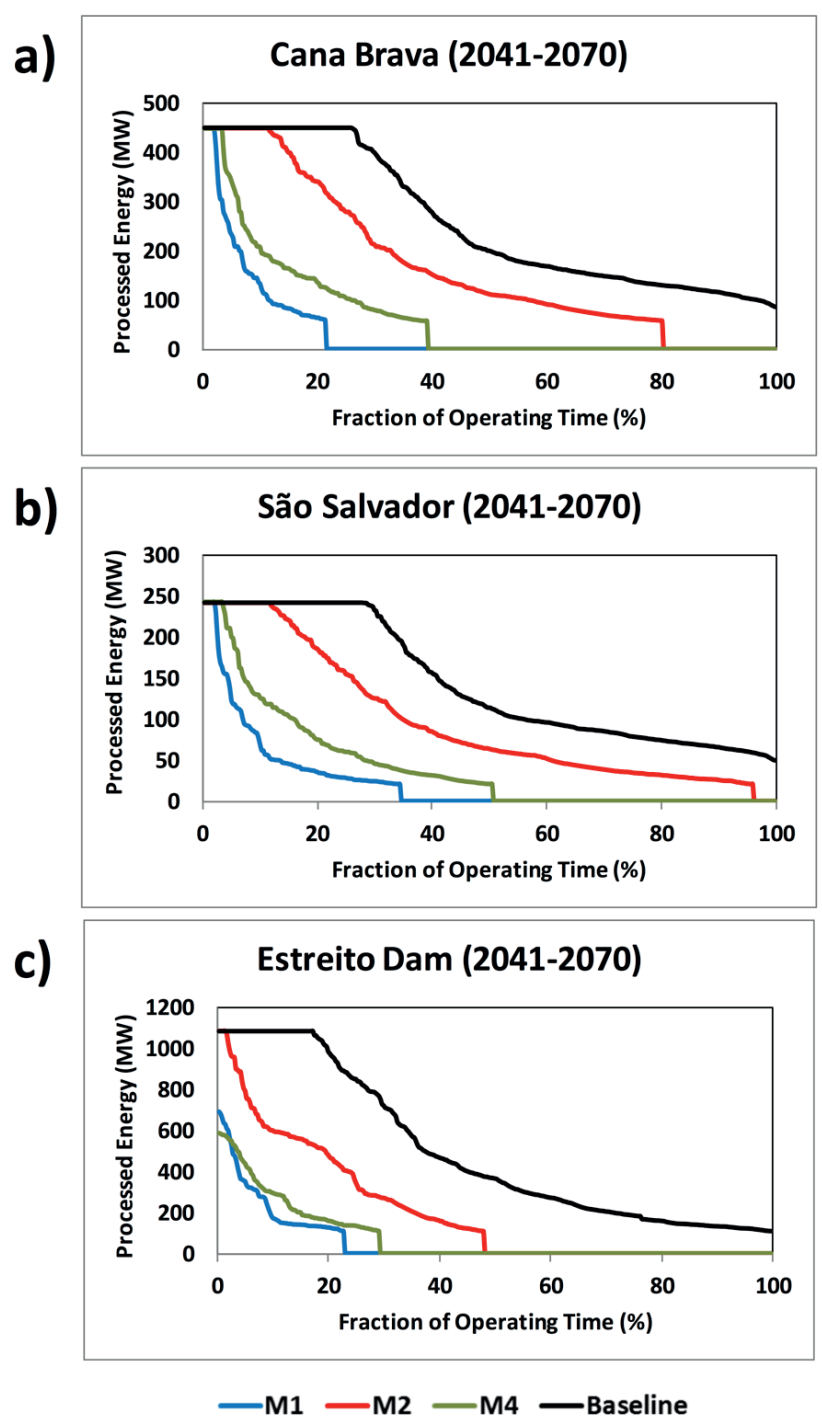

Figure 5.4 Annual processed power duration curves based on median daily values at Tocantins runof-river HPPs for the period between 1970 and 1990 (baseline, black lines) and 2041 and 2070 (future simulations, colored lines). The baselines are obtained using observed data as input. 


\subsection{Conclusions}

CC projections of reduced rainfall over Tocantins basin induced decreases in discharge simulated by the MHD-INPE hydrological model in the entire basin. However, this reduction was weakened when land use change scenarios provided by the LUCC-ME model were included in the simulations. These changes increased the discharge when only deforestation, without regrowth, was considered. The weakening occurred mainly in scenario $\mathrm{C} 1$, which considers significant social inequality and the depletion of natural resources, i.e., high deforestation. However, when the regrowth of secondary vegetation in deforested area is considered in LULCC scenario C1, the effects are of similar magnitude to the CC-only impacts, and even enhanced in sustainable scenario A as a result of the high evapotranspiration rate of secondary forests in comparison with the evapotranspiration of pastures and primary forests.

The energy potential of large dams and the expected operating time of ROR HPPs decrease significantly as a result of the decrease in discharge due to CC. Additionally, LULCC moderately counteracts these effects. Nevertheless, the region of the Tucuruí HPP includes an area of secondary forest and the decrease in its energy potential may again become pronounced when scenario A is considered due to the deceleration of deforestation and the conversion of pasture into secondary forest.

Due to the uncertainties about the rules of operation of the Brazilian interconnected system under climate change scenarios, the operational rule adopted in this study maximize the generation of each power plant. Future studies should consider the large varieties of conditions that would affect the generation of the reservoir cascade of the basin. Also, our simulations did not include scenarios involving water consumption. In these cases, the reduction in potential energy production may be further magnified.

Despite the high variability among the climate model integrations, the annual energy production is likely to decrease based on the analyzed projections and the current HPP design. However, MHD does not consider the effects of erosion and consequent silting caused by deforestation, and these factors would affect water production.

Our results highlight the importance of including the effects of CC and LULCC, such as deforestation and secondary forest growth, in assessments of the water resource availability, energy production and the feasibility of HPP deployment. 


\section{Chapter 6}

\section{Synthesis}

\subsection{General discussion}

The objectives of this thesis are to investigate how the evapotranspiration changes spatially and seasonally in pasture areas; to compare the evapotranspiration of deforested with undisturbed areas; and to understand the potential effects of forest regrowth after the abandonment of deforested areas on the water cycle. Furthermore, from the knowledge acquired on evapotranspiration in different land covers, to analyze the future water production under climate change scenarios. To achieve these objectives, data collected at two different regions in Amazonia were analyzed: one in Southwestern, with a well-defined dry season and one in Central region, where the seasonality of climate is less pronounced. At both regions, sites covered by pastures and primary forests were investigated, and in Central Amazonia, one additional site covered by a 20 years old secondary growth was also analyzed. Besides the field data collection, this work is one of the first to consider the hydrological impacts of secondary forest on water production, using a hydrological model driven by different climate change scenarios (CC) and two future socioeconomic-based potential land-cover land-use change scenarios (LCLUC) on regional scale.

It is known that the conversion of forest to pasture reduces the evapotranspiration. The two pasture sites analyzed in this study present much lower evapotranspiration than in forests during the dry season, and with only one of them reaching an amount similar to the primary vegetation in the wet season (Chapter 2). Investigating what controls the evapotranspiration in pastures in comparison with the primary forest, in Chapter $\mathbf{3}$ it was found that the pasture evapotranspiration is primarily controlled by the atmospheric conditions during the wet season. But, during the dry season, a significant biological control of transpiration by the pasture is observed especially in the afternoon. Then, in its turn, after pastures are abandoned as a result of low productivity, the secondary growth that replaces those areas reaches higher rates of evapotranspiration than in primary forests (Chapter4). Considering different land use covers on the hydrological modeling under climate change scenarios (CC) in Chapter 5, the model projected a decrease in discharge, but 
when deforestation scenarios without secondary growth are considered, the effects of CC are weakened. Nonetheless, when secondary growth is considered, the effects of CC are enhanced.

From the data presented some parameters calculated in the Chapters 2 to 3 were used in Chapter 5 to calibrate and validate MHD model against the measured discharge of Tocantins river basin. After the calibration of the model, the parameters resulted from measurements and calculations of Chapter 4 could be used to also include the effects of secondary growth on water cycle of the basin under future land use and climate change scenarios.

Five research questions (RQs) were addressed to investigate the variation of evapotranspiration on different land uses in different Amazon regions and the impacts that the changes on land cover could cause on water production. The answers and the scientific context of these research questions are presented below. Section 6.2 presents the scientific contribution of the present research and the Section 6.3 presents the outlook and recommendations for future research.

RQ 1 Are there spatial variabilities between pastures in Central and Southwestern Amazonia associated to seasonality differences?

From previous studies in Amazonia, scientists have known that pastures have shallow root systems and suffer stress during dry periods (Da Rocha et al., 2009; Negron-Juárez et al., 2007; Von Randow et al., 2004). However, with observations restricted to only few sites it is difficult to know to what extent this stress differs, since the magnitude of seasonal variability, as the length of the dry season for instance, is not the same across Amazonia. This work contributes to better understand this spatial variability by analyzing data collected in-situ in sites with distinct seasonality.

The results showed that evapotranspiration is around $2.5 \mathrm{~mm} \mathrm{day}^{-1}$ during the dry season in Central and South-western Amazonia, while during the wet season it is $2.1 \mathrm{~mm}^{- \text {day }^{-1}}$ in Central Amazonia and 3.5 mm.day ${ }^{-1}$ in the South-western. This shows that the evapotranspiration was low at both locations during the dry season as expected due to the water stress, but, unexpectedly, during the wet season, the evapotranspiration remained low at Central Amazonia site, associated with much lower net radiation, lower biomass and LAI in that site, compared to the Southwestern site, where evapotranspiration increases significantly. 
$R Q 2$ What are the controls of evapotranspiration in pastures of different regions in Amazon?

To address this question, the main drivers of evapotranspiration were identified at both Southwestern and Central Amazonia, calculating the decoupling factor $(\Omega)$ proposed by (Jarvis and McNaughton, 1986). The decoupling factor is an index that indicates whether the evapotranspiration is controlled by the vegetation through the stomatal resistance or is decoupled from the surface and controlled by the energy available. The closer to 1 the greater the control of the atmospheric conditions (mainly available energy), while a value close to 0 indicates a strong influence of vegetation (strong coupling between the evapotranspiration and biological activity of stomata opening or closing).

Analyzing hourly averages of $\Omega$ during dry seasons, a similar pattern and magnitude of the coupling at both sites was observed, with well coupled conditions between the transpiration and the biological activity of the plants at the two locations. This suggests that, in general, pasture vegetation controls dry season water loss across the whole region, even in areas with modest dry periods.

In the wet season, the pattern and magnitudes of $\Omega$ differed between the two sites. On one hand, $\Omega$ still indicates coupling between the evapotranspiration and the pasture controls at Central Amazonia, but on the other hand, there is very little control of water loss by the Southwestern pasture, and the evapotranspiration is generally directly related to the available energy. 
$R Q 3 H o w$ does pasture differ from the forest on the evapotranspiration control in the wet and dry seasons?

From previous studies, it is known that the evapotranspiration differs between forests and pastures in Amazonia (e.g. Souza-Filho et al., 2005, Hasler and Avissar, 2007, Costa et al., 2010, Christoffersen et al., 2014, von Randow et al. 2004; von Randow et al. 2012, D'Almeida et al. 2007). Pastures like Colosso, presented in Chapter 2, presents a significant reduction in evapotranspiration in comparison to primary forest during the entire year. Nonetheless, to answer the RQ3, the analysis went a bit further to focus on finding the differences on the control of evapotranspiration between forests in Central and Southwestern Amazonia and a pasture in the Southwestern. Chapter 3 shows that during the wet season, evapotranspiration is energy-controlled during the morning at forest sites and during all day for the pasture site. During the afternoon the control is exerted by the vegetation at both forests. During the dry season, evapotranspiration control is mainly exerted by the vegetation at both forests and during the afternoon in the pasture. Similar results were obtained by Mallick et al. (2016), using a different approach to calculate a canopy-scale estimate of stomatal and aerodynamic conductances. The authors have also obtained that wet season transpiration is predominantly driven by the net available energy at forests and the in same pasture analysed in this work, and that biophysical control on transpiration is dramatically increased during dry periods.

Synthesizing the values found in this thesis, aerodynamic resistance in the forests is around 20 to $40 \mathrm{~s} . \mathrm{m}^{-1}$ during wet and dry seasons, while it varies from 70 to $100 \mathrm{~s} . \mathrm{m}^{-1}$ at pasture. Stomatal resistance varies daily and seasonally, being higher in the afternoon and in the dry season for all sites. During wet season, rs is almost the same in the three sites, varying from 50 to $150 \mathrm{~s} . \mathrm{m}^{-1}$ during the day. During the dry season, rs increases up to $500 \mathrm{s.m}^{-1}$ in the forests sites, while in the pasture it reaches $1800 \mathrm{~s} . \mathrm{m}^{-1}$ due to the lower water availability and shallow root depth. 
RQ4 What are the potential effects of secondary regrowth after abandonment of deforested areas on evapotranspiration and water use efficiency?

Knowing the high potentiality of abandonment of pastures due to low productivity in Amazonia, the evapotranspiration from a 20 years old secondary forest against the evapotranspiration from a primary forest, both at Central Amazonia, were investigated in Chapter 4. On average, over 4 years of concurrent measurements, evapotranspiration was $20 \%$ higher in the secondary forest $\left(3.6 \mathrm{~mm} \cdot \mathrm{day}^{-1}\right)$ than in the primary forest $\left(3.1 \mathrm{~mm}\right.$.day $\left.{ }^{-1}\right)$, while gross primary productivity was only $5 \%$ higher $\left(8.0 \mathrm{gC}^{-\mathrm{m}^{-2}}\right.$. day ${ }^{-1}$ in the secondary forest, $7.7 \mathrm{gC} . \mathrm{m}-2$. day -1 in the primary forest), except during the dry season, when the gross carbon uptake was the same in both sites. Conversely, water use efficiency was lower in the secondary than in the primary forest $(10 \%$ during the wet season and $15 \%$ during the dry season), showing that the secondary forest seems to have less control over water loss to assimilate the same amount of carbon.

These results highlight the importance of secondary regrowth on the Amazon regional water balance, with potential to compensate for evapotranspiration reduction of deforested and unproductive areas.

RQ 5 What are the potential effects of climate change and land cover change, including secondary growth, on the local hydrology and possible impacts on ecosystem services?

GCM models indicate that climate change will alter the hydrological regime, with a majority of projections decreasing precipitation in Eastern Amazon over the $21^{\text {st }}$ century (Malhi et al., 2009). This will change the river discharge, affecting all the ecosystem services related to water availability. In Chapter 5, the MHD-INPE hydrological model was used to simulate future discharge for the Tocantins basin, the eastern most large tributary of the Amazon basin, driven by three climate change scenarios of the regional atmospheric model Eta-INPE, and projected large decreases in discharge (up to $39 \%$ in the first time slice of future climate analyzed, reaching $65 \%$ 
reduction in the end of the century, compared to a baseline period from 1970-1990), induced by projections of reduced rainfall and increased temperatures.

Similar hydrological projections under different climate change scenarios are found in the literature for the Southern Amazon tributaries as Purus, Madeira, Tapajós and Xingu. The projections for Madeira river that used different climate models and scenarios resulted in reductions in lower and higher discharges with different extents between models (Siqueira Jr. et al., 2015). Similar to this work, climate change is projected to reduce the Tapajós river discharge for most of the scenarios, except for one model that showed a significant increase in the discharge (Mohor et al., 2015), and reductions in discharge were also found for Purus basin (Dalagnol et al., 2017).

In Chapter 5, when the model simulates effects of both climate change and deforestation in the future, the previous projections of reductions in discharge are slightly weakened, projecting a reduction of up to $35 \%$ in the first analyzed time slice, reaching $63 \%$ of reduction on discharge in the end of the century. The same was observed on projections considering the conversion of tropical forest to pasture or farming at Madeira river basin (Siqueira Jr et al., 2015) and over the entire Amazon basin (Guimberteau et al., 2017) as a result of the decrease of evapotranspiration and consequent increase on discharge.

Nonetheless, none of the previous modelling exercises in the literature considered the secondary forest growth as taken in account in this study. Depending on the socioeconomic scenario considered, a substantial part of the current and future deforested areas in the lower Tocantins basin may be restored with secondary forest regrowth. When these secondary regrowth scenarios are included in the model, combined to the effects of climate change, the modeled discharge suffered an enhanced reduction on top of the climate change effects (up to $41 \%$ in the first future time slice analyzed, reaching $67 \%$ reduction in the end of the century, on the more sustainable land use scenario) due to the high evapotranspiration of secondary forests. The potential energy production of Tocantins river was analyzed under all previous land use change scenarios for Tucuruí power plant, and a decrease in energy production was projected accordingly, with up to $58 \%$ of reduction in 2041 to 2070 time slice. More importantly, even in the case of some CC scenarios, which predict that climate change is no likely to affect significantly future Tocantins basin mean annual river discharges, increased discharge seasonality (and consequently reduced river regularization) will reduce hydropower outputs in all cases analyzed. 


\subsection{Scientific contributions of this work}

In this thesis, water and carbon fluxes were measured under three different land covers in Central and Southwestern Amazonia during several years. Although surface fluxes and carbon uptake has been measured in pasture and forests sites in Amazonia before, eddy covariance measurements of secondary vegetation areas were not available until now, which makes the results of this study unique. Furthermore, parameterizations of conductance are used in most climate models, therefore, understanding the functioning of vegetation cover is important for environmental studies. The parameterizations provided in this work contributed to guide studies developed on other regions on better understanding the spatial and seasonal variability of different land covers, and the role of them on water cycle components, energy balance partitioning, climate factors influences on soil moisture (Da Silva Júnior et al., 2017; Feng, 2016; Feng and Liu, 2015; Ferreira et al., 2013; Harper et al., 2014; Hirano et al., 2015; Mallick et al., 2016; Rodrigues et al., 2016; Salazar et al., 2018; Souza et al., 2012; Xu et al., 2018).

This work found that secondary forest growth plays an important role in minimizing the impacts of land cover and land use changes from primary forest to pasture on the water balance in Amazonia, since the secondary forest contributes with higher transpiration than pastures, and even higher than in the primary forest. This indicates that secondary forests can contribute to the maintenance of moisture production of the Amazon region and the transport of moisture to the subtropical region of South America, feeding its precipitation regime.

Also, secondary forest takes more carbon from the atmosphere than pasture sites, playing an important role on carbon uptake from the atmosphere together with primary forest, minimizing emissions from deforestation.

Modeling the CC and LULCC impacts on water production considering the main vegetation types of rainforest biome (including secondary growth) studied in this work, promotes a more realistic projection of water yield and the future effects on the ecosystems services depending on it. This result was mentioned in the work of Fearnside (2019) about hydropower plants in Amazonia, arguing whether the environmental and social impacts of those types of constructions pays off under climate change scenarios. The modeling results of this work and the way that it was conducted, analyzing the extremes conditions of land use change scenarios developed by Aguiar et al. (2016), could inspire follow-up studies in other basins in the region (e.g. Farinosi et al., 2019). 


\subsection{Implications and recommendations for future work}

Considering that tree restoration might be perceived as one of the most effective strategies for climate change mitigation, data on the potential benefits of secondary regrowth on carbon uptake are essential for quantifying the economic and social benefits of mitigation policies. In addition to the benefits in terms of carbon fixation, secondary forests may provide an important contribution to the water cycle of the region, with higher evaporative fraction than that of primary forests, which can partially compensate for the effects of the conversion of forest to pasture and agriculture on energy and water balances. Results of this thesis also suggest that secondary forest will impact hydroelectricity under a changing climate, therefore water consumption in secondary forest might have additional implications for competing water uses. Nonetheless, this study presents only one site of secondary forest, that might be not representative of all Amazon biome, since the chapters 2 and 3 showed that there is spatial variability on the other vegetation covers. Therefore, it is important to collect data of secondary forest on other regions of Amazon.

Higher evapotranspiration rates in the secondary forest compared to the primary forest could not be explained by a clear difference in the available energy, temperature or humidity at the sites. Still, seasonal changes in albedo present different patterns between the sites. At primary forest, albedo peaks in the beginning of the dry season, probably in response to flushing of new leaves, a result pointed out by several recent papers (Restrepo et al., 2013; Wu et al., 2016), while at the secondary forest, the albedo peaks later, at the end of the dry season. The peak of albedo at the primary forest suggests an evolutionary strategy of leaf phenology pattern among leaf flushing species to increase ecosystem-scale photosynthetic capacity, as the amount of light increases as a result of the decrease of cloud cover during the dry season (Lopes et al., 2016; Wu et al. 2016), and the pioneer species of the secondary regrowth likely miss the same evolutionary strategy. A more detailed study of the leaf phenology on secondary species is needed to confirm this hypothesis.

It is also important to mention that the model simulations used in this thesis considers direct effects of climate change on discharge but did not include feedbacks between the changes in the land use to rainfall production in the basins. For instance, deforestation might impact regional climate in the long term by reducing precipitation recycling in the region, which then may feedback reducing discharge (Lima et al., 2014). Investigating the potential impacts of deforestation and 
possible regrowth of secondary forests throughout the Amazon using coupled climatic and hydrologic models is important.

Results of Chapter 5 highlight the importance of including the effects of CC and LCLUC, including forest regrowth, in assessments of the water resource availability, energy production, and the feasibility of hydropower deployment. But the simulations did not include scenarios involving water consumption or erosion. In these cases, the reduction in potential energy production may be further magnified. Also due to the uncertainties about the rules of operation of the Brazilian interconnected energy system under climate change scenarios, the operational rule adopted in this study maximizes the generation of each power plant. Future studies should consider the large varieties of conditions that would affect the generation of the reservoir cascade of the basin.

Based on the implications discussed above, future investigations recommended by this work are indicated as follows:

- Collect new data on other secondary forests in different Amazon sites to better understand the spatial variability of this type of vegetation in the entire biome;

- Investigate the phenology of secondary forests in terms of albedo and leaf dynamics and their relationship with seasonal patterns of luminosity and water availability;

- Work with coupled climatic and hydrologic models, including secondary growth to evaluate their impact on future river discharge;

- Study the effects of CC and LULCC on water yield and consequently on energy production in the interconnected energy system.

Secondary forest plays an important role on the maintenance of moisture production and transport to other regions of South America and on partial re-absorption of carbon emitted during deforestation. And, in spite of the higher uptake of carbon from secondary forest, observations revealed that the primary forest over performed the secondary regrowth in terms of water use efficiency, indicating that carbon fixation in the secondary forest occur at the expense of higher water loss and consequently on ecosystem services, which indicates that avoiding deforestation is more efficient than promoting tree regrowth. Therefore, secondary forest can be considered an allied of primary forest to minimize the effects of deforestation, but never a substitute. 


\section{References}

Aguiar, A. P. D., Ometto, J. P., Nobre, C., Lapola, D. M., Almeida, C., Vieira, I. C., ... CastillaRubio, J. C. (2012). Modeling the spatial and temporal heterogeneity of deforestation-driven carbon emissions: the INPE-EM framework applied to the Brazilian Amazon. Global Change Biology, 18(11), 3346-3366. https://doi.org/10.1111/j.1365-2486.2012.02782.x

Aguiar, A. P. D., Vieira, I. C. G., Assis, T. O., Dalla-Nora, E. L., Toledo, P. M. de, Araújo, R., ... Ometto, J. P. H. (2016). Land use change emission scenarios: anticipating a forest transition process in the Brazilian Amazon. Global Change Biology, 22(5), 1821-1840. https://doi.org/10.1111/gcb.13134

Alcamo, J. (2001). Scenarios as tools for international environmental assessments. In Environmental issues report. Retrieved from http://www.eea.europa.eu/publications/environmental_issue_report_2001_24/issue_report_no_ 24.pdf

Allen, R. G., Pereira, L. S., Raes, D., \& Smith, M. (1998). Irrigation and Drainage. In Crop evapotranspiration-Guidelines for computing crop water requirements-FAO Irrigation and drainage paper 56 (FAO, p. Paper No. 56). Rome.

Almeida, C. A., Valeriano, D. M., Isabel, M., Escada, S., \& Rennó, D. (2010). Estimativa de área de vegetação secundária na Amazônia Legal Brasileira. Acta Amazonica, 40(2), 289-302. https://doi.org/10.1175/2009EI290.1

ANA - Agencia Nacional de Aguas. (2006). Plano Estratégico de Recursos Hídricos da Bacia dos Rios Tocantins e Araguaia: Relatório Diagnóstico, Anexo 14, Geração de Energia No 1329-RFIN-PLD-15-01 ANA. Retrieved January 15, 2018, from http://central2.to.gov.br/arquivo/31/933

ANTAQ - Agência Nacional de Transportes Aquaviários. (2013). Bacia do Tocantins-Araguaia: Plano Nacional de Integração Hidroviária: Desenvolvimento de Estudos e Análises das Hidrovias Brasileiras e suas Instalações Portuárias com Implantação de Base de Dados Georreferenciada e Sistema de Informações Geográficas UFS. Retrieved January 15, 2018, from http://web.antaq.gov.br/Portal/PNIH/RTBaciaTocantinsAraguaia.pdf

Aragão, L. E. O. C., Poulter, B., Barlow, J. B., Anderson, L. O., Malhi, Y., Saatchi, S., ... Gloor, E. (2014). Environmental change and the carbon balance of Amazonian forests. Biological Reviews, 89(4), 913-931. https://doi.org/10.1111/brv.12088

Araújo, A. C., Nobre, A. D., Kruijt, B., Elbers, J. A., Dallarosa, R., Stefani, P., ... Kabat, P. (2002). Comparative measurements of carbon dioxide fluxes from two nearby towers in a central Amazonian rainforest: The Manaus LBA site. Journal of Geophysical Research, 107, 1-20. https://doi.org/10.1029/2001JD000676

Arraut, J. M., Nobre, C., Barbosa, H. M. J., Obregon, G., \& Marengo, J. (2012). Aerial rivers and lakes: Looking at large-scale moisture transport and its relation to Amazonia and to subtropical rainfall in South America. Journal of Climate, 25(2), 543-556. https://doi.org/10.1175/2011JCLI4189.1

Asner, G. P., Townsend, A. R., Bustamante, M. M. C., Nardoto, G. B., \& Olander, L. P. (2004). 
Pasture degradation in the central Amazon: linking changes in carbon and nutrient cycling with remote sensing. Global Change Biology, 10(5), 844-862. https://doi.org/10.1111/j.15298817.2003.00766.x

Bárdossy, A., \& Pegram, G. (2011). Downscaling precipitation using regional climate models and circulation patterns toward hydrology. Water Resources Research, 47(4). https://doi.org/10.1029/2010WR009689

Bastable, H. G., Shuttleworth, W. J., Dallarosa, R. L. G., Fisch, G., \& Nobre, C. A. (1993). Observations of climate, albedo, and surface radiation over cleared and undisturbed amazonian forest. International Journal of Climatology, 13(7), 783-796. https://doi.org/10.1002/joc.3370130706

Bastin, J.-F., Finegold, Y., Garcia, C., Mollicone, D., Rezende, M., Routh, D., ... Crowther, T. W. (2019). The global tree restoration potential. Science, 365(6448), 76-79. https://doi.org/10.1126/science.aax0848

BRASIL. (2013). PAC2 - Programa de Aceleração do Crescimento $8^{\circ}$ BALANÇO MAIO. Retrieved January 15, 2018, from http://www.pac.gov.br/pub/up/relatorio/ffaff442f57973143fbd0a6c39b8ae69.pdf

Bravo, J. M., Collischonn, W., da Paz, A. R., Allasia, D., \& Domecq, F. (2014). Impact of projected climate change on hydrologic regime of the Upper Paraguay River basin. Climatic Change, 127(1), 27-41. https://doi.org/10.1007/s10584-013-0816-2

Broedel, E., Tomasella, J., Cândido, L. A., \& von Randow, C. (2017). Deep soil water dynamics in an undisturbed primary forest in central Amazonia: Differences between normal years and the 2005 drought. Hydrological Processes, 31(9), 1749-1759. https://doi.org/10.1002/hyp.11143

Bruijnzeel, L. A. (1991). Predicting the hydrological impacts of land cover transformation in the humid tropics: the need for integrated research. In J. H. C. Gash, C. A. Nobre, J. M. Roberts, \& R. L. Victoria (Eds.), Amazonian deforestation and climate. (pp. 15-55). Chichester, UK: Wiley.

Cassol, H. L. G., Carreiras, J. M. de B., Moraes, E. C., de Aragão, L. E. O. e. C., Silva, C. V. de J., Quegan, S., \& Shimabukuro, Y. E. (2019). Retrieving secondary forest aboveground biomass from polarimetric ALOS-2 PALSAR-2 data in the Brazilian Amazon. Remote Sensing, 11(1). https://doi.org/10.3390/rs11010059

Castro, C. P. (2006). Plantio de grãos em áreas de fronteira, ação antrópica e desmatamento: Estudo do processo de incorporação ao mercado nacional de novas terras na Amazônia. Proponente: In P. Jacobi \& L. Ferreira (Eds.), Diálogos em ambiente e sociedade no Brasil. (pp. 105-121). Retrieved from https://papers.ssrn.com/sol3/papers.cfm?abstract_id=2437140\&download=yes

Chauvel, A, Lucas, Y., \& Boulet, R. (1987). On the genesis of the soil mantle of the region of Manaus, Central Amazonia, Brazil. Experientia, 43(3), 234-241. https://doi.org/10.1007/BF01945546

Chauvel, Armand. (1982). Os latossolos amarelos, álicos, argilosos dentro dos ecossistemas das bacias experimentais do INPA e da região vizinha. Acta Amazonica, 12, 47-60. Retrieved from http://www.scielo.br/scielo.php?script=sci_arttext\&pid=S0044-59671982000600047\&nrm=iso

Chiabai, A., Travisi, C. M., Markandya, A., Ding, H., \& Nunes, P. A. L. D. (2011). Economic Assessment of Forest Ecosystem Services Losses: Cost of Policy Inaction. Environmental and Resource Economics, 50(3), 405-445. https://doi.org/10.1007/s10640-011-9478-6

Chou, S. C., Marengo, J. A., Lyra, A. A., Sueiro, G., Pesquero, J. F., Alves, L. M., ... Tavares, P. 
(2012). Downscaling of South America present climate driven by 4-member HadCM3 runs. Climate Dynamics, 38(3), 635-653. https://doi.org/10.1007/s00382-011-1002-8

Choudhury, B. J., DiGirolamo, N. E., Susskind, J., Darnell, W. L., Gupta, S. K., \& Asrar, G. (1998). A biophysical process-based estimate of global land surface evaporation using satellite and ancillary data II. Regional and global patterns of seasonal and annual variations. Journal of Hydrology, 205(3), 186-204. https://doi.org/https://doi.org/10.1016/S0022-1694(97)00149-2

Christensen, J. H., Kanikicharla, K. K., Aldrian, E., An, S.-I., Cavalcanti, I. F. A., de Castro, M., ... Zhou, T. (2013). Climate Phenomena and their Relevance for Future Regional Climate Change. In T. F. Stocker, D. Qin, G.-K. Plattner, M. Tignor, S. K. Allen, J. Boschung, ... P. M. Midgley (Eds.), Climate Change 2013: The Physical Science Basis. Contribution of Working Group I to the Fifth Assessment Report of the Intergovernmental Panel on Climate Change (pp. 1217-1308).

Christoffersen, B. O., Restrepo-Coupe, N., Arain, M. A., Baker, I. T., Cestaro, B. P., Ciais, P., ... Saleska, S. R. (2014). Mechanisms of water supply and vegetation demand govern the seasonality and magnitude of evapotranspiration in Amazonia and Cerrado. Agricultural and Forest Meteorology, 191, 33-50. https://doi.org/https://doi.org/10.1016/j.agrformet.2014.02.008

Cidade Tucuruí. (2016). Technical Specifications (in Portuguese). Retrieved January 15, 2018, from http://cidadedetucurui.com/inicio/usina_hidreletrica_tucurui/USINA_HIDRELETRICA_TUC URUI.htm

Cloke, H. L., Wetterhall, F., He, Y., Freer, J. E., \& Pappenberger, F. (2013). Modelling climate impact on floods with ensemble climate projections. Quarterly Journal of the Royal Meteorological Society, 139(671), 282-297. https://doi.org/10.1002/qj.1998

Coe, M. T., Costa, M. H., \& Soares-Filho, B. S. (2009). The influence of historical and potential future deforestation on the stream flow of the Amazon River - Land surface processes and atmospheric feedbacks. Journal of Hydrology, 369(1), 165-174. https://doi.org/https://doi.org/10.1016/j.jhydrol.2009.02.043

Collins, M., Tett, S. F. B., \& Cooper, C. (2001). The internal climate variability of HadCM3, a version of the Hadley Centre coupled model without flux adjustments. Climate Dynamics, 17(1), 61-81. https://doi.org/10.1007/s003820000094

Collins, Matthew, Booth, B. B. B., Harris, G. R., Murphy, J. M., Sexton, D. M., \& Webb, M. J. (2006). Towards quantifying uncertainty in transient climate change. Climate Dynamics, 27(2), 127-147. https://doi.org/10.1007/s00382-006-0121-0

Corrêa da Silva, R., de Marchi Neto, I., \& Seifert, S. S. (2016). Electricity supply security and the future role of renewable energy sources in Brazil. Renewable and Sustainable Energy Reviews, 59, 328-341. https://doi.org/https://doi.org/10.1016/j.rser.2016.01.001

Costa, Marcos H, Biajoli, M. C., Sanches, L., Malhado, A. C. M., Hutyra, L. R., da Rocha, H. R., ... de Araújo, A. C. (2010). Atmospheric versus vegetation controls of Amazonian tropical rain forest evapotranspiration: Are the wet and seasonally dry rain forests any different? Journal of Geophysical Research: Biogeosciences, 115(G4). https://doi.org/10.1029/2009JG001179

Costa, Marcos Heil, Botta, A., \& Cardille, J. A. (2003). Effects of large-scale changes in land cover on the discharge of the Tocantins River, Southeastern Amazonia. Journal of Hydrology, 283(1), 206-217. https://doi.org/https://doi.org/10.1016/S0022-1694(03)00267-1 
Culf, A. D., Fisch, G., \& Hodnett, M. G. (1995). The albedo of Amazonian forest and ranch land. Journal of Climate, 8(6), 1544-1554. https://doi.org/10.1175/15200442(1995)008<1544:TAOAFA $>2.0 . \mathrm{CO} ; 2$

D’Almeida, C., Vörösmarty, C. J., Hurtt, G. C., Marengo, J. A., Dingman, S. L., \& Keim, B. D. (2007). The effects of deforestation on the hydrological cycle in Amazonia: a review on scale and resolution. International Journal of Climatology, 27(5), 633-647. https://doi.org/10.1002/joc. 1475

Da Rocha, H. R., Manzi, A. O., Cabral, O. M., Miller, S. D., Goulden, M. L., Saleska, S. R., ... Maia, J. F. (2009). Patterns of water and heat flux across a biome gradient from tropical forest to savanna in Brazil. Journal of Geophysical Research: Biogeosciences, 114(1), 1-8. https://doi.org/10.1029/2007JG000640

Da Rocha, H. R., Nobre, C. A., Bonatti, J. P., Wright, I. R., \& Sellers, P. J. (1996). A vegetationatmosphere interaction study for Amazonia deforestation using field data and a 'single column' model. Quarterly Journal of the Royal Meteorological Society, 122(531), 567-594. https://doi.org/10.1002/qj.49712253102

Da Silva Júnior, R. O., de Souza, E. B., Tavares, A. L., Mota, J. A., Ferreira, D. B. S., Souza-Filho, P. W. M., \& da Rocha, E. J. P. (2017). Three decades of reference evapotranspiration estimates for a tropical watershed in the eastern Amazon. Anais Da Academia Brasileira de Ciencias, 89(3), 1985-2002. https://doi.org/10.1590/0001-3765201720170147

Dalagnol, R., Borma, L. de S., Mateus, P., \& Rodriguez, D. A. (2017). Assessment of climate change impacts on water resources of the Purus Basin in the southwestern Amazon. Acta Amazonica, 47, 213-226. Retrieved from http://www.scielo.br/scielo.php?script=sci_arttext\&pid=S0044-59672017000300213\&nrm=iso

Davidson, E. a., de Araújo, A. C., Artaxo, P., Balch, J. K., Brown, I. F., C. Bustamante, M. M., ... Wofsy, S. C. (2012). The Amazon basin in transition. Nature, 481(7381), 321-328. https://doi.org/10.1038/nature10717

Davidson, E. A., De Carvalho, C. J. R., Figueira, A. M., Ishida, F. Y., Ometto, J. P. H. B., Nardoto, G. B., ... Martinelli, L. A. (2007). Recuperation of nitrogen cycling in Amazonian forests following agricultural abandonment. Nature, 447(7147), 995-998. https://doi.org/10.1038/nature05900

De Bruin, H. A. R., Kohsiek, W., \& Van Den Hurk, B. J. J. M. (1993). A verification of some methods to determine the fluxes of momentum, sensible heat, and water vapour using standard deviation and structure parameter of scalar meteorological quantities. Boundary-Layer Meteorology, 63(3), 231-257. https://doi.org/10.1007/BF00710461

Demaria, E. M. C., Maurer, E. P., Thrasher, B., Vicuña, S., \& Meza, F. J. (2013). Climate change impacts on an alpine watershed in Chile: Do new model projections change the story? Journal of Hydrology, 502, 128-138. https://doi.org/https://doi.org/10.1016/j.jhydrol.2013.08.027

Dickinson, R. E., \& Henderson-Sellers, A. (1988). Modelling tropical deforestation: A study of GCM land-surface parametrizations. Quarterly Journal of the Royal Meteorological Society, 114(480), 439-462. https://doi.org/10.1002/qj.49711448009

Dijkshoorn, J. A., Huting, J. R. M., \& Tempel, P. (2005). Update of the 1:5 million Soil and Terrain 9 Database for Latin America and the Caribbean (SOTERLAC; version 20) Report 10 2005/01. Wageningen.

Dolman, A.Johannes, Gash, J. H. C., Roberts, J., \& Shuttleworth, W. J. (1991). Stomatal and 
surface conductance of tropical rainforest. Agricultural and Forest Meteorology, 54(2), 303318. https://doi.org/https://doi.org/10.1016/0168-1923(91)90011-E

Dolman, A J, Stewart, J. B., \& Cooper, J. D. (1988). Predicting forest transpiration from climatological data. Agricultural and Forest Meteorology, 42(4), 339-353. https://doi.org/https://doi.org/10.1016/0168-1923(88)90042-1

Duan, Q., Sorooshian, S., \& Gupta, V. (1992). Effective and efficient global optimization for conceptual rainfall-runoff models. Water Resources Research, 28(4), 1015-1031. https://doi.org/10.1029/91WR02985

Duan, Q., Sorooshian, S., \& Gupta, V. K. (1994). Optimal use of the SCE-UA global optimization method for calibrating watershed models. Journal of Hydrology, 158(3-4), 265-284.

Elbers, J. A., Jacobs, C. M. J., Kruijt, B., Jans, W. W. P., \& Moors, E. J. (2011). Assessing the uncertainty of estimated annual totals of net ecosystem productivity: A practical approach applied to a mid latitude temperate pine forest. Agricultural and Forest Meteorology, 151(12), 1823-1830. https://doi.org/10.1016/J.AGRFORMET.2011.07.020

Ellison, D., Morris, C. E., Locatelli, B., Sheil, D., Cohen, J., Murdiyarso, D., ... Sullivan, C. A. (2017). Trees, forests and water: Cool insights for a hot world. Global Environmental Change, 43, 51-61. https://doi.org/https://doi.org/10.1016/j.gloenvcha.2017.01.002

ENGIE. (2016). Datasheet (in Portuguese). Retrieved January 15, 2018, from http://www.engieenergia.com.br/wps/portal/internet/parque-gerador/usinas-hidreletricas/.

EPE - Empresa de Pesquisa Energética. (2006). Plano Nacional de Energia 2030 (in Portuguese)/ Ministério de Minas e Energia Empresa de Pesquisa Energética Brasília: MME/EPE.

EPE - Empresa de Pesquisa Energética. (2012). Plano Decenal de Expansão de Energia 2021 (in Portuguese)/ Ministério de Minas e Energia Empresa de Pesquisa Energética Brasília: $M M E / E P E$.

Falck, A. S., Maggioni, V., Tomasella, J., Vila, D. A., \& Diniz, F. L. R. (2015). Propagation of satellite precipitation uncertainties through a distributed hydrologic model: A case study in the Tocantins-Araguaia basin in Brazil. Journal of Hydrology, 527, 943-957. https://doi.org/https://doi.org/10.1016/j.jhydrol.2015.05.042

Falge, E., Baldocchi, D., Olson, R., Anthoni, P., Aubinet, M., Bernhofer, C., ... Wofsy, S. (2001). Gap filling strategies for defensible annual sums of net ecosystem exchange. Agricultural and Forest Meteorology, 107(1), 43-69. https://doi.org/https://doi.org/10.1016/S01681923(00)00225-2

Farinosi, F., Arias, M. E., Lee, E., Longo, M., Pereira, F. F., Livino, A., ... Briscoe, J. (2019). Future Climate and Land Use Change Impacts on River Flows in the Tapajós Basin in the Brazilian Amazon. Earth's Future, 7(8), 993-1017. https://doi.org/10.1029/2019EF001198

Farr, T. G., Rosen, P. A., Caro, E., Crippen, R., Duren, R., Hensley, S., ... Alsdorf, D. (2007). The Shuttle Radar Topography Mission. Reviews of Geophysics, 45(2). https://doi.org/10.1029/2005RG000183

Fearnside, P. M. (2019). Hidrelétricas na Amazônia: impactos ambientais e sociais na tomada de decisões sobre grandes obras (in portuguese) (Vol. 3). Retrieved from http://inctservamb.inpa.gov.br/publ_livres/2019/Hidro-v3/Livro_Hidrelétricas_Vol_3.pdf\#page=7

Feldpausch, T R, Lloyd, J., Lewis, S. L., Brienen, R. J. W., Gloor, M., Monteagudo Mendoza, A., ... Phillips, O. L. (2012). Tree height integrated into pantropical forest biomass estimates. Biogeosciences, 9(8), 3381-3403. https://doi.org/10.5194/bg-9-3381-2012 
Feldpausch, Ted R, Rondon, M. A., Fernandes, E. C. M., Riha, S. J., \& Wandelli, E. (2004). Carbon and nutrient accumulation in secondary forests regenerating on pastures in Central Amazonia. Ecological Applications, 14(sp4), 164-176. https://doi.org/10.1890/01-6015

Feng, H. (2016). Individual contributions of climate and vegetation change to soil moisture trends across multiple spatial scales. Scientific Reports, 6(August), 1-6. https://doi.org/10.1038/srep32782

Feng, H., \& Liu, Y. (2015). Combined effects of precipitation and air temperature on soil moisture in different land covers in a humid basin. Journal of Hydrology, 531, 1129-1140. https://doi.org/10.1016/j.jhydrol.2015.11.016

Ferreira Junior, P., Sousa, A. M., Vitorino, M. I., Souza, E. B. De, \& Souza, P. J. O. P. de. (2013). Estimate of evapotranspiration in eastern Amazonia using SEBAL. Revista de Ciências Agrarias - Amazon Journal of Agricultural and Environmental Sciences, 56(1), 33-39. https://doi.org/10.4322/rca.2013.001

Finnigan, J. J., Clement, R., Malhi, Y., Leuning, R., \& Cleugh, H. A. (2003). A Re-Evaluation of Long-Term Flux Measurement Techniques Part I: Averaging and Coordinate Rotation. Boundary-Layer Meteorology, 107(1), 1-48. https://doi.org/10.1023/A:1021554900225

Fitzjarrald, D. R., Stormwind, B. L., Fisch, G., \& Cabral, O. M. R. (1988). Turbulent transport observed just above the Amazon forest. Journal of Geophysical Research: Atmospheres, 93(D2), 1551-1563. https://doi.org/10.1029/JD093iD02p01551

Foken, T. (2008). The energy balance closure problem: an overview. Ecological Applications, 18(6), 1351-1367. https://doi.org/10.1890/06-0922.1

Folhes, R. T., Aguiar, A. P. D. de, Stoll, E., Dalla-Nora, E. L., Araújo, R., Coelho, A., \& Canto, O. do. (2015). Multi-scale participatory scenario methods and territorial planning in the Brazilian Amazon. Futures, 73, 86-99. https://doi.org/10.1016/j.futures.2015.08.005

Franken, W., \& Leopoldo, P. (1984). Hydrology of catchment areas of Central-Amazonian forest streams. In Sioli H (Ed.), The Amazon: limnology and landscape ecology of a mighty tropical river and its basin (pp. 501-519). Dordrecht: Junk,.

Fu, R., \& Li, W. (2004). The influence of the land surface on the transition from dry to wet season in Amazonia. Theoretical and Applied Climatology, 78(1), 97-110. https://doi.org/10.1007/s00704-004-0046-7

FURNAS Centrais Elétricas SA. (1996). Reservatório UHE Serra da Mesa Minaçu, Goiás.

Fyllas, N. M., Patiño, S., Baker, T. R., Bielefeld Nardoto, G., Martinelli, L. A., Quesada, C. A., ... Lloyd, J. (2009). Basin-wide variations in foliar properties of Amazonian forest: phylogeny, soils and climate. Biogeosciences, 6(11), 2677-2708. https://doi.org/10.5194/bg-6-2677-2009

Gama, W. N. G. (1997). O Projeto Dinâmica Biológica de Fragmentos Florestais - PDBFF (INPA/SMITHSONIAN) : uma base científica norte-americana na Amazônia Brasileira. Federal University of Pará.

Gehring, C., Denich, M., \& Vlek, P. L. G. (2005). Resilience of secondary forest regrowth after slash-and-burn agriculture in central Amazonia. Journal of Tropical Ecology, 21(5), 519-527. https://doi.org/10.1017/s0266467405002543

Giambelluca, T. W. (2002). Hydrology of altered tropical forest. Hydrological Processes. https://doi.org/10.1002/hyp.5021

Giambelluca, T. W., Hölscher, D., Bastos, T. X., Frazão, R. R., Nullet, M. A., \& Ziegler, A. D. 
(1997). Observations of Albedo and Radiation Balance over Postforest Land Surfaces in the Eastern Amazon Basin. JOURNAL OF CLIMATE, 10, 919-928.

Giambelluca, T. W., Ziegler, A. D., Nullet, M. a., Truong, D. M., \& Tran, L. T. (2003). Transpiration in a small tropical forest patch. Agricultural and Forest Meteorology, 117(1-2), 1-22. https://doi.org/10.1016/S0168-1923(03)00041-8

Gordon, C., Cooper, C., Senior, C. A., Banks, H., Gregory, J. M., Johns, T. C., ... Wood, R. A. (2000). The simulation of SST, sea ice extents and ocean heat transports in a version of the Hadley Centre coupled model without flux adjustments. Climate Dynamics, 16(2), 147-168. https://doi.org/10.1007/s003820050010

Gu, L., Massman, W. J., Leuning, R., Pallardy, S. G., Meyers, T., Hanson, P. J., ... Yang, B. (2012). Agricultural and Forest Meteorology The fundamental equation of eddy covariance and its application in flux measurements §. 152, 135-148. https://doi.org/10.1016/j.agrformet.2011.09.014

Guimberteau, M., Ciais, P., Pablo Boisier, J., Paula Dutra Aguiar, A., Biemans, H., De Deurwaerder, H., ... Verbeeck, H. (2017). Impacts of future deforestation and climate change on the hydrology of the Amazon Basin: A multi-model analysis with a new set of land-cover change scenarios. Hydrology and Earth System Sciences, 21(3). https://doi.org/10.5194/hess21-1455-2017

Hahner, I. (2009). Luis Eduardo Magalhães - Lajeado Hydroelectric Power Plant on The Tocantins River. In Main Brazilians Dams III - Design, Construction and Performance, 2009. Retrieved from http://www.cbdb.org.br/documentos/mbdiii/lajeado.pdf

Harper, A., Baker, I. T., Denning, A. S., Randall, D. A., Dazlich, D., \& Branson, M. (2014). Impact of evapotranspiration on dry season climate in the Amazon forest. Journal of Climate, 27(2), 574-591. https://doi.org/10.1175/JCLI-D-13-00074.1

Hartogensis, O. K., Watts, C. J., Rodriguez, J.-C., \& De Bruin, H. A. R. (2003). Derivation of an Effective Height for Scintillometers: La Poza Experiment in Northwest Mexico. Journal of Hydrometeorology, 4(5), 915-928. Retrieved from https://doi.org/10.1175/15257541(2003)004\%3C0915:DOAEHF\%3E2.0.CO

Hasler, N., \& Avissar, R. (2007). What Controls Evapotranspiration in the Amazon Basin? Journal of Hydrometeorology, 8(3), 380-395. Retrieved from http://www.jstor.org/stable/24911441

Hemakumara, H. M., Chandrapala, L., \& Moene, A. F. (2003). Evapotranspiration fluxes over mixed vegetation areas measured from large aperture scintillometer. Agricultural Water Management, 58(2), 109-122. https://doi.org/https://doi.org/10.1016/S0378-3774(02)00131-2

Hill, R. J. (1992). Review of optical scintillation methods of measuring the refractive-index spectrum, inner scale and surface fluxes. Waves in Random Media, 2(3), 179-201. https://doi.org/10.1088/0959-7174/2/3/001

Hirano, T., Kusin, K., Limin, S., \& Osaki, M. (2015). Evapotranspiration of tropical peat swamp forests. Global Change Biology, 21(5), 1914-1927. https://doi.org/10.1111/gcb.12653

Hodnett, M. G., da Silva, L. P., da Rocha, H. R., \& Senna, R. C. (1995). Seasonal soil water storage changes beneath central Amazonian rainforest and pasture. Journal of Hydrology, 170(1), 233254. https://doi.org/https://doi.org/10.1016/0022-1694(94)02672-X

Hodnett, M. G., Oyama, M. D., Tomasella, J., \& Marques-Filho, A. O. (1996). Comparison of longterm soil water storage behaviour under pasture and forest in three areas of Amazonia. In J. H. C. Gash, C. A. Nobre, J. ROBERTS, \& R. L. Victoria (Eds.), Amazonian deforestation and 
climate. (pp. 57-77).

Hodnett, M. G., Tomasella, J., Marques-Filho, A. O., \& Oyama, M. D. (1996). Deep soil water uptake by forest and pasture in central Amazonia: predictions from long-term daily rainfall data using a simple water balance model. In John H C Gash, C. A. Nobre, J. ROBERTS, \& R. L. Victoria (Eds.), Amazonian Deforestation and Climate (pp. 79-99).

Horner, N., Silberglitt, R., Poppe, M. K., \& Rocha, B. B. (2016). Energy foresight, scenarios and sustainable energy policy in Brazil. Foresight, 18(5), 535-550. https://doi.org/10.1108/FS-062015-0035

IBGE. (1992). RADAM - Banco de dados georeferenciado sobre recursos naturais Instituto Brasileiro de Geografia e Estatística. Retrieved January 15, 2018, from http://mapas.ibge.gov.br/bases-e-referenciais/bases-cartograficas/cartas

INPE. (2016). TerraClass - Amazon land use database. Retrieved May 8, 2019, from http://www.inpe.br/cra/projetos_pesquisas/arquivos/TerraClass_2014_v3.pdf

IPCC. (2013). Climate Change 2013: The Physical Science Basis. Contribution of Working Group I to the Fifth Assessment Report of the Intergovernmental Panel on Climate Change (T. F. Stocker, D. Qin, G.-K. Plattner, M. Tignor, S. K. Allen, J. Boschung, ... P. M. Midgley, Eds.).

Iwata, H., Malhi, Y., \& von Randow, C. (2005). Gap-filling measurements of carbon dioxide storage in tropical rainforest canopy airspace. Agricultural and Forest Meteorology, 132(3), 305-314. https://doi.org/https://doi.org/10.1016/j.agrformet.2005.08.005

Jarvis, P. G. (1976). The interpretation of the variations in leaf water potential and stomatal conductance found in canopies in the field. Philosophical Transactions of the Royal Society of London. B, Biological Sciences, 273(927), 593-610. https://doi.org/10.1098/rstb.1976.0035

Jarvis, P. G., \& McNaughton, K. G. (1986). Stomatal Control of Transpiration: Scaling Up from Leaf to Region (A. MacFadyen \& E. D. Ford, Eds.). In (pp. 1-49). https://doi.org/https://doi.org/10.1016/S0065-2504(08)60119-1

Joly, C., Scarano, F., Seixas, C., Metzger, J., Ometto, J., Bustamante, M., ... Toledo, P. (2019). $1^{\circ}$ Diagnóstico Brasileiro de Biodiversidade \& Serviços Ecossistêmicos. https://doi.org/10.4322/978-85-60064-88-5

Jones, R. N. (2000). Managing Uncertainty in Climate Change Projections - Issues for Impact Assessment. Climatic Change, 45(3), 403-419. https://doi.org/10.1023/A:1005551626280

Juárez, R. I. N., Hodnett, M. G., Fu, R., Goulden, M. L., \& von Randow, C. (2007). Control of Dry Season Evapotranspiration over the Amazonian Forest as Inferred from Observations at a Southern Amazon Forest Site. Journal of Climate, 20(12), 2827-2839. https://doi.org/10.1175/JCLI4184.1

Kanda, M., Inagaki, A., Letzel, M. O., Raasch, S., \& Watanabe, T. (2004). LES Study of the Energy Imbalance Problem with Eddy Covariance Fluxes. Boundary-Layer Meteorology, 110(3), 381404. https://doi.org/10.1023/B:BOUN.0000007225.45548.7a

Krause, P., Boyle, D. P., \& Bäse, F. (2005). Comparison of different efficiency criteria for hydrological model assessment. Advances in Geosciences, 5, 89-97. https://doi.org/10.5194/adgeo-5-89-2005

Kruijt, B., Elbers, J. A., von Randow, C., Araújo, A. C., Oliveira, P. J., Culf, A., .. Moors, E. J. (2004). The robustness of eddy correlation fluxes for Amazon rain forest conditions. Ecological Applications, 14(sp4), 101-113. https://doi.org/10.1890/02-6004 
Kunert, N., Aparecido, L. M. T., Higuchi, N., Santos, J. dos, \& Trumbore, S. (2015). Higher tree transpiration due to road-associated edge effects in a tropical moist lowland forest. Agricultural and Forest Meteorology, 213, 183-192. https://doi.org/10.1016/j.agrformet.2015.06.009

Lambers, H., Chapin, R. S., \& Pons, T. L. (2008). Plant Phydiological Ecology. New York: Springer.

Lasslop, G., Reichstein, M., Papale, D., Richardson, A., Arneth, A., Barr, A., ... Wohlfahrt, G. (2010). Separation of net ecosystem exchange into assimilation and respiration using a light response curve approach: Critical issues and global evaluation. Global Change Biology, 16(1), 187-208. https://doi.org/10.1111/j.1365-2486.2009.02041.x

Lathuillière, M. J., Johnson, M. S., \& Donner, S. D. (2012). Water use by terrestrial ecosystems: Temporal variability in rainforest and agricultural contributions to evapotranspiration in Mato Grosso, Brazil. Environmental Research Letters, 7(2). https://doi.org/10.1088/17489326/7/2/024024

Laurance, W. F., \& Williamson, G. B. (2001). Positive Feedbacks among Forest Fragmentation, Drought, and Climate Change in the Amazon. Conservation Biology, 15(6), 1529-1535. https://doi.org/10.1046/j.1523-1739.2001.01093.x

Leite, C. C., Costa, M. H., de Lima, C. A., Ribeiro, C. A. A. S., \& Sediyama, G. C. (2011). Historical reconstruction of land use in the Brazilian Amazon (1940-1995). Journal of Land Use Science, 6(1), 33-52. https://doi.org/10.1080/1747423X.2010.501157

Lenderink, G., Buishand, A., \& van Deursen, W. (2007). Estimates of future discharges of the river Rhine using two scenario methodologies: direct versus delta approach. Hydrology and Earth System Sciences, 11(3), 1145-1159. https://doi.org/10.5194/hess-11-1145-2007

Leuning, R. (2007). The correct form of the Webb, Pearman and Leuning equation for eddy fluxes of trace gases in steady and non-steady state, horizontally homogeneous flows. BoundaryLayer Meteorology, 123(2), 263-267. https://doi.org/10.1007/s10546-006-9138-5

Ley, R., Casper, M. C., Hellebrand, H., \& Merz, R. (2011). Catchment classification by runoff behaviour with self-organizing maps (SOM). Hydrology and Earth System Sciences. https://doi.org/10.5194/hess-15-2947-2011

Lima, L. S., Coe, M. T., Soares Filho, B. S., Cuadra, S. V., Dias, L. C. P., Costa, M. H., ... Rodrigues, H. O. (2014). Feedbacks between deforestation, climate, and hydrology in the Southwestern Amazon: Implications for the provision of ecosystem services. Landscape Ecology, 29(2), 261-274. https://doi.org/10.1007/s10980-013-9962-1

Lopes, A. P., Nelson, B. W., Wu, J., Graça, P. M. L. de A., Tavares, J. V., Prohaska, N., ... Saleska, S. R. (2016). Leaf flush drives dry season green-up of the Central Amazon. Remote Sensing of Environment, 182, 90-98. https://doi.org/10.1016/j.rse.2016.05.009

Lucas, R. M., Honzák, M., Amaral, I. Do, Curran, P. J., \& Foody, G. M. (2002). Forest regeneration on abandoned clearances in central Amazonia. International Journal of Remote Sensing, 23(5), 965-988. https://doi.org/10.1080/01431160110069791

Macedo, M. N., DeFries, R. S., Morton, D. C., Stickler, C. M., Galford, G. L., \& Shimabukuro, Y. E. (2012). Decoupling of deforestation and soy production in the southern Amazon during the late 2000s. Proceedings of the National Academy of Sciences, 109(4), 1341-1346. https://doi.org/10.1073/pnas.1111374109

Malhi, Y., Aragão, L. E. O. C., Galbraith, D., Huntingford, C., Fisher, R., Zelazowski, P., ... Meir, 
P. (2009). Exploring the likelihood and mechanism of a climate-change-induced dieback of the Amazon rainforest. Proceedings of the National Academy of Sciences, 106(49), 20610-20615. https://doi.org/10.1073/pnas.0804619106

Malhi, Y., Aragão, L. E. O. C., Metcalfe, D. B., Paiva, R., Quesada, C. A., Almeida, S., ... Teixeira, L. M. (2009). Comprehensive assessment of carbon productivity, allocation and storage in three Amazonian forests. Global Change Biology, 15(5), 1255-1274. https://doi.org/10.1111/j.1365-2486.2008.01780.x

Mallick, K., Trebs, I., Boegh, E., Giustarini, L., Schlerf, M., Drewry, D. T., ... Wofsy, S. C. (2016). Canopy-scale biophysical controls of transpiration and evaporation in the Amazon Basin. Hydrology and Earth System Sciences, 20(10). https://doi.org/10.5194/hess-20-4237-2016

Marengo, J. A., Miller, J. R., Russell, G. L., Rosenzweig, C. E., \& Abramopoulos, F. (1994). Calculations of river-runoff in the GISS GGM: impact of a new land-surface parameterization and runoff routing model on the hydrology of the Amazon River. Climate Dynamics, 10(6-7), 349-361. https://doi.org/10.1007/BF00228032

Marengo, Jose A., Soares, W. R., Saulo, C., \& Nicolini, M. (2004). Climatology of the low-level jet east of the Andes as derived from the NCEP-NCAR reanalyses: Characteristics and temporal variability. Journal of Climate, 17(12), 2261-2280. https://doi.org/10.1175/15200442(2004)017<2261:COTLJE >2.0.CO;2

Marengo, Jose A, Chou, S. C., Kay, G., Alves, L. M., Pesquero, J. F., Soares, W. R., ... Tavares, P. (2012). Development of regional future climate change scenarios in South America using the Eta CPTEC/HadCM3 climate change projections: climatology and regional analyses for the Amazon, São Francisco and the Paraná River basins. Climate Dynamics, 38(9), 1829-1848. https://doi.org/10.1007/s00382-011-1155-5

Marques, J. D. de O., Luizão, F. J., Teixeira, W. G., Sarrazin, M., Ferreira, S. J. F., Beldini, T. P., \& Marques, E. M. de A. (2015). Distribution of Organic Carbon in Different Soil Fractions in Ecosystems of Central Amazonia. Revista Brasileira de Ciência Do Solo, 39(1), 232-242. https://doi.org/10.1590/01000683rbcs20150142

Marques, J. D. O. M. (2009). Influência De Atributos Físicos E Hídricos Do Solo Na Dinâmica Do Carbono Orgânico Sob Diferentes Coberturas Vegetais Na Amazonia Central. 279.

Martins-Filho, G., Porto, M. A., \& Werner Jr, D. (2009). The Peixe Angical Hydroelectric Development on the Tocantins River. In Main Brazilians Dams III - Design, Construction and Performance. Retrieved from http://www.cbdb.org.br/documentos/mbdiii/peixeang.pdf

Martins, P. T. de A., Matos, R. M. P., Bueno, A. F., \& Paixão, A. C. S. S. (2015). Land use and land cover change of high Tocantins river basin (Goias, Brazil): Influence of physical characteristics and the relation with the indigenous communities. Ciência e Natura; Vol 37, No 3 (2015). https://doi.org/10.5902/2179460X15780

Massman, W. J., \& Lee, X. (2002). Eddy covariance flux corrections and uncertainties in long-term studies of carbon and energy exchanges.

McGrath, D. A., Smith, C. K., Gholz, H. L., \& Oliveira, F. de A. (2001). Effects of Land-Use Change on Soil Nutrient Dynamics in Amazônia. Ecosystems, 4(7), 625-645. https://doi.org/10.1007/s10021-001-0033-0

McMillen, R. T. (1988). An eddy correlation technique with extended applicability to non-simple terrain. Boundary-Layer Meteorology, 43(3), 231-245. https://doi.org/10.1007/BF00128405

MCTIC. (2017). Sistema de Registro Nacional de Emissões. 
Meijninger, W. M. L., Hartogensis, O. K., Kohsiek, W., Hoedjes, J. C. B., Zuurbier, R. M., \& De Bruin, H. A. R. (2002). Determination of Area-Averaged Sensible Heat Fluxes with a Large Aperture Scintillometer over a Heterogeneous Surface -- Flevoland Field Experiment. Boundary-Layer Meteorology, 105(1), 37-62. https://doi.org/10.1023/A:1019647732027

Meir, P., Brando, P. M., Nepstad, D., Vasconcelos, S., Costa, A. C. L., Davidson, E., ... Cardinot, G. (2013). The Effects of Drought on Amazonian Rain Forests. In Amazonia and Global Change (pp. 429-449). https://doi.org/10.1029/2008GM000718

Mesquita, R. C. G., Ickes, K., Ganade, G., \& Williamson, G. B. (2001). Alternative successional pathways in the Amazon Basin. 528-537.

MMA. (2006). Caderno da Região Hidrográfica do Tocantins-Araguaia Ministério do Meio Ambiente Brasília, DF, Brazil. Retrieved from http://www.mma.gov.br/estruturas/161/_publicacao/161_publicacao02032011035943.pdf

Mohor, G. S., Rodriguez, D. A., Tomasella, J., \& Siqueira Júnior, J. L. (2015). Exploratory analyses for the assessment of climate change impacts on the energy production in an Amazon run-ofriver hydropower plant. Journal of Hydrology: Regional Studies, 4, 41-59. https://doi.org/10.1016/j.ejrh.2015.04.003

Moncrieff, J. B., Massheder, J. M., de Bruin, H., Elbers, J., Friborg, T., Heusinkveld, B., ... Verhoef, A. (1997). A system to measure surface fluxes of momentum, sensible heat, water vapour and carbon dioxide. Journal of Hydrology, 188-189, 589-611. https://doi.org/https://doi.org/10.1016/S0022-1694(96)03194-0

Moreira, M. P. (2003). Uso de sensoriamento remoto para avaliar a dinâmica de sucessão secundária na Amazônia Central. Universidade Federal do Amazonas.

Moriasi, D. N., Arnold, J. G., Van Liew, M. W., Bingner, R. L., Harmel, R. D., Veith, T. L., ... L. Veith, T. (2007). Model Evaluation Guidelines for Systematic Quantification of Accuracy in Watershed Simulations. Transactions of the ASABE, 50(3), 885-900. https://doi.org/https://doi.org/10.13031/2013.23153

Nakicenovic, N. J., Alcamo, J., Davis, G., Vries, B., Fenhann, J., Gaffin, S., ... Z., D. (2000). IPCC Special Report on Emissions Scenarios. Retrieved from https:/www.ipcc.ch/pdf/specialreports/emissions_scenarios.pdf

Nee, M. (1995). Flora preliminar do Projeto Dinâmica Biológica de Fragmentos Florestais $(P D B F F)$. Retrieved from https://books.google.com.br/books?id=ThAmAQAAMAAJ

Nobre, C. A., Fisch, G., da Rocha, H. R., Lyra, R. F., da Rocha, E. P., da Costa, A. C. L., \& Ubarana, V. N. (1996). Observations of the atmospheric boundary layer in Rondônia. In J.H.C. Gash, C. A. Nobre, J. Roberts, \& R. L. Victoria (Eds.), Amazonian deforestation and climate (pp. 437-458). Wiley, Chichester.

Nóbrega, M. T., Collischonn, W., Tucci, C. E. M., \& Paz, A. R. (2011). Uncertainty in climate change impacts on water resources in the Rio Grande Basin, Brazil. Hydrology and Earth System Sciences, 15(2), 585-595. https://doi.org/10.5194/hess-15-585-2011

Oliveira, M. B. L., von Randow, C., Manzi, A. O., Alvalá, R. C. S., Sá, L. D. A., Leitão, M. M. V. B. R., \& Souza, A. (2006). Fluxos turbulentos de energia sobre o Pantanal Sul MatoGrossense. Revista Brasileira de Meteorologia, 21(3), 371-377. Retrieved from http://www.rbmet.org.br/port/revista/revista_artigo.php?id_artigo=232

Oliveira Mesquita, S. H. (2006). Consequências de sítios arqueológicos escavados e não inundados pelo lago da usina Hidrelétrica de Serra da Mesa (in portuguese). Pontifícia Universidade 


\section{Católica de Goiás.}

Paish, O. (2002). Small hydro power: technology and current status. Renewable and Sustainable Energy Reviews, 6(6), 537-556. https://doi.org/10.1016/S1364-0321(02)00006-0

Pan, Y., Birdsey, R. A., Fang, J., Houghton, R., Kauppi, P. E., Kurz, W. A., ... Hayes, D. (2011). A large and persistent carbon sink in the world's forests. Science, 333(6045), 988-993. https://doi.org/10.1126/science.1201609

Papale, D., Reichstein, M., Aubinet, M., Canfora, E., Bernhofer, C., Kutsch, W., ... Yakir, D. (2006). Towards a standardized processing of Net Ecosystem Exchange measured with eddy covariance technique: algorithms and uncertainty estimation. Biogeosciences, 3(4), 571-583. https://doi.org/10.5194/bg-3-571-2006

Poveda, G., Jaramillo, L., \& Vallejo, L. F. (2014). Seasonal precipitation patterns along pathways of South American low-level jets and aerial rivers. Water Resources Research, 50(1), 98-118. https://doi.org/10.1002/2013WR014087

Prestele, R., Alexander, P., Rounsevell, M., Arneth, A., Calvin, K., Doelman, J., ... Verburg, P. H. (2016). Hotspots of uncertainty in land use and land cover change projections: a global scale model comparison. Global Change Biology. https://doi.org/10.1111/gcb.13337

Ranzani, G. (1980). Identificação e caracterização de alguns solos da Estação Experimental de Silvicultura Tropical do INPA. Acta Amazonica, 10, 7-41.

Raskin, P., Monks, F., Ribeiro, T., van Vuuren, D., \& Zurek, M. (2005). Global scenarios in historical perspectives. In P. Carpenter, E. Bennett, \& M. Zurek (Eds.), Ecosystems and human well-being: scenarios volume 2: findings of the scenarios working group of the millennium ecosystem assessment (pp. 35-34). Washington, DC: Island Press.

Reichstein, M., Falge, E., Baldocchi, D., Papale, D., Aubinet, M., Berbigier, P., ... Valentini, R. (2005). On the separation of net ecosystem exchange into assimilation and ecosystem respiration: review and improved algorithm. Global Change Biology, 11(9), 1424-1439. https://doi.org/10.1111/j.1365-2486.2005.001002.x

Restrepo-Coupe, N., da Rocha, H. R., Hutyra, L. R., da Araujo, A. C., Borma, L. S., Christoffersen, B., ... Saleska, S. R. (2013). What drives the seasonality of photosynthesis across the Amazon basin? A cross-site analysis of eddy flux tower measurements from the Brasil flux network. Agricultural and Forest Meteorology, 182-183, 128-144. https://doi.org/10.1016/j.agrformet.2013.04.031

Roberts, J. M. (2009). The role of forests in the hydrological cycle. In J. N. Owens \& H. Gyde Lund (Eds.), Forests And Forest Plants - Volume III (pp. 42-76). EOLSS Publications.

Rocha, G. P. E., Vieira, D. L. M., \& Simon, M. F. (2016). Fast natural regeneration in abandoned pastures in southern Amazonia. Forest Ecology and Management, 370, 93-101. https://doi.org/10.1016/j.foreco.2016.03.057

Rodrigues, T. R., Vourlitis, G. L., Lobo, F. de A., Santanna, F. B., de Arruda, P. H. Z., \& Nogueira, J. de S. (2016). Modeling canopy conductance under contrasting seasonal conditions for a tropical savanna ecosystem of south central Mato Grosso, Brazil. Agricultural and Forest Meteorology, 218-219, 218-229. https://doi.org/10.1016/j.agrformet.2015.12.060

Rodriguez, D. A., \& Tomasella, J. (2016). On the ability of large-scale hydrological models to simulate land use and land cover change impacts in Amazonian basins. Hydrological Sciences Journal, 61(10), 1831-1846. https://doi.org/10.1080/02626667.2015.1051979

Rodriguez, D. A., Tomasella, J., \& Linhares, C. (2010). Is the forest conversion to pasture affecting 
the hydrological response of Amazonian catchments? Signals in the Ji-Paraná Basin. Hydrological Processes, 24(10), 1254-1269. https://doi.org/10.1002/hyp.7586

Salati, E., \& Nobre, C. A. (1991). Possible climatic impacts of tropical deforestation. Climatic Change, 19(1), 177-196. https://doi.org/10.1007/BF00142225

Salazar, J. F., Villegas, J. C., Rendón, A. M., Rodríguez, E., Hoyos, I., Mercado-bettín, D., \& Poveda, G. (2018). Scaling properties reveal regulation of river flows in the Amazon through a “ forest reservoir ." Hydrol. Earth Syst. Sci., 22, 1735-1748. https://doi.org/10.5194/hess-22$1735-2018$

Schotanus, R., Nieuwstadt, F. T. M., \& De Bruin, H. A. R. (1983). Temperature measurements with a sonic anemometer and its application to heat and moisture fluxes. Boundary-Layer Meteorology, 26, 81-93.

Sellers, P. J., Mintz, Y., Sud, Y. C., \& Dalcher, A. (1986). A Simple Biosphere Model (SIB) for Use within General Circulation Models. Journal of the Atmospheric Sciences, 43(6), 505-531. https://doi.org/10.1175/1520-0469(1986)043<0505:ASBMFU>2.0.CO;2

Sestini, M. F., Alvala, R. C. S., Mello, E. M. K., Valeriano, D. M., Chou, S. C., Nobre, C. A., ... Reimer, E. S. (2002). Elaboração de Mapas de Vegetação para Utilização em Modelos Meteorológicos e Hidrológicos - PROVEG (In Portuguese). Retrieved from http://proveg.cptec.inpe.br/ rproveg/pdf/relatorio_proveg.pdf

Shuttleworth, W. J. (1988). Evaporation from Amazonian rainforest. Proceedings - Royal Society of London, Series B, 233(1272), 321-346. https://doi.org/10.1098/rspb.1988.0024

Shuttleworth, W. J., Gash, J. H. C., Lloyd, C. R., Moore, C. J., Roberts, J. T., Filho, A. O. M., ... Moraes, J. C. (1984). Eddy correlation measurements of energy partition for Amazonian forest. Quarterly Journal of the Royal Meteorological Society, 110(466), 1143-1162. https://doi.org/10.1002/qj.49711046622

SIPOT-Eletrobrás. (2018). Potencial Hidrelétrico Brasileiro em Cada Estágio por Bacia Hidrográfica (in Portuguese). Retrieved December 8, 2019, from https://eletrobras.com/pt/AreasdeAtuacao/geracao/sipot/Potencial Hidrelétrico Brasileiro por Bacias - Dezembro 2018.pdf

Siqueira Jr, J. L., Tomasella, J., \& Rodriguez, D. A. (2015). Impacts of future climatic and land cover changes on the hydrological regime of the Madeira River basin. Climatic Change, 129(1), 117-129. https://doi.org/10.1007/s10584-015-1338-x

Soares, W., \& Marengo, J. (2009). Assessments of moisture fluxes east of the Andes in South America in a global warming scenario. International Journal of Climatology, 29, 1395-1414. https://doi.org/10.1002/joc. 1800

Souza, P. J. de O. P. de, Ribeiro, A., Rocha, E. J. P. da, Farias, J. R. B., \& Souza, E. B. de. (2012). Sazonalidade no balanço de energia em áreas de cultivo de soja na Amazônia. Bragantia, 71(4), 548-557. https://doi.org/10.1590/S0006-87052012000400013

Souza Filho, J. D. da C., Ribeiro, A., Costa, M. H., \& Cohen, J. C. P. (2005). Mecanismos de controle da variação sazonal da transpiração de uma floresta tropical no nordeste da amazônia . Acta Amazonica, Vol. 35, pp. 223-229. scielo .

Staal, A., Tuinenburg, O. A., Bosmans, J. H. C., Holmgren, M., Nes, E. H. Van, Scheffer, M., ... Dekker, S. C. (2018). Forest-rainfall cascades buffer against drought across the Amazon. Nature Climate Change. https://doi.org/10.1038/s41558-018-0177-y

Stewart, J. W. B. (1988). Modelling Surface Conductance of Pine Forest. Elsevier - Agricultural 
and Forest Meteorology, 43(1), 19-35. https://doi.org/10.1016/0168-1923(88)90003-2

Stickler, C. M., Coe, M. T., Costa, M. H., Nepstad, D. C., McGrath, D. G., Dias, L. C. P., ... Soares-Filho, B. S. (2013). Dependence of hydropower energy generation on forests in the Amazon Basin at local and regional scales. Proceedings of the National Academy of Sciences of the United States of America, 110(23), 9601-9606. https://doi.org/10.1073/pnas.1215331110

Teutschbein, C., \& Seibert, J. (2013). Is bias correction of regional climate model (RCM) simulations possible for non-stationary conditions? Hydrology and Earth System Sciences, 17(12), 5061-5077. https://doi.org/10.5194/hess-17-5061-2013

Tomasella, J., Rodriguez, D., Cuartas, L., Ferreira, M., Ferreira, J., \& Marengo, J. (2009). Estudo de impacto das mudanças climáticas sobre os recursos hídricos superficiais e sobre os níveis dos aquíferos na bacia do rio Tocantins (in Portuguese). Convênio de Cooperação TécnicoCientífica INPE-VALE, INPE, São José dos Campos, SP, Brazil.

Tomasella, Javier, Hodnett, M. G., Cuartas, L. A., Nobre, A. D., Waterloo, M. J., \& Oliveira, S. M. (2008). The water balance of an Amazonian micro-catchment: the effect of interannual variability of rainfall on hydrological behaviour. HYDROLOGICAL PROCESSES, 22(13), 2133-2147. https://doi.org/10.1002/hyp.6813

Tractebel Energia. (2010). Demonstrações contábeis dos exercícios de 2009 e de 2008 (in portuguese). $\quad$ Retrieved January 15, 2018, from http://www.engieenergia.com.br/wps/wcm/connect/138172b9-bbc5-4ab4-9417-

7121359fec17/231636pdf?MOD=AJPERES\&CACHEID=ROOTWORKSPACE138172b9bbc5-4ab4-9417-7121359fec17

Van Baalen, A. (2010). Evapotranspiration in a secondary rainforest in Amazonia. The effect of forest fragmentation on the hydrological cycle. Wageningen University and Research centre, Wageningen, The Netherlands.

Verburg, R., Rodrigues, S., Lindoso, D., Debortoli, N., Litre, G., \& Bursztyn, M. (2014). Land Use Policy The impact of commodity price and conservation policy scenarios on deforestation and agricultural land use in a frontier area within the Amazon. Land Use Policy, 37, 14-26. https://doi.org/10.1016/j.landusepol.2012.10.003

Victoria, R. L., Martinelli, L. A., Mortatti, J., \& Richey, J. (1991). Mechanisms of Water Recycling in the Amazon Basin: Isotopic Insights. Ambio, 20(8), 384-387. Retrieved from http://www.jstor.org/stable/4313869

Vieira, E., \& Martin, P. (2015). Forest Ecology and Management Secondary vegetation in central Amazonia: Land-use history effects on aboveground biomass. Forest Ecology and Management, 347, 140-148. https://doi.org/10.1016/j.foreco.2015.03.020

Vogel, R., \& Fennessey, N. (1994). Flow-Duration Curves. I: New Interpretation and Confidence Intervals. Journal of Water Resources Planning and Management, 120(4), 485-504. https://doi.org/10.1061/(ASCE)0733-9496(1994)120:4(485)

Vogel, R. M., \& Fennessey, N. M. (1995). Flow duration curves ii: A review of applications in water resources planning. Journal of the American Water Resources Association, 31(6), 10291039. https://doi.org/10.1111/j.1752-1688.1995.tb03419.x

Von Randow, C., Manzi, A. O., Kruijt, B., de Oliveira, P. J., Zanchi, F. B., Silva, R. L., ... Kabat, P. (2004). Comparative measurements and seasonal variations in energy and carbon exchange over forest and pasture in South West Amazonia. Theoretical and Applied Climatology, 78(1- 


\section{3), 5-26. https://doi.org/10.1007/s00704-004-0041-z}

Von Randow, C., Zeri, M., Restrepo-Coupe, N., Muza, M. N., de Gonçalves, L. G. G., Costa, M. H., ... Yang, Z. L. (2013). Inter-annual variability of carbon and water fluxes in Amazonian forest, Cerrado and pasture sites, as simulated by terrestrial biosphere models. Agricultural and Forest Meteorology, 182-183, 145-155. https://doi.org/10.1016/j.agrformet.2013.05.015

Von Randow, R. C. S., Tomasella, J., Von Randow, C., Araújo, A. C. de, \& Manzi, A. O. (2017). Secondary forest as a counterbalance on the deforestation effects: its role on evapotranspiration and water use efficiency. 19th EGU General Assembly, EGU2017-10724. Vienna: Geophysical Research Abstracts.

Von Randow, R. C. S., Von Randow, C., Hutjes, R. W. A., Tomasella, J., \& Kruijt, B. (2012). Evapotranspiration of deforested areas in central and southwestern Amazonia. Theoretical and Applied Climatology, 109(1-2), 205-220. https://doi.org/10.1007/s00704-011-0570-1

Von Randow, R. C. S., Rodriguez, D. A., Tomasella, J., Aguiar, A. P. D., Kruijt, B., \& Kabat, P. (2019). Response of the river discharge in the Tocantins River Basin, Brazil, to environmental changes and the associated effects on the energy potential. Regional Environmental Change, 19(1), 193-204. https://doi.org/10.1007/s10113-018-1396-5

Vörösmarty, C. J., Moore III, B., Grace, A. L., Gildea, M. P., Melillo, J. M., Peterson, B. J., ... Steudler, P. A. (1989). Continental scale models of water balance and fluvial transport: An application to South America. Global Biogeochemical Cycles, 3(3), 241-265. https://doi.org/10.1029/GB003i003p00241

Walker, R., Defries, R., Vera-diaz, M. C., Shimabukuro, Y., \& Venturieri, A. (2009). The Expansion of Intensive Agriculture and Ranching in Brazilian Amazonia. In M. Keller, M. Bustamante, J. Gash, \& P. S. Dias (Eds.), Amazonia and Global Change (1st ed., pp. 61-81). Washington, DC: American Geophysical Union.

Wang, Y. Q., \& Shao, M. A. (2013). Spatial variability of soil physical properties in a region of the Loess plateau of PR China subject to wind and water erosion. Land Degradation \& Development, 24(3), 296-304. https://doi.org/10.1002/ldr.1128

Werth, D., \& Avissar, R. (2004). The Regional Evapotranspiration of the Amazon. Journal of Hydrometeorology, 5(1), 100-109. https://doi.org/10.1175/15257541(2004)005<0100:TREOTA $>2.0 . \mathrm{CO} ; 2$

Wesely, M. L. (1976). A comparison of two optical methods for measuring line averages of thermal exchanges above warm water surfaces. J Appl Meteorol, 15, 1177-1188.

Wood, A. W., Leung, L. R., Sridhar, V., \& Lettenmaier, D. P. (2004). Hydrologic Implications of Dynamical and Statistical Approaches to Downscaling Climate Model Outputs. Climatic Change, 62(1), 189-216. https://doi.org/10.1023/B:CLIM.0000013685.99609.9e

Wood, Andrew W, Maurer, E. P., Kumar, A., \& Lettenmaier, D. P. (2002). Long-range experimental hydrologic forecasting for the eastern United States. Journal of Geophysical Research: Atmospheres, 107(D20), ACL 6-1-ACL 6-15. https://doi.org/10.1029/2001JD000659

Wright, I R, Gash, J. H. C., Da Rocha, H. R., Shuttleworth, W. J., Nobre, C. A., Maitelli, G. T., ... Carvalho, P. R. A. (1992). Dry Season Micrometeorology of Central Amazonian Ranchland. Quarterly Journal of the Royal Meteorological Society, 118(508), 1083-1099. https://doi.org/10.1002/qj.49711850804

Wright, I R, Manzi, A. O., \& da Rocha, H. R. (1995). Surface conductance of Amazonian pasture: 
model application and calibration for canopy climate. Agricultural and Forest Meteorology, 75(1), 51-70. https://doi.org/https://doi.org/10.1016/0168-1923(94)02203-V

Wright, Ivan R, Gash, J. H. C., Rocha, H. R. Da, \& Roberts, J. M. (1996). Modelling surface conductance for Amazonian pasture and forest. In John H C Gash, C. A. Nobre, J. M. Roberts, \& R. L. Victoria (Eds.), Amazonian deforestation and climate (pp. 437-458). Wiley, Chichester.

Xu, S., Yu, Z., Zhang, K., Ji, X., Yang, C., \& Sudicky, E. A. (2018). Simulating canopy conductance of the Haloxylon ammodendron shrubland in an arid inland river basin of northwest China. Agricultural and Forest Meteorology, 249(320), 22-34. https://doi.org/10.1016/j.agrformet.2017.11.015

Yilmaz, K. K., Gupta, H. V, \& Wagener, T. (2008). A process-based diagnostic approach to model evaluation: Application to the NWS distributed hydrologic model. Water Resources Research, 44(9). https://doi.org/10.1029/2007WR006716

Zanchi, F. B., Waterloo, M. J., Aguiar, L. J. G., Randow, C. Von, Kruijt, B., Cardoso, F. L., \& Manzi, A. O. (2009). Estimativa do Índice de Área Foliar (IAF) e Biomassa em pastagem no estado de Rondonia, Brasil Estimate of the Leaf Area Index ( LAI) and Biomass in pasture in the state of. 39(2), 335-348.

Zarin, D. J., Davidson, E. a, Brondizio, E., Vieira, I. C. G., Sá, T., Schuur, E. a G., ... Denich, M. (2005). Legacy of fire slows carbon accumulation in. Ecology, 3(7), 365-369. https://doi.org/10.1890/1540-9295(2005)003\%5B0365:LOFSCA\%5D2.0.CO;2

Zemp, D. C., Schleussner, C. F., Barbosa, H. M. J., Van Der Ent, R. J., Donges, J. F., Heinke, J., ... Rammig, A. (2014). On the importance of cascading moisture recycling in South America. Atmospheric Chemistry and Physics, 14(23), 13337-13359. https://doi.org/10.5194/acp-14$13337-2014$

Zeng, N. (1998). Understanding Climate Sensitivity to Tropical Deforestation in a Mechanistic Model. Journal of Climate, 11(8), 1969-1975. https://doi.org/10.1175/1520-0442-11.8.1969 
Supplementary Information 
The following information constitutes supplementary material to Chapter 2.

Table S2.1: Instruments installed at FNS and CO sites

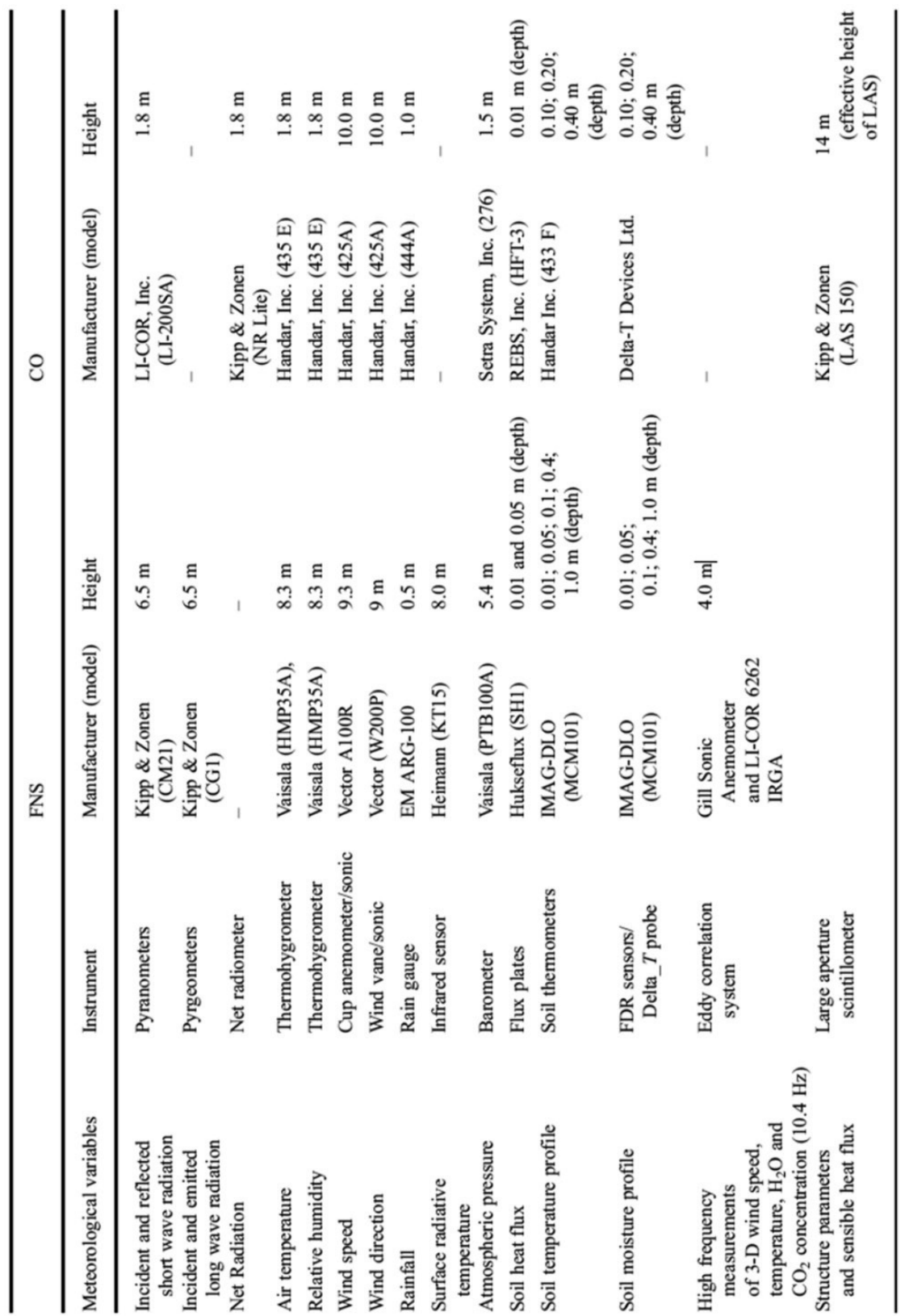


The following information constitutes supplementary material to Chapter $\mathbf{5}$.
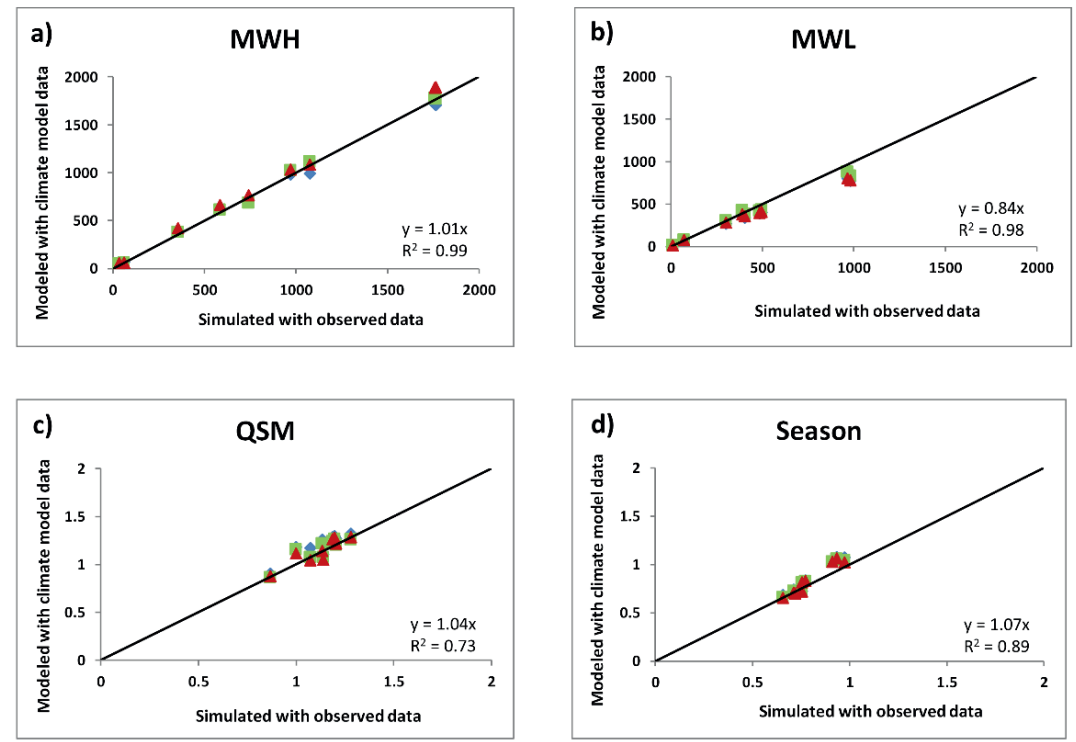

- M1 $\triangle \mathrm{M} 2-\mathrm{M} 4$

Figure S5.1 Plots comparing indices derived from flow duration curves (FDCs) of simulation of MHD fed with observed data and MHD fed with climate model data for historical period (19701990). a) high-flow segment volume of FDC (MWH); b) flow segment volume of FDC (MWL); c) slope between the 0.2 and 0.8 quantiles of FDC (QSM) and d) the difference between dry and wet seasons (SEASON). The values of discharges are in $\mathrm{m}^{3} \cdot \mathrm{s}^{-1}$. 

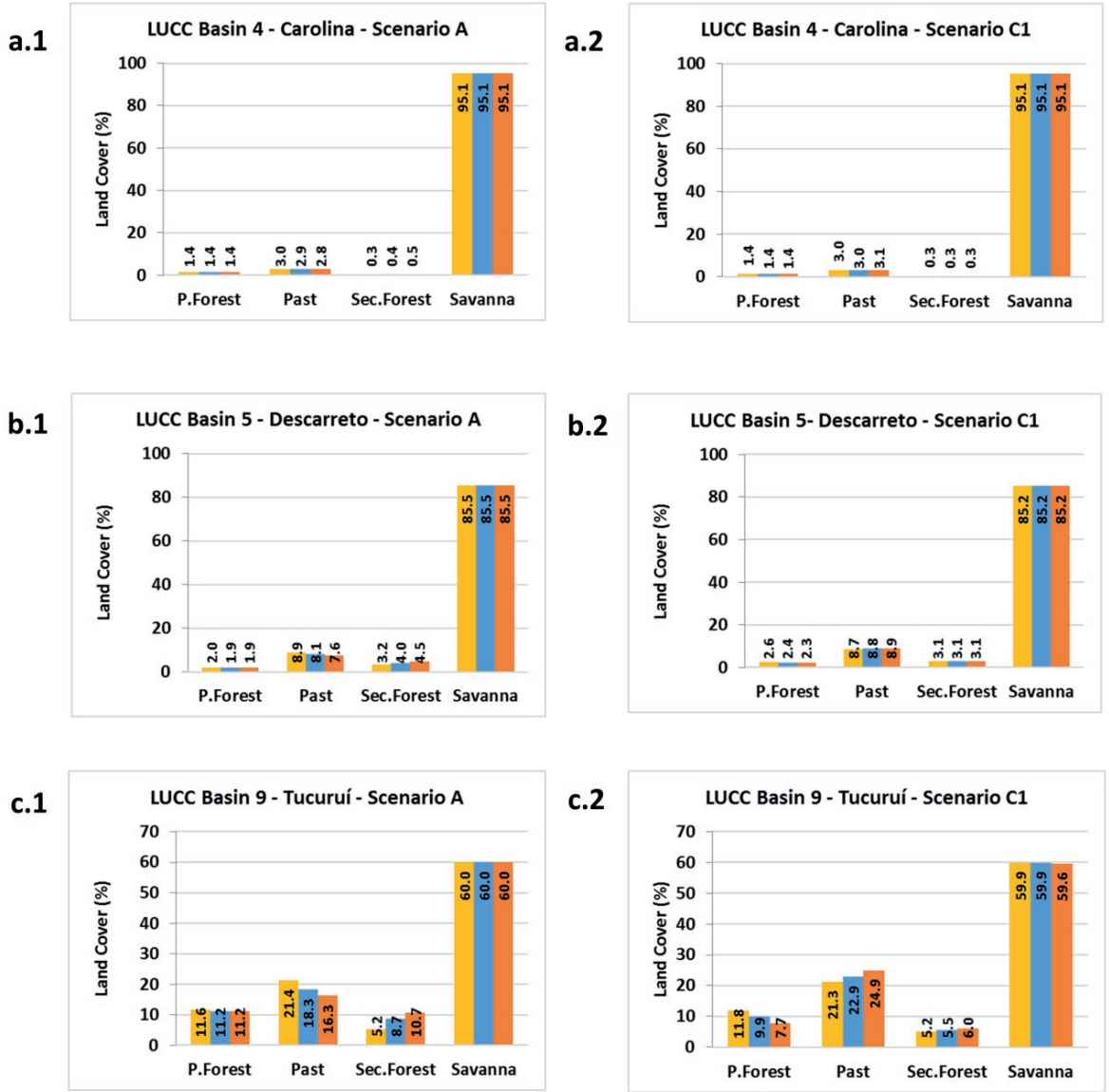

\section{$2008 \square 2011-2040 \square$ 2041-2070}

Figure S5.2 Percentage of land use and land cover change projected by LUCC-ME for A) Carolina sub-basin; B) Descarreto sub-basin and C) Tucuruí sub-basin. The first column presents the results of scenario A, and the second column presents the results of scenario $\mathrm{C} 1$. 


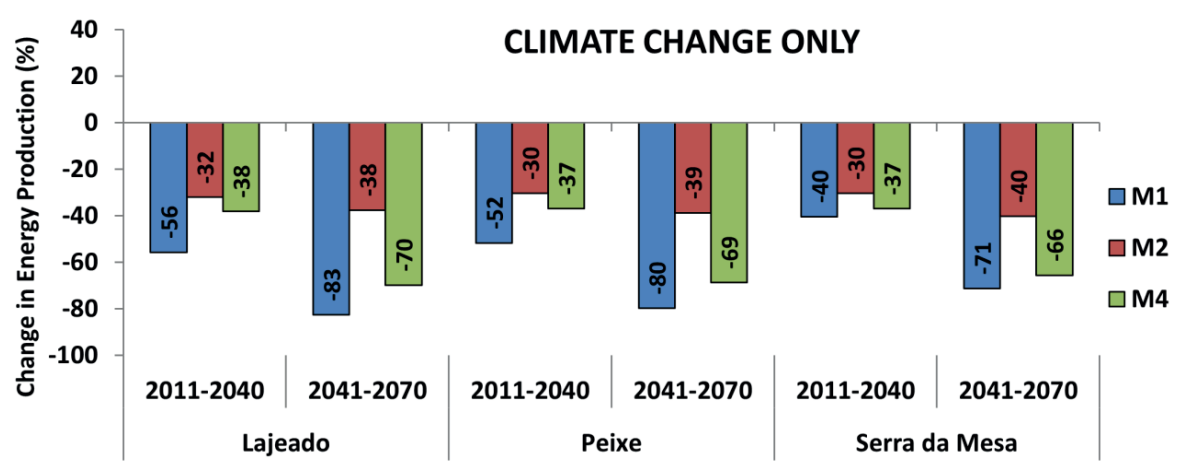

Figure S5.3 Projected effect on the energy potential at the Lajeado, Peixe and Serra da Mesa dams caused by climate change only

TableS5.1: Change in evapotranspiration (percentage) at the Tucuruí basin based on LULCC scenarios $\mathrm{A}$ and $\mathrm{C} 1$ in comparison with CC only (EtaM1)

\begin{tabular}{|c|c|c|c|c|c|}
\hline \multicolumn{2}{|c|}{$\begin{array}{c}\text { Evapotranspiration } \\
\left(\mathrm{mm} . \mathrm{year}^{-1}\right)\end{array}$} & \multicolumn{2}{|c|}{$\begin{array}{l}\text { Deforestation w/o } \\
\text { secondary forest }\end{array}$} & \multicolumn{2}{|c|}{$\begin{array}{l}\text { Deforestation w/ } \\
\text { secondary forest }\end{array}$} \\
\hline & ${ }^{1} \mathrm{CC}$ only & $\begin{array}{c}\text { ScenA } \\
(\%)\end{array}$ & $\begin{array}{c}\text { ScenC1 } \\
(\%)\end{array}$ & $\begin{array}{c}\text { ScenA } \\
(\%)\end{array}$ & $\begin{array}{c}\text { ScenC1 } \\
(\%)\end{array}$ \\
\hline Baseline & 1084.83 & & & & \\
\hline $2011-2040$ & 1007.65 & -1.7 & -2.2 & 1.1 & -0.5 \\
\hline $2041-2070$ & 900.80 & -1.5 & -2.6 & 1.6 & -1.0 \\
\hline
\end{tabular}

${ }^{1}$ For CC only, LULCC was fixed based on the land use and land cover in 2008. 
The objective function used in MHD model optimization for the SCE-UA (Shuffle Complex Evolution - University of Arizona) is based on the average of Nash-Sutcliffe and Nash-Sutcliffe of discharges logarithms efficiency coefficients. Convergence criteria is defined based on the minimal percentage of improvement in the objective function, which was fixed in 0.001 . Model calibration was based on 9 parameters related to the soil water distribution described in the Table S5.2. Table S5.3 shows the results of the calibration procedure of the hydrological model using observed data for the period 1970 - 1990 as input.

Table S5.2: Soil Parameters used in the MHD calibration.

\begin{tabular}{lll}
\hline Symbol & Unit & Description of the parameter \\
\hline $\mathrm{D} 1$ & $\mathrm{~m}$ & Thickness of the upper soil layer \\
$\mathrm{D} 2$ & $\mathrm{~m}$ & Thickness of the intermediate layer \\
$\mathrm{D} 3$ & $\mathrm{~m}$ & Thickness of the bottom layer \\
$\mathrm{K}_{\mathrm{ss}}$ & $\mathrm{m} \cdot \mathrm{day}^{-1}$ & Saturated hydraulic conductivity \\
$\mathrm{T}_{\text {sub }}$ & $\mathrm{m}^{2} \cdot \mathrm{day}^{-1}$ & Maximum transmissivity of the bottom layer \\
$\mu$ & - & A parameter that represents the decay of the transmissivity \\
$\mathrm{C}_{\mathrm{CSI}}$ & $\%$ & with the thickness of the saturated zone \\
$\mathrm{C}_{\text {sup }}$ & $\mathrm{sec}$ & Minimum subterraneous storage that generates flow \\
$\mathrm{C}_{\mathrm{b}}$ & $\mathrm{sec}$ & In-cell routing parameter for surface and subsurface flows \\
\hline
\end{tabular}


Table S5.3: Soil Parameters for the calibration period 1970-1990.

\begin{tabular}{llllllllll}
\hline BACIA & D1 & D2 & D3 & $\mathrm{K}_{\text {SS }}$ & $\mathrm{T}_{\text {SUB }}$ & $\mu$ & $\mathrm{CSI}$ & $\mathrm{C}_{\text {sup }}$ & $\mathrm{C}_{\mathrm{b}}$ \\
\hline 1 & 0.58 & 0.04 & 9.52 & 0.49 & 2.20 & 1.99 & 1.00 & 0.17 & 0.07 \\
2 & 1.00 & 5.26 & 23.84 & 0.09 & 0.01 & 2.00 & 0.96 & 2.80 & 9.97 \\
3 & 0.25 & 1.17 & 23.90 & 0.28 & 1.12 & 2.00 & 0.13 & 2.18 & 2.53 \\
4 & 0.68 & 0.30 & 2.44 & 0.03 & 2.97 & 1.00 & 0.98 & 0.32 & 0.42 \\
5 & 0.69 & 0.83 & 0.04 & 0.01 & 284.97 & 1.50 & 0.85 & 4.95 & 0.01 \\
6 & 0.03 & 6.68 & 40.95 & 1.25 & 35.82 & 1.09 & 0.01 & 5.72 & 0.04 \\
7 & 1.00 & 0.01 & 0.01 & 14.97 & 483.70 & 1.02 & 0.00 & 0.93 & 9.99 \\
8 & 0.91 & 1.20 & 83.57 & 0.04 & 245.60 & 1.07 & 0.14 & 99.07 & 0.01 \\
9 & 0.00 & 14.84 & 99.99 & 0.00 & 11.17 & 1.01 & 0.00 & 32.60 & 9.99 \\
\hline
\end{tabular}

Table S5.4: FDC's signature measures used for the validation of the hydrological model.

\begin{tabular}{lcl}
\hline Name & \multicolumn{1}{c}{ Equation } & Description \\
\hline Season & $\frac{\text { meanWet - meanDry }}{\text { mean }}$ & $\begin{array}{l}\text { Differences between wet } \\
\text { and dry seasons discharges }\end{array}$ \\
\cline { 2 - 3 } & $\frac{0.8 \text { quantile }-0.2 \text { quantile }}{\text { mean }}$ & $\begin{array}{l}\text { Slope of the FDC at the } \\
\text { medium range, indicating } \\
\text { the variability in the } \\
\text { medium range of the runoff } \\
\text { coefficients }\end{array}$ \\
\hline$M W H$ & $\frac{\sum_{1}^{H} Q h}{H}$ & $\begin{array}{l}\text { High flow segment of the } \\
\text { FDC, which indicates the } \\
\text { watershed response to large } \\
\text { precipitation events }\end{array}$ \\
\hline$M W L$ & $h=1,2, \ldots H$ flows with exceedance probabilities $<0.02$ & $\begin{array}{l}\text { Low-flow segment of the } \\
\text { FDC. Indicates the long- } \\
\text { term sustainability of flow }\end{array}$ \\
\hline
\end{tabular}


Figure S5.4 Hydrographs for the nine gauging stations simulated (red) and observed (blue) daily discharges for the calibration of the period 1970-1990
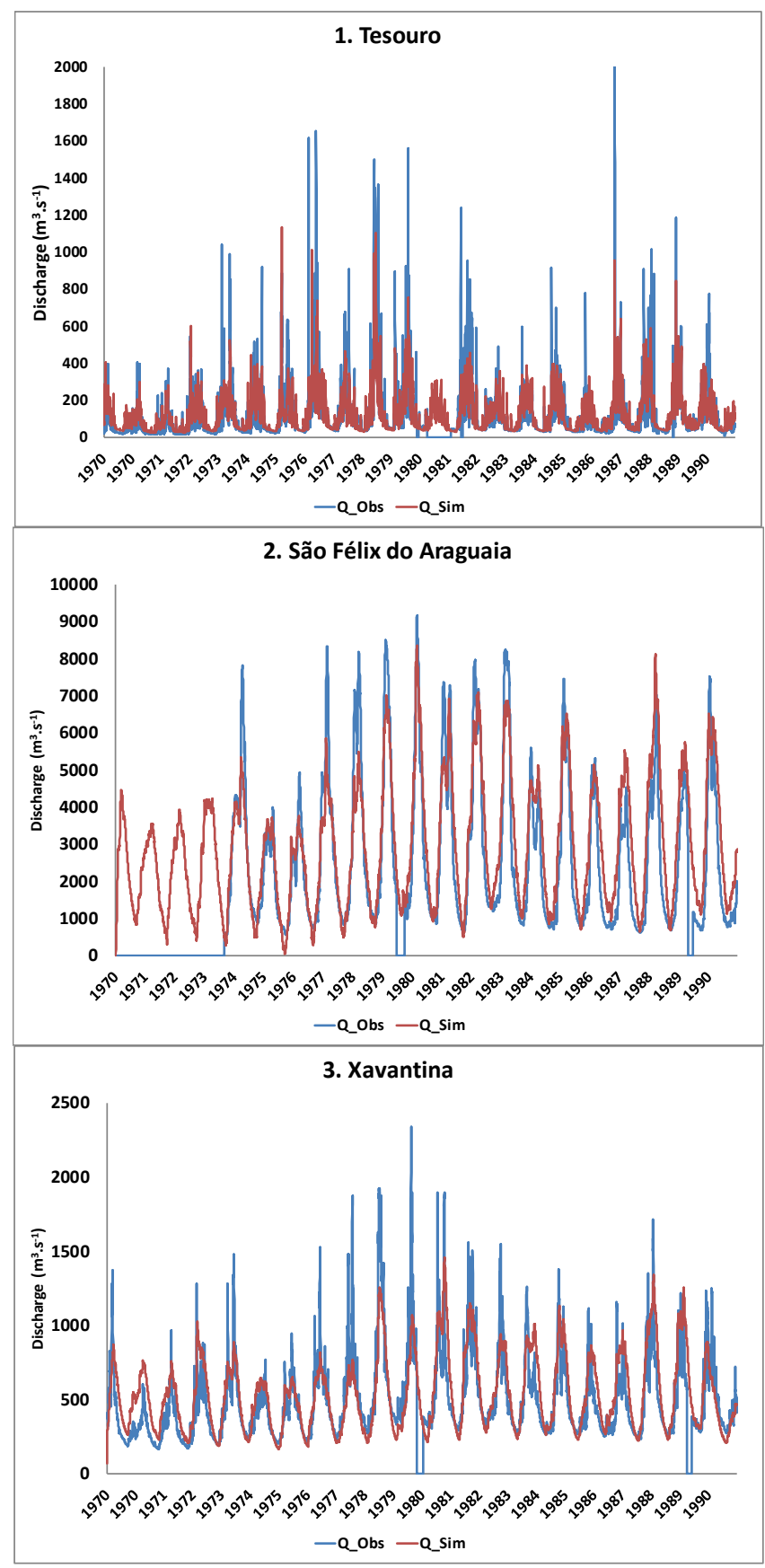
Figure S5.4 (Continuation)
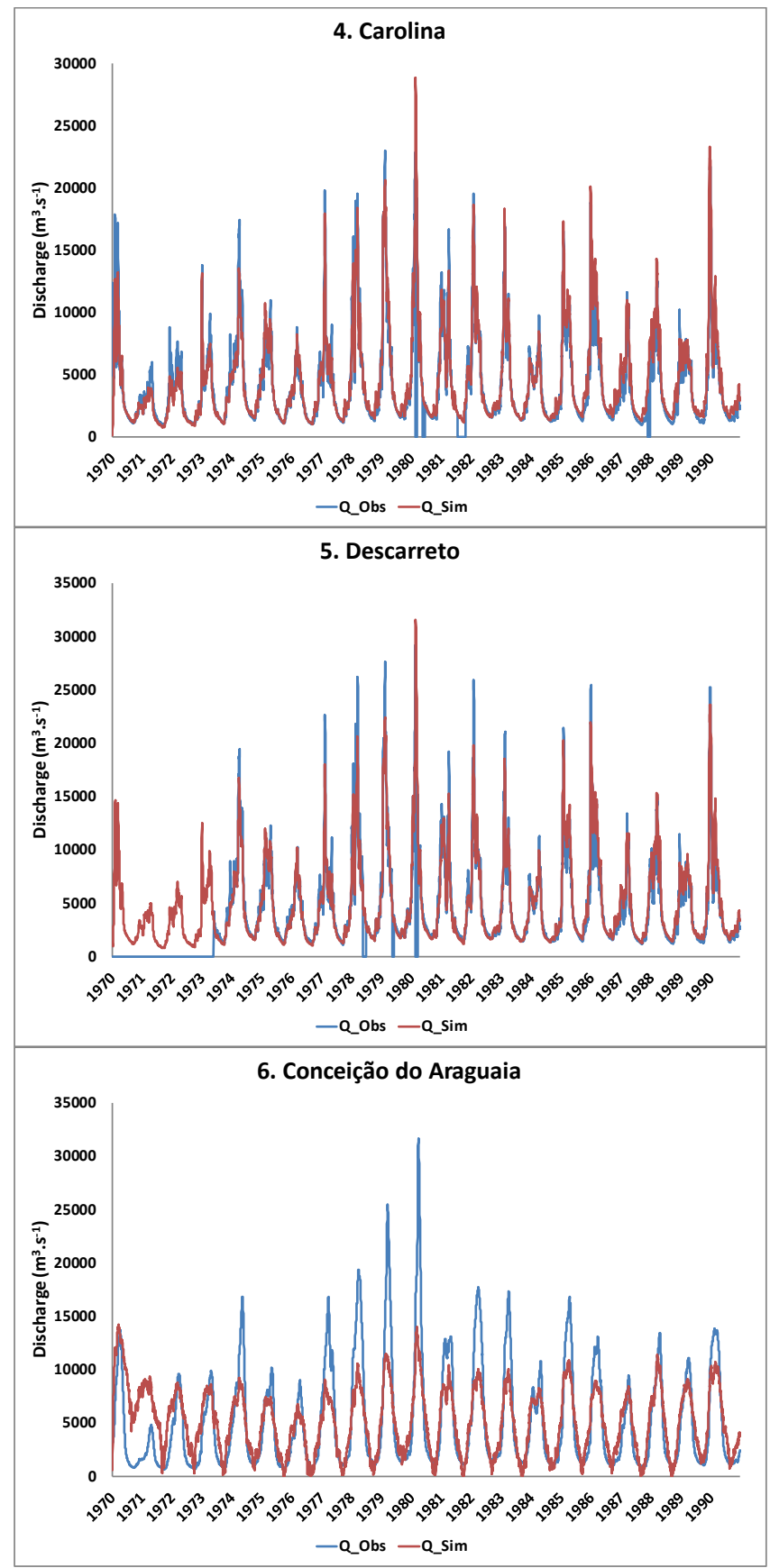
Figure S5.4 (Continuation)

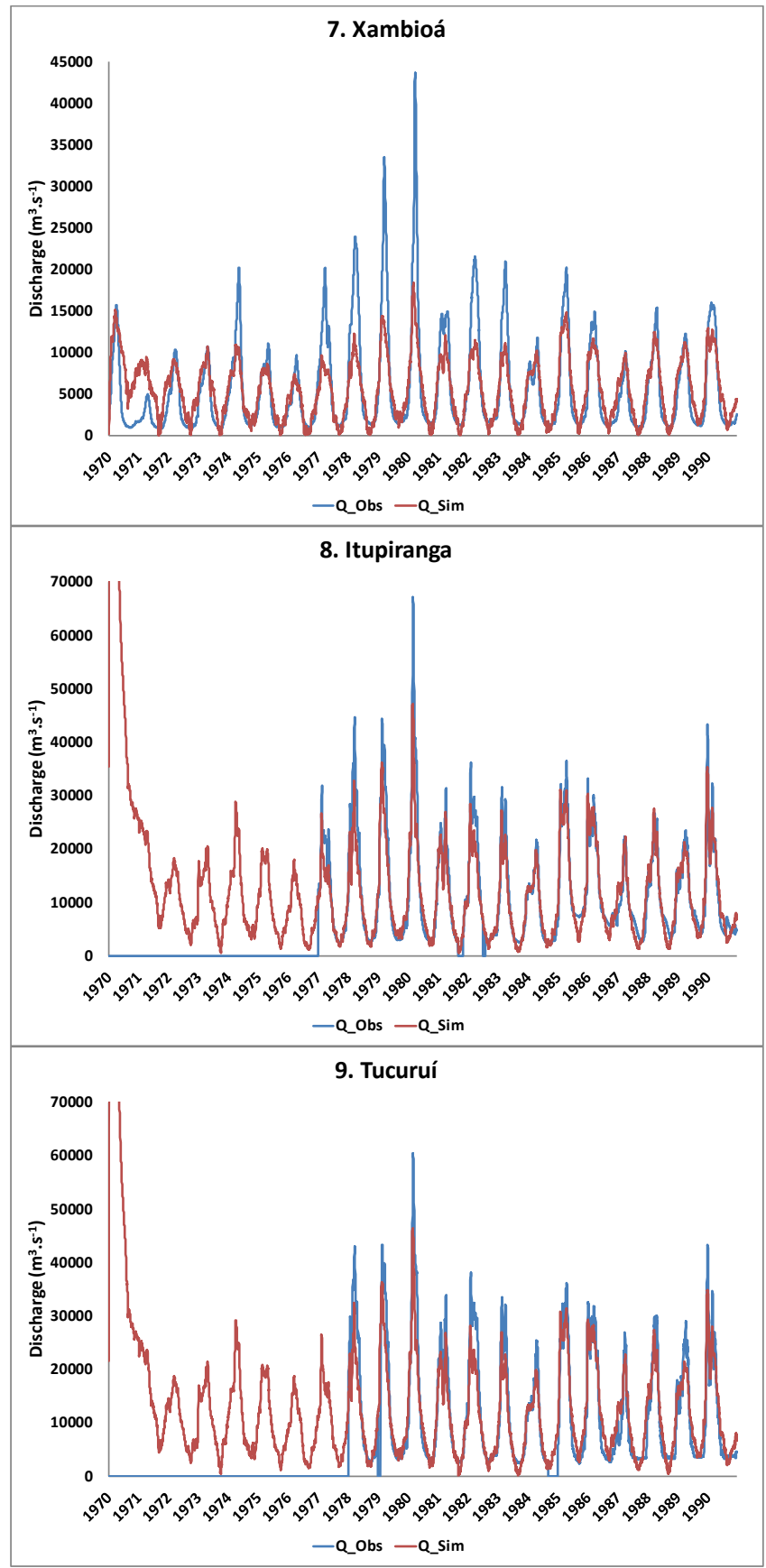

134 


\section{Summary}

The Amazon rainforest, the world's largest tropical rainforest, plays an important role on climate regulation by carbon fixation and cooling temperature throughout its high evapotranspiration rates. Nonetheless, the biome is pressured by deforestation on large part of its territory. The abandonment of deforested area due to low productivity and natural resources exhaustion, have resulted in a landscape characterized by a mosaic of several land covers, mainly the natural forest, pastures and secondary growth. This thesis aims to evaluate the seasonal and spatial variability of the fluxes of evapotranspiration over diverse Amazon land covers, with the purpose of investigating whether natural recovery counterbalances the effects caused by anthropogenic actions on the water cycle components. Besides that, the impact of future scenarios of land use and land cover change in combination with global climate change on river discharges and hydropower was also evaluated in an Amazon tributary by explicitly modeling the role of each land cover on evapotranspiration.

Water and carbon fluxes were measured by eddy covariance and scintilometry besides other micrometeorological data, in three different land covers in Central and Southwestern Amazonia, in order to compare the effects of deforestation and natural regrowth on the water cycle components.

The conversion of forest to pasture reduces the evapotranspiration. Two pasture sites analyzed present much lower evapotranspiration than in forests during the dry season, and with only one of them reaching the same rates of evaporation of primary vegetation during the wet season. Nonetheless, when pastures are abandoned due to low productivity, the secondary growth that replaces those areas reaches evapotranspiration $20 \%$ higher than that in primary forest at both dry and wet seasons. The gross primary productivity of the secondary vegetation is also higher than the primary in the wet season, but in a lower percentage ( $5 \%$ higher), and the same during the dry season.

Besides the field data collection, this work is one of the first to consider the impacts of secondary forest in the hydrological modeling driven by different climate change scenarios (CC) and two future socioeconomic-based potential land-cover land-use change scenarios (LCLUC) on regional scale. The model projected a decrease on discharge under $\mathrm{CC}$ scenarios, and when 
deforestation scenarios without secondary growth are considered, the effects of CC are weakened. However, when secondary growth is also considered, the effects of CC are slightly enhanced. Results suggest that different aspects of environmental change, such as secondary growth, may affect water production and the sectors depending on it. For example, the potential energy production for Tucuruí power plant, is projected to decrease of up to $58 \%$ under all land use change scenarios in 2041 to 2070 time slice.

Secondary forest growth plays an important role in minimizing the impacts of land cover and land use changes from primary forest to pasture on the water balance in Amazonia, since the secondary forest contributes with higher transpiration than pastures, and even higher than in the primary forest. This indicates that secondary forests can contribute to the maintenance of moisture production of the Amazon region.

In addition, secondary forest takes more carbon from the atmosphere than pasture sites, playing an important role on carbon uptake from the atmosphere together with primary forest, minimizing emission from deforestation. 


\title{
Acknowledgements
}

\author{
"Persistence is the way to success" \\ (Attributed to Charlie Chaplin)
}

A PhD is a title held by one person that was supported by many, sometimes invisible, hands of others. Here, I would like to thank all those hands that supported me, scientifically, emotionally or motivationally. All of them were substantially important to the accomplishment of this highly meaningful achievement of my life.

First of all, I would like to thank my day-to-day supervisors. In The Netherlands, Dr. Ronald Hutjes, for the warmth with which he received me my first time abroad, helping me to solve all the bureaucracy a foreigner needs to follow to live in another country. I still remember the beautiful tulips he left in my student flat to make it a bit cozier. In the scientific field, I am grateful for his patience in teaching me the first steps of research and scientific writing at the beginning of my $\mathrm{PhD}$. Simple things that remind me the master when I routinely repeat nowadays. In Brazil, Dr. Javier Tomasella, who introduced me to Hydrology and gave me the first opportunity to visit the Amazon forest. Who taught me the theory and showed me the practice. Dr. Javier is a person I admire and who gives inspiration to work in science because of his energy and brightness.

I am also grateful to my promotor Prof. Pavel Kabat, for accepting to be my supervisor and for believing that I could accomplish this task. The happiness that he demonstrated every time that he received a step forward that I made on the thesis encouraged me to go on.

I also would like to give my special thanks to Dr. Bart Kruijt, who first was the coordinator of the NWO-WOTRO project number W.01.65.217.00, for which I received my PhD grant (and also acknowledge here). But later he turned into a friend who was always present and taught me that being a good and well known researcher can go together with being a simple, friendly and unostentatious person. I also need to give my gratitude to Dr. Maarten Waterloo, who taught me a lot about field work hydrology, and who made some time available on his agenda to discuss solutions for my first article, opening the track for this journey. I am honored for having all of you involved in the foundation of my career.

Doing a $\mathrm{PhD}$ is a task that goes smoothly when one has a good atmosphere and good facilities to work in. I had the luck of having good facilities and great colleagues in the first period of planning the $\mathrm{PhD}$ at Lumen in Alterra, and the last period of data analysis at Atlas, also in Alterra. I would like to thank all the colleagues there. Some of them are listed here; others for some unfortunate reason, I might have forgotten. I would like to thank my office mate Jan Elbers for the nice day-to-day of sharing, Wilma Jans for the nice talks during lunch and for taking me to climb the Loobos tower on a cold and wet day (getting that frozen hands was one of my memorable field experiences), Judith for having the care of showing me a Dutch dinner with a Dutch family at her house, and all the others for the tea breaks, writing weeks, team outings: Cor, Saskia, Isabel, Jeroen, Herbert, Ann-Marie, Fons, Catharien, Hester, Petra, Olaf, Obbe, Ruud and our head of office, Eddy Moors, now professor Eddy Moors, who pointed out the importance of a sunny day for the Dutch, 
and of leading a group with smiles and lightness. In Brazil, the doors were always open for me at CPTEC/INPE in the beginning of the PhD during the preparation of field work, and after the end of the project. At INPA, in Manaus, our project was also welcomed, and I would like to thank Dr. Antonio Manzi for the effort of making everything happen under the logistical limitations. In special, I thank Maria Terezinha Monteiro for the friendship and Antonio Huxley. All the data collected during the field work was possible because of your professionalism, commitment and companionship. Of course, all the LBA team is mentioned here, the Micrometeorology group, especially Marta, Paulo and Dr. Alessandro Carioca. At CCST/INPE, I would like to thank Dr. Jean Pierre Ometto, for providing the facilities to develop the final chapters of this thesis. Without this support, the conclusion of this work would have been more difficult.

All the work started together with my colleagues from WOTRO/PhD, Dr. Fabrício Berton Zanchi and Dr. Luciana de Souza Soler. Thank you for the enthusiasm that connected us to work on this project, in spite of all the ups and downs that we faced during the process.

Science showed to be mainly the exercise of sharing knowledge for the good of spreading knowledge. I could see this when I asked for help from Martin Hodnett, Dr. Beto Quesada and Dr. Luz Adriana Cuartas. I was impressed with the way that they stopped their busy lives to give away what they had already learnt. Thank you very much!

Not just through work is a $\mathrm{PhD}$ thesis done. The periods of rest and breathing between the periods of work for a Brazilian are based on the energy of getting together with friends, and I am thankful for the energy that I received from you, my Brazilian family in the Netherlands. In special Anabele and Wiebe, for opening the doors of your warm Brazilian/Dutch house for barbecues, dinners, birthdays, Sinterklaas and my first Christmas far from home. At Anabele and Wiebe's house, or in De Vlaamsche Reus, or in De Zaaier, or in the Bornsesteeg building, I thank you for the friendship Glaciela Kaschuk, Odair Alberton, Marcia Barcellos, Saulo Alves, Michael Daamen, Carol and Denis, Flávia Talarico Saia, Érica Duarte, Haíssa Cardarelli, Priscilla Sabadin, Priscila Rosseto, Mário and Ana, Isabella Nougalli, Stefano Ciannamea, Betânia, Flávio (coffee expert and responsible for preparing us memorable meals), Dulce Silva and Margriet Groenendijk (my sweet Dutch friend, who gave me the opportunity to know the life of Amsterdam). I cannot forget the Sundays in Almere with Alessandro, Jacqueline and their daughters. Thank you! Also to Gisleine and Marcelo, in EU and BR. In Manaus, Brazil, I thank Rosa Maria Nascimento, Theo Pauliquevis, Janete, Carina, Ana, James, Jair and Rielva, Aline and Anouk van Baalen. In Cachoeira Paulista, thank you for receiving me at your home Alexandra and Daniel and for giving me support during the hard time of importation and customs, and for empanadas and wine during the free time. In Guaratinguetá, for our brothers Daniel and Félix, the uncles of our son, the family that we had chosen there and now in Rio de Janeiro. In São José dos Campos, thank you for the Cerveja Barata WhatsApp group: Aline, Rosa Zamora, Chica Veloso, Karine, Gilney, Alex, Graciela, Déia Thomaz, Fabi, and Mariane. And for the children that play with our son during the barbecues, holidays, birthdays or any get together that we find a reason to be united: Lara, Pedrinho, Sofia and Ricardinho. You are our family in São José dos Campos, and gave me, during all these years, support and strength to keep on going to reach this milestone. Also thanks to Bons Fluidos WhatsApp group for the wines and laughs, in special to Peter Toledo, Mauro Assis, Maria Cristina Forti and Jean Ometto for all the knowledge that you share with us, and Cileia Ometto for opening 
your house so many times to receive all these exchange. For all these people that I met during these years, thank you! Without this exchange of energy, I think I could not afford to reach this goal.

One special paragraph needs to be reserved for Dr. Daniel Andrés Rodriguez. He is cited in several paragraphs because he arrived in my life as a friend, then we became colleagues at work, then he became my boss and more than all places listed above, he was responsible for making me believe that I was adequate to finish this thesis. Thank you for believing in me and for making me believe in myself.

Now, I need to thank the people that are the basis of all I became: my parents Maria Aparecida da Cruz Silva and Francilino Angelo da Silva, and my sisters Ariana Silva and Francilini Silva. Mãe e pai, muito obrigada por terem me mostrado a importância e terem me dado acesso ao que vocês não tiveram oportunidade: Educação. Seus esforços me trouxeram à luz do conhecimento e me fizeram ir longe para alcançar meus sonhos. Graças a vocês, hoje vejo que o mundo é feito de várias realidades. Ariana e Fran, obrigada pelo apoio, pelo orgulho que sentem por mim, isso me dá forças para não desistir e para continuar. Tio Maicon, obrigada pelo carinho com que trata meus amores. Obrigada a vocês todos por me ajudarem nessa tese. Ao cuidarem e amarem meu filho enquanto eu debruçava sobre essas linhas, vocês também escreveram grande parte deste livro.

Não posso esquecer de dedicar esse livro à minha avó Aparecida Rosa da Cruz (in memorian), que infelizmente não conseguiu esperar a conclusão desta tese, mas que com certeza serviu de inspiração para que ela fosse feita, pois ao vê-la forte, destemida e guerreira, foi plantada em mim uma semente para eu lutar contra minha natureza e tentar chegar ao menos um pouquinho perto do que ela representa.

Finally, I thank the family that I have built. My beloved husband Dr. Celso von Randow, who surely is the person that deserves to be in all positions of this acknowledgment. He is my friend, my colleague, my co-supervisor, the love of my life and the one responsible for helping me to accomplish my biggest dream: being a mother. Thank you for your support, for your patience, for being the peace when my thoughts are chaotic, the hands when I am sinking and the safe island when I am tired and need to rest. Thank you for giving me Pedro, the sweetest child I've ever met. He looks like you, so I am doubly gifted. And last, but not least, my son Pedro. Thank you for choosing me! I hope this achievement makes you proud and understanding for the time that I've been away. Eu te amo, filho! 


\section{About the Author}

Rita von Randow was born in Cajuru, Brazil, on December $20^{\text {th }}$, 1974. In 1995, she joined the Bachelor in Mathematics at the Universidade Paulista Júlio de Mesquita Filho (UNESP - Rio Claro Campus). During the last three years of the undergraduate course, she was awarded with a grant from Capes, in the Special Training Program (PET), on which she developed many activities related not only to scientific initiation studies, but also social, literature and arts tasks.

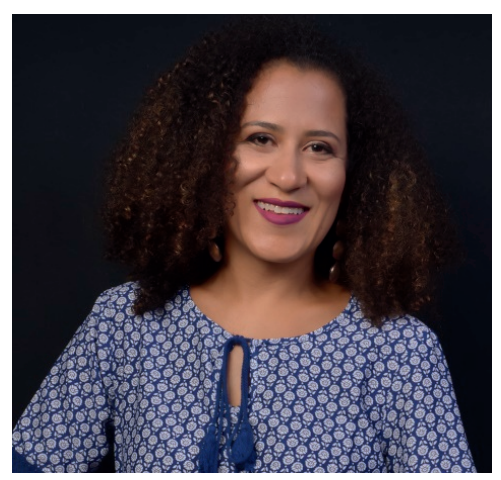

Following her interest on applied mathematics, in 1999 she was awarded with a grant from CNPq (Conselho Nacional de Desenvolvimento Científico e Tecnológico) to pursue a master's degree in Meteorology at National Institute for Space Research (INPE) in São José dos Campos, Brazil. The subject of her research was the Radiation Balance in Pantanal, Mato Grosso do Sul, Brazil. From 2002 to 2005, she worked for the Hydrology group at Center for Weather Forecast and Climate Studies (CPTEC/INPE) in Cachoeira Paulista being responsible for monitoring the aridity indicators of Brazilian Northeast region, and in order to satisfy the desire to study the hydrological importance of the Amazon, in parallel, she developed a research on evapotranspiration in the Amazon and Pantanal. With financial support from NWO-WOTRO (The Netherlands Foundation for the Advancement of Tropical Research), in 2005 she started a Sandwich $\mathrm{PhD}$ at Alterra/WUR to work exclusively with hydrology in the Amazon. In this period, she acquired field experience in water measurements in situ. Back to Brazil, in 2011, she developed the hydrological study for AMAZALERT project at Earth System Science Center (CST/INPE). Since 2012, she has been working as a lecturer in the Technological Faculty of Sao Paulo (FATEC) on Basic Hydrology, Meteorology and Climatology, Linear Algebra and Statistics. 


\section{Publications}

\section{Peer reviewed papers}

1. Von Randow, R. C. S., Rodriguez, D. A., Tomasella, J., Aguiar, A. P. D., Kruijt, B., \& Kabat, P. (2019). Response of the river discharge in the Tocantins River Basin, Brazil, to environmental changes and the associated effects on the energy potential. Regional Environmental Change, 19(1), 193-204. https://doi.org/10.1007/s10113-018-1396-5

2. Guimberteau, M., Ciais, P., Ducharne, A., Boisier, J.P., Dutra Aguiar, A.P., Biemans, H., De Deurwaerder, H., Galbraith, D., Kruijt, B., Langerwisch, F, Poveda, G., Rammig, A., Rodriguez, D.A., Tejada, G., Thonicke, K., Von Randow, C.o , Von Randow, R.C.S., Zhang, K., Verbeeck, H.. (2017). Impacts of future deforestation and climate change on the hydrology of the Amazon Basin: A multi-model analysis with a new set of land-cover change scenarios. Hydrology and Earth System Sciences, 21(3). https://doi.org/10.5194/hess-21-1455-2017

3. Paulino Junior, N., Von Randow, R. C. S., \& Von Randow, C. (2017). Analysis of biological and meteorological controls of evapotranspiration in pristine forests and a pasture site in Amazonia. Revista Ambiente e Agua, 12(2). https://doi.org/10.4136/ambi-agua.1832

4. Von Randow, R. C. S., Von Randow, C., Hutjes, R. W. A., Tomasella, J., \& Kruijt, B. (2012). Evapotranspiration of deforested areas in central and southwestern Amazonia. Theoretical and Applied Climatology, 109(1-2), 205-220. https://doi.org/10.1007/s00704-011-0570-1

5. Cuartas, L. A., Tomasella, J., Nobre, A. D., Nobre, C. A., Hodnett, M. G., Waterloo, M. J., Oliveira, S.M., Von Randow, R.C., Trancoso, R., Ferreira, M. (2012). Distributed hydrological modeling of a micro-scale rainforest watershed in Amazonia: Model evaluation and advances in calibration using the new HAND terrain model. Journal of Hydrology, 462463. https://doi.org/10.1016/j.jhydrol.2011.12.047

6. Alvalá, R. C. S., \& Von Randow, R. C. S. (2009). Study of the Radiation Balance in the Southern Mato Grosso Pantanal Wetland. AIP Conference Proceedings, 1100(1), 439-442. https://doi.org/10.1063/1.3117014

7. Von Randow, R. C. S., \& Alvala, R. C. S. (2006). Estimativa da radiação de onda longa atmosférica no Pantanal Sul Mato-Grossense durante os periodos secos de 1999 e 2000. Revista Brasileira de Meteorologia, 21(3), 398-412. 



\section{SENSE}

Netherlands Research School for the

Socio-Economic and Natural Sciences of the Environment

\section{I P L O M A}

For specialised PhD training

The Netherlands Research School for the Socio-Economic and Natural Sciences of the Environment (SENSE) declares that

\section{Rita de Cassia Silva von Randow}

born on 20 December 1974 in Cajuru/Sao Paulo, Brazil

has successfully fulfilled all requirements of the Educational Programme of SENSE.

Wageningen, 14 April 2020

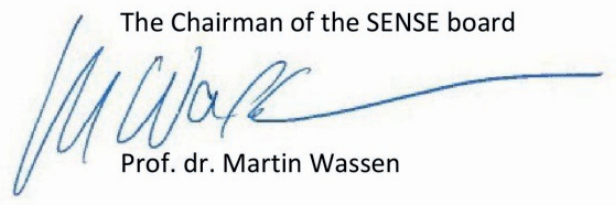

the SENSE Director of Education

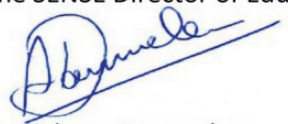

Dr. Ad van Dommelen

The SENSE Research School has been accredited by the Royal Netherlands Academy of Arts and Sciences (KNAW)

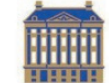

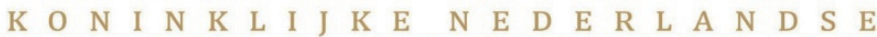

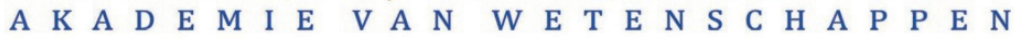




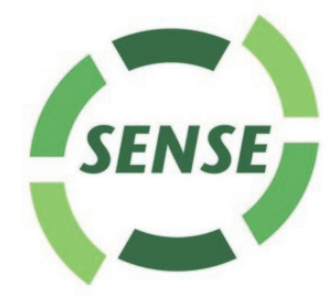

The SENSE Research School declares that Rita de Cassia Silva von Randow has successfully fulfilled all requirements of the Educational PhD Programme of SENSE with a work load of $46.2 \mathrm{EC}$, including the following activities:

\section{SENSE PhD Courses}

- Research in context activity: 'Initiating and organizing Workshop on Climate and Environmental Modeling of Amazonia (9-10 October 2007 -- Manaus, Brazil)'

\section{Other PhD and Advanced MSc Courses}

- Field course Hydrology, VU Amsterdam (2005)

- Project and time management, Wageningen Graduate Schools (2005)

- Field Experiment Meteorology and Air Quality - WUR (2006)

- Surface Fluxes $\mathrm{H}$ and $\lambda \mathrm{E}$ using Scintilometry, National Institute for Research in the Amazon (2006)

- Systems approach to model, National Institute for Space Research (2006)

- Summerschool Ecohydrology, VU Amsterdam (2007)

- Biosphere-Atmosphere interactions, National Institute for Research in the Amazon (2008)

- Techniques for writing and presenting scientific papers, Wageningen Graduate Schools (2009)

- Introduction to Fortan, Unicamp (2011)

- Hydrological processes, National Institute for Space Research (2011)

\section{Management and Didactic Skills Training}

- Supervising MSc student with thesis entitled 'Evapotranspiration in a secondary rainforest in Amazonia: The effect of forest fragmentation on the hydrological cycle' (2010)

- Supervising six BSc student with thesis (2016-2018)

- Teaching at Technology University of Sao Paulo State in the disciplines: Hydrology, Meteorology and Climatology (2013-2019)

\section{Oral Presentations}

- A comparison between the components of hydrological cycle on micro-basins of primary forest and fragmented forest in the Central Amazon. Amazon in Perspective, 17-2November 2008, Manaus, Brazil

- Modeling the hydrological effects of secondary forest growth in abandoned deforested areas in Amazonia. AGU Fall Meeting, 3-7 December 2012, San Francisco, United States of America

SENSE Coordinator PhD Education

Dr. ir. Peter Vermeulen

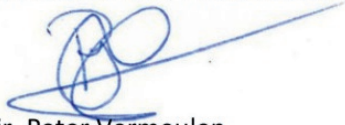



The research described in this thesis was financially supported by the Dutch foundation NWOWOTRO.

Cover designed by: Rita C. S. von Randow

Cover photos by: Rita C.S. von Randow; Bart Kruijt and Flavio Magina

Printed by: Digiforce 


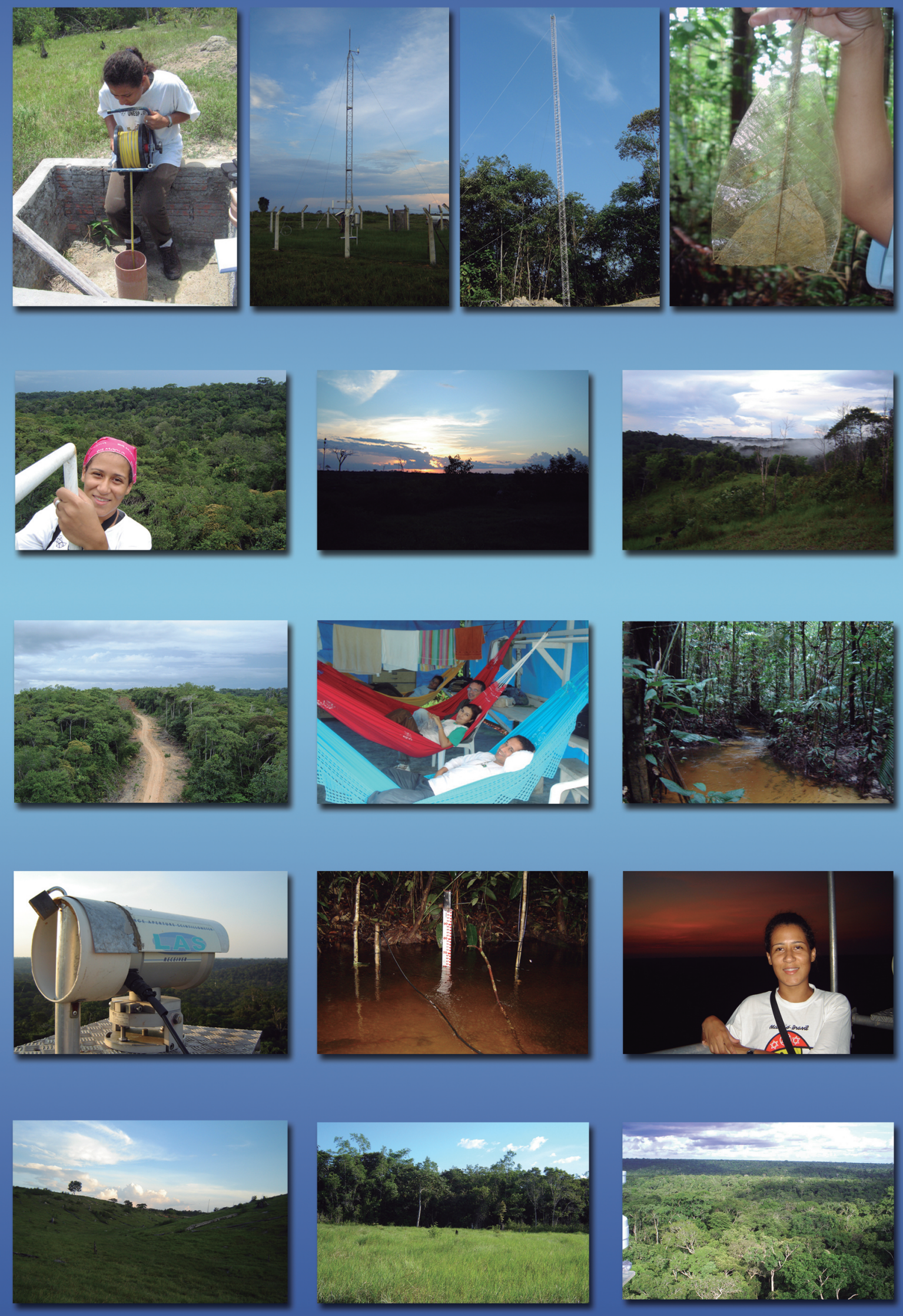